Installation Restoration Research Program

Strategic Environmental Research and Development Program

Dissolution Kinetics of High Explosive Compounds (TNT, RDX, HMX)

Jason C. Lynch

September 2002

US Army Corps of Engineers ${ }_{\circledast}$

Engineer Research and Development Center

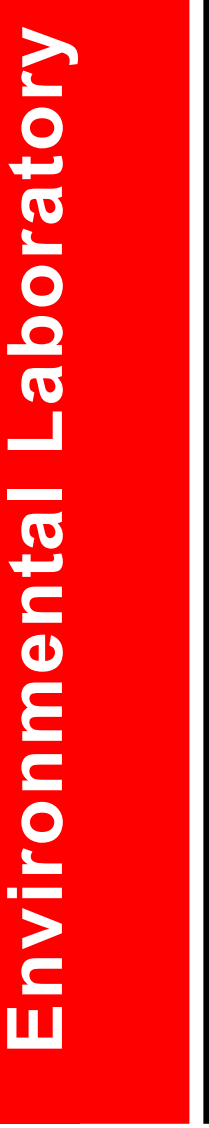

Approved for public release; distribution is unlimited. 
The contents of this report are not to be used for advertising, publication, or promotional purposes. Citation of trade names does not constitute an official endorsement or approval of the use of such commercial products.

The findings of this report are not to be construed as an official Department of the Army position, unless so designated by other authorized documents. 


\title{
Dissolution Kinetics of High Explosive Compounds (TNT, RDX, HMX)
}

by Jason C. Lynch

\author{
Environmental Laboratory \\ U.S. Army Engineer Research and Development Center \\ 3909 Halls Ferry Road \\ Vicksburg, MS 39180-6199
}

Final report

Approved for public release; distribution is unlimited

\author{
Prepared for U.S. Army Corps of Engineers \\ Washington, DC 20314-1000 \\ Under SERDP Project No. CP1155
}


TABLE OF CONTENTS

page

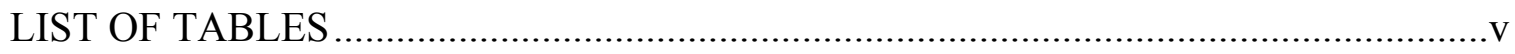

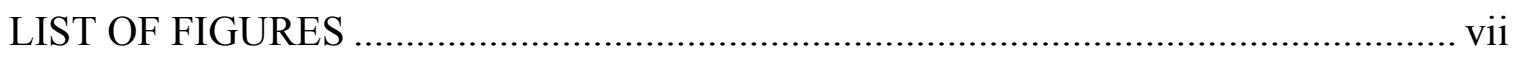

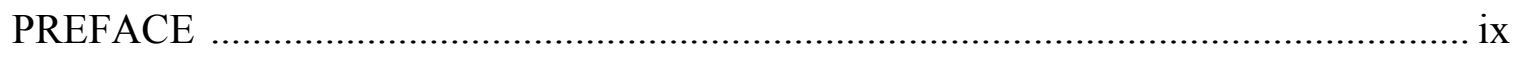

\section{CHAPTERS}

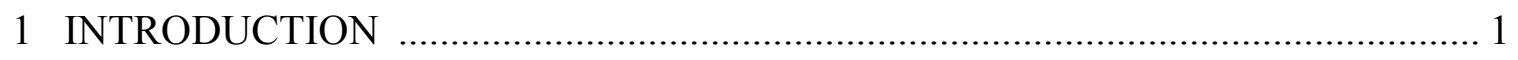

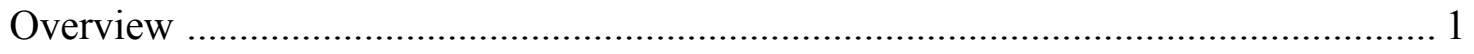

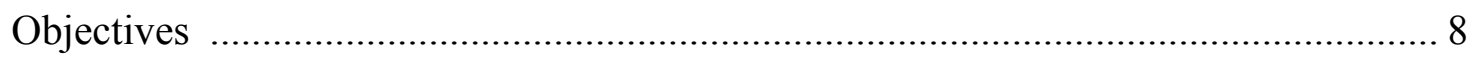

2 DISSOLUTION RATES OF THREE HIGH EXPLOSIVE COMPOUNDS:

TNT, RDX, AND HMX …………………………........................................... 10

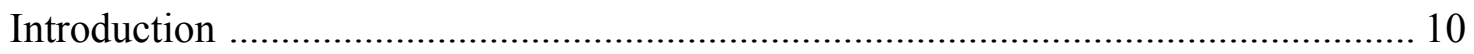

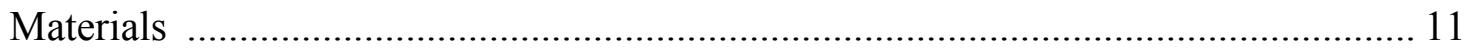

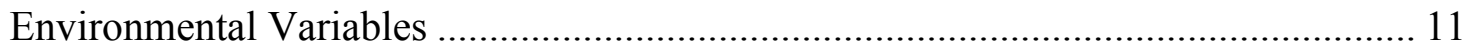

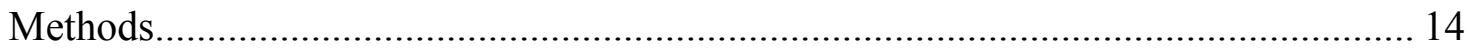

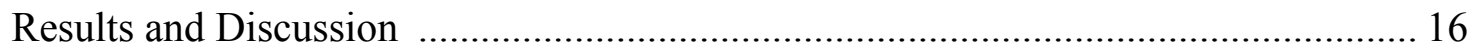

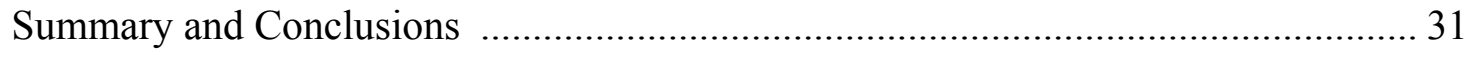

3 EFFECTS OF $\mathrm{pH}$ AND TEMPERATURE ON THE AQUEOUS SOLUBILITY AND DISSOLUTION RATE OF TNT, RDX, AND HMX ……………………...... 34

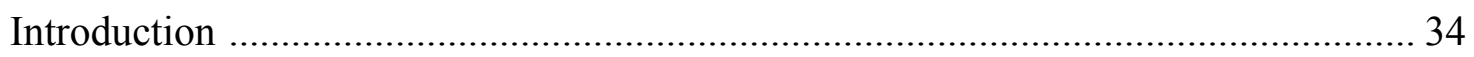

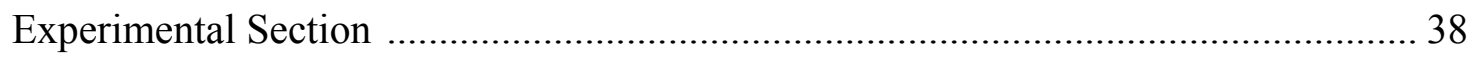

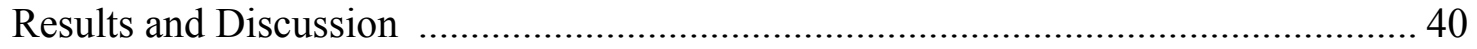

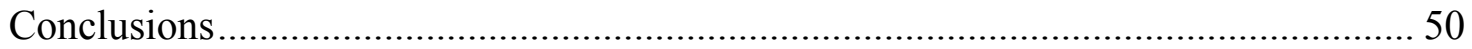

4 EFFECTS OF COMPONENT INTERACTIONS ON THE AQUEOUS SOLUBILITIES AND DISSOLUTION RATES OF THE EXPLOSIVE FORMULATIONS OCTOL, COMPOSITION B, AND LX-14 ................................ 51

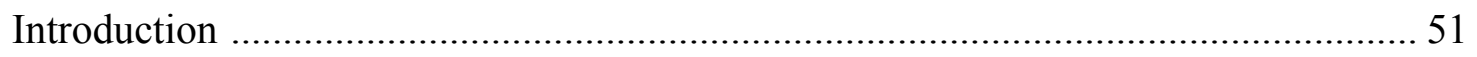

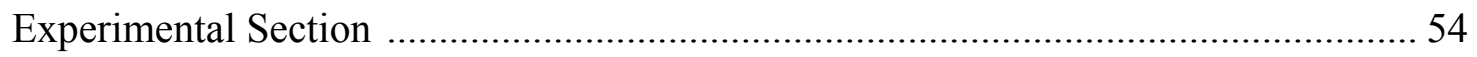

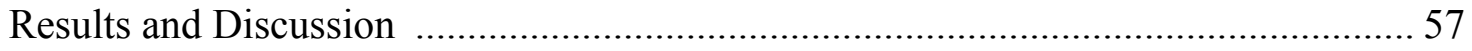


Conclusions

5 MODELING EXPLOSIVE COMPOUND PERSISTENCE AND FLUX USING

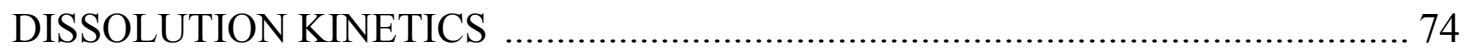

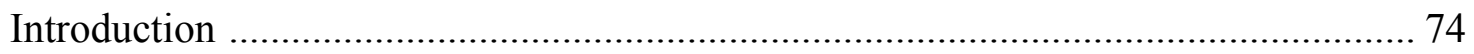

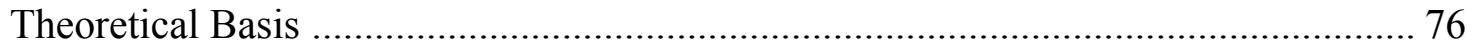

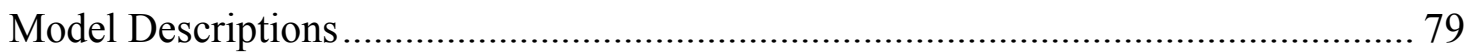

Example Description....................................................................................... 83

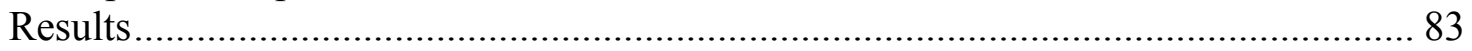

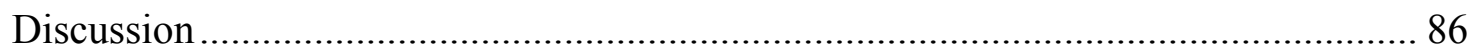

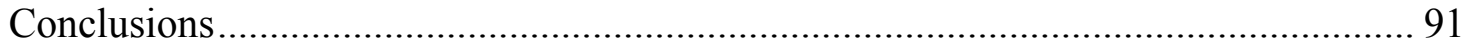

6 SUMMARY, CONCLUSIONS, AND RECOMMENDATIONS............................ 93

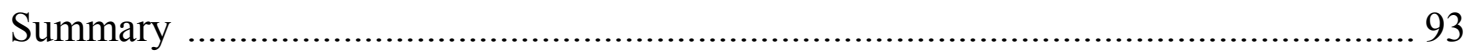

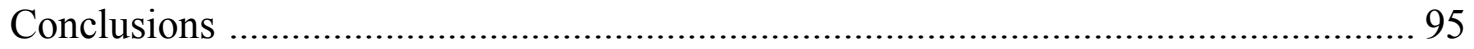

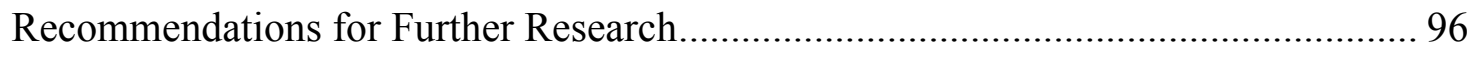

\section{APPENDIX}

A SUPPLEMENTAL INFORMATION: INDIVIDUAL EXPLOSIVE

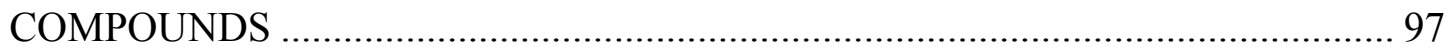

B SUPPLEMENTAL INFORMATION: EXPLOSIVE COMPOUND

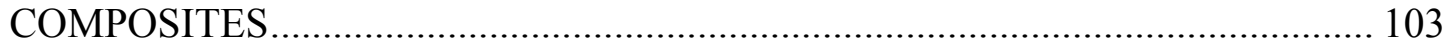

C SUPPLEMENTAL INFORMATION: PRECISION AND ACCURACY DATA .. 111

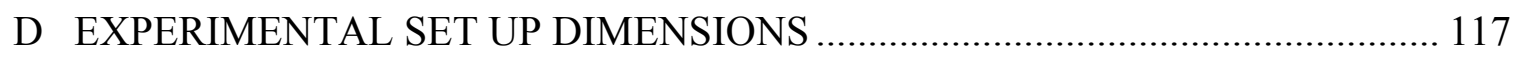

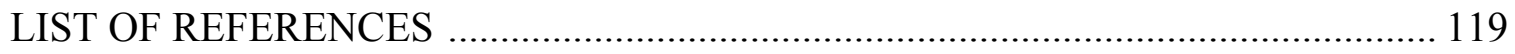

SF 298 


\section{LIST OF TABLES}

$\underline{\text { Table }}$

page

1-1 Explosive Compound Health Effects Summary from ATSDR Toxicological Profiles.

1-2 Explosive Compound Regulations and Advisories Summary from ATSDR

Toxicological Profiles (ATSDR, 2002)

1-3 Study Objectives and Chapter Affiliation 9

2-1 Correlation of Explosive Compound Dissolution Rates, $r\left(\mathrm{mg} \mathrm{min}^{-1}\right)$ and Surface Area, $a\left(\mathrm{~cm}^{2}\right)$, at $150 \mathrm{rpm}$ and Specified Temperatures . 18

2-2 Correlation of Explosive Compound Dissolution Rates, $r\left(\mathrm{mg} \mathrm{min}^{-1}\right)$ and Temperature, $T\left({ }^{\circ} \mathrm{C}\right)$, at $150 \mathrm{rpm}$ and Specified Explosive Surface Areas

2-3 Correlation of Explosive Compound Dissolution Rates, $r\left(\mathrm{mg} \mathrm{min}^{-1}\right)$ and Mixing Rate, $m$ (rpm), Using Surface Areas as Given in the Text and Specified Temperatures.

2-4 Average Percent Difference Comparisons Among Dissolution Rates, $r$ $\left(\mathrm{mg} \mathrm{min}^{-1}\right)$ for RDX

3-1 Solubilities of High Explosive Compounds as a Function of $\mathrm{pH}$ and Temperature

3.2 Summary of Mass of High Explosive Dissolved at Specified Sampling Times and $\mathrm{pH}$ Normalized for Solid Explosive Surface Area

3-3 Zero-Order pH-Related Explosive Dissolution Rates Measured at 30 $\mathrm{C}, 2.5 \mathrm{rps}$ Mixing, and Normalized Solid Explosive Surface Area

4-1 Dissolution Rates, $r$, of Explosive Compounds Measured Separately and in Mixtures $\left(\mathrm{mg} \mathrm{s}^{-1} \mathrm{~cm}^{-2}\right)$ Stirred at $2.5 \mathrm{rps}$ and Measured at Temperatures Shown.... 58

4-2 Dissolution Rates, $r$, of Explosive Compounds Found in Formulations and TNT Mold Measured at Temperature Indicated and Mixed at $2.5 \mathrm{rps}$ 
4-3 Formulation Dissolution Rate $\left(\mathrm{mg} \mathrm{s}^{-1} \mathrm{~cm}^{-2}\right)$ Correlations and $\mathrm{r}^{2}$ Values for Explosive Compounds Mixed at $2.5 \mathrm{rps}$ as a Function of Temperature Over (10 $-30)^{\circ} \mathrm{C}$

4-4 Solubilities of Explosive Compounds Determined Independently and in a NonBound Mixture with Correlation Predictions and the Average Percent Difference (APD) between Measurements and Predictions

4-5 Solubilities of Explosive Compounds in Formulations Compared to Correlation

Predictions with Average Percent Difference

5-1 Evaluation Models for the Dissolution of TNT and HMX from Correlation Equations Using a Mixing Speed of $150 \mathrm{rpm}$ and a Temperature of $10^{\circ} \mathrm{C}$

5-2 Explosive Compound Properties Using a Mixing Speed of $150 \mathrm{rpm}$ and $10^{\circ} \mathrm{C}$ for Model Comparison 85

5-3 Comparison of Model-Predicted TNT Loading $\left(\mathrm{mg} \mathrm{s}^{-1}\right)$ into Water from the Solid Explosive at $10^{\circ} \mathrm{C}$ and Determined at Four Different Times.

A-1 Average Percent Difference Comparisons Among Dissolution Rates, $r$ (mg $\min ^{-1}$ ) for TNT

A-2 Average Percent Difference Comparisons Among Dissolution Rates, $r$ (mg $\min ^{-1}$ ) for HMX

C-1 TNT Replicate Samples and Average Percent Differences for Precision Determination

C-2 RDX Replicate Samples and Average Percent Differences for Precision Determination

C-3 HMX Replicate Samples and Average Percent Differences for Precision Determination

C-4 Replicate Samples and Average Percent Differences for Explosive Formulations and TNT Mold Precision Determination

C-5 Replicate Standard Analyses for Average Percent Recoveries for Accuracy... 


\section{LIST OF FIGURES}

Figure $\quad \underline{\text { page }}$

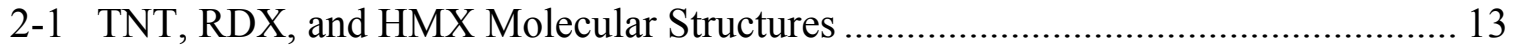

2-2 Comparison of Dissolution Rates for Explosive Compounds with Different

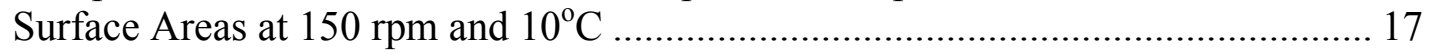

2-3 Dissolution Rate vs. Mixing Speed Comparison ................................................... 21

2-4 Comparison of HMX Multi-Variable Equation Plots to This Study's

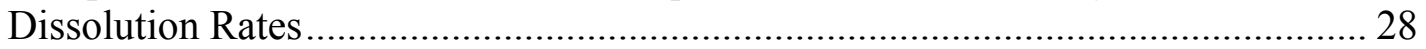

2-5 Comparison of TNT Multi-Variable Equation Plot and the Levins-Glastonbury Plot to This Study Data Determined at $150 \mathrm{rpm}$.................................................... 30

3-1 Reported TNT Solubility Prediction Curves in the Literature .............................. 36

3-2 Comparison of Literature TNT Solubility to This Study ................................... 43

3-3 Comparison of Literature RDX Solubility to This Study ................................... 44

3-4 Comparison of Literature HMX Solubility to This Study …................................. 45

3-5 Composite Explosive Solubility Prediction Correlations ..................................... 46

3-6 Comparison of Explosive Dissolution Rates at Three $\mathrm{pH}$ Values ........................... 48

4-1 Comparison of TNT Dissolution Rates Individually and in Various Non-bound Mixtures at Various Temperatures ..................................................................... 60

4-2 Comparison of TNT Dissolution Rates among the Various Experimental Runs at $2.5 \mathrm{rps}$

4-3 Comparison of HMX Dissolution Rates among the Various Experimental Runs at $2.5 \mathrm{rps}$

4-4 Comparison of RDX Dissolution Rates between RDX Crystals and RDX in Composition B at $2.5 \mathrm{rps}$ 
4-5 Comparison of Explosive Compound Solubility to that Predicted by Eqs $4-6$ at $2.5 \mathrm{rps}$

5-1 Depiction of the Dissolution Process Followed by the Three Models Over Time... 81

5-2 Comparison of the persistence of TNT using Models 1, 2, and 3 (Table 1) at $10^{\circ} \mathrm{C}$

5-3 Comparison of the persistence of HMX using Models 1, 2, and 3 (Table 1) at $10^{\circ} \mathrm{C}$

A-1 Comparison of RDX Multi-Variable Equation Plot to This Study's Dissolution Rates 100

A-2 Comparison of TNT Multi-Variable Equation Plot to This Study's Dissolution

Rates 101

B-1 Comparison of Surface Area Effects on Explosive Compound Dissolution Rate Measured at $10^{\circ} \mathrm{C}$ and $2.5 \mathrm{rps}$

B-2 Comparison of Temperature Effects on Explosive Compound Dissolution Rate Measured at $2.5 \mathrm{rps}$

B-3 Explosive Compound Dissolution Rate Determination Using Composite $\mathrm{pH}$ Data Measured at $30^{\circ} \mathrm{C}$ and $2.5 \mathrm{rps}$..... 105

B-4 Comparison of the Length of Time to Reach Solubility Using Eq. (3-4) for Different Explosive Compounds at $30^{\circ} \mathrm{C}$

B-5 Comparison of RDX Dissolution Rates Individually and in Various Non-Bound Mixtures at Various Temperatures

B-6 Comparison of HMX Dissolution Rates Individually and in Various NonBound Mixtures at Various Temperatures 108 


\section{Preface}

This report was prepared in partial fulfillment of the requirements for the degree of Doctor of Philosophy in the Department of Environmental Engineering Sciences at the University of Florida, Gainesville, FL. The Headquarters, U. S. Army Corps of Engineers (HQUSACE), Installation Restoration Research Program (IRRP), Fate and Effects Thrust Area, primarily sponsored this research. The Work Area was entitled Fate and Transport of Explosives Contaminants. The research was partially funded by the Strategic Environmental Research and Development Program (SERDP), Arlington, VA, under Compliance Project Number CP1155. Mr. Clem Myer was the IRRP Coordinator at the Directorate of Research and Development, HQUSACE, the IRRP Program Manager was Dr. M. John Cullinane, U.S. Army Engineer Research and Development Center (ERDC), Environmental Laboratory (EL). Mr. Bradley P. Smith was the Executive Director and Dr. Jeff Marqusee was the Technical Director of SERDP.

This report was prepared in partial fulfillment of the requirements for the degree of Doctor of Philosophy, University of Florida.

This report was written by LTC Jason C. Lynch, U.S. Army. The study was conducted under the direct supervision of Dr. Richard E. Price, Chief, EPED, EL, and Dr. Edwin A. Theriot, Director, EL.

At the time of publication of this report, Director of ERDC was Dr. James R. Houston. Commander and Executive Director was COL John W. Morris III, EN.

This report should be cited as follows:

Lynch, J. C. (2002). "Dissolution kinetics of high explosive compounds (TNT, RDX, HMX)," ERDC/EL TR-02-23, U.S. Army Engineer Research and Development Center, Vicksburg, MS.

The contents of this report are not to be used for advertising, publication, or promotional purposes. Citation of trade names does not constitute an official endorsement or approval of the use of such commercial products. 


\section{CHAPTER 1 \\ INTRODUCTION}

\section{Overview}

The Department of Defense faces a unique challenge in executing its mission of defending the nation from harm. On one hand its forces must be equipped with the necessary tools and must be trained realistically in the use of these tools to deter aggression, and, when deterrence fails, to fight and win the nation's wars. On the other hand, some materials used by the Department of Defense are known to be hazardous and their release into the environment during training poses potential risks to those the Department of Defense is charged to protect. Such is the issue involving several high explosive compounds; essential components of munitions yet at the same time health hazards to those incidentally exposed.

High explosive compounds are characterized by how quickly they decompose and release energy after initiation by a blow or shock. The susceptibility to rapidly decompose, or detonate, as a result of a stimulus such as an electrical charge separates explosive compounds into two groups: primary and secondary explosives. Primary explosives, for example lead azide, are very susceptible to detonation. Secondary explosives, for example tetryl, are not as susceptible to detonation. Because of their greater stability, secondary explosives often serve as the main charge in munitions, initiated by the detonation of a primary explosive present in smaller quantities (Van Deuren et al., 1977). What makes most high explosive compounds unstable are tightly 
packed nitro groups arranged on an organic backbone. When sufficiently strained, these nitro bonds break, releasing a great deal of energy and setting off a chain reaction throughout the other explosive molecules (May, 2001).

Three commonly used secondary high explosive compounds are 2,4,6trinitrotoluene (TNT), hexahydro-1,3,5-trinitro-1,3,5-triazine (RDX), and octahydro1,3,5,7-tetranitro-1,3,5,7-tetrazocine (HMX). These explosives, though, are often not used in weapons as individual compounds. Munitions like mortar rounds, anti-tank projectiles, and bombs are designed to be most effective in destroying intended targets. Part of this design is to combine different explosive compounds, together or alone, with binders and desensitizers to attain the degree of energy and sensitivity required by a particular munition. The various combinations of explosives and other additives are commonly referred to as explosive formulations. Two common categories of explosive formulations are those that take advantage of the low boiling point of TNT (melt-cast explosives) to bind the formulation together; and those that rely on other materials like plastics to bind the components together (plastic bonded explosives). An example of a melt-cast explosive formulation is octol (composed of TNT and HMX). An example of a plastic-bonded explosive formulation is LX-14 (composed of HMX and a polyurethane).

Explosive compounds that meet the definition of a solid waste as defined by the Resource Conservation and Recovery Act (RCRA), are by their characteristic of reactivity, also considered to be a hazardous waste (EPA, 1999). In addition to meeting the characteristic criteria, explosive compounds can also be considered listed wastes under subpart D of RCRA. Specifically, wastewater treatment sludges from the manufacturing and processing of explosives (K044), spent carbon from the treatment of 
wastewater containing explosives (K045), and pink/red water from TNT operations (K046) are identified in this subsection. Two intermediate products in the production of TNT (2,4-dinitrotoluene and 2,6-dinitrotoluene) are listed as hazardous waste because of their toxicity (U105 and U106 respectively). As a hazardous waste, explosive compounds are subject to cradle-to-grave management, and when improperly disposed, these sites must be cleaned up.

Besides the concern that these explosive compounds may explode, TNT, RDX, and HMX are known to cause various degrees of health effects to humans. In many cases these human health effects are assumptions based on available animal study results and the limited number of human-related case studies observed. The Agency for Toxic Substances and Disease Registry (ATSDR) has a web site that highlights pertinent information regarding the toxicological profile for these explosive compounds (ATSDR, 2002). Summaries of the existing information related to human and animal health effects for these three explosive compounds from each profile are found in Table 1-1. National regulations and guidelines applicable to these three explosive compounds based on these health effects from the profile for each explosive compound are summarized in Table 1-2.

Sites where individual explosive compounds were manufactured (such as the Holston Army Ammunition Plant), weaponized (loading, assembly, and packaging facilities such as the Nebraska Ordnance Plant), and stored (such as the Hawthorne Navy Ammunition Depot) were the first locations identified as being contaminated with explosive compounds and targeted for remediation under RCRA. Besides the Department of Defense, the Department of Energy also has lands that were contaminated with explosive compounds. These include facilities like the Pantex Ordnance Plant that 


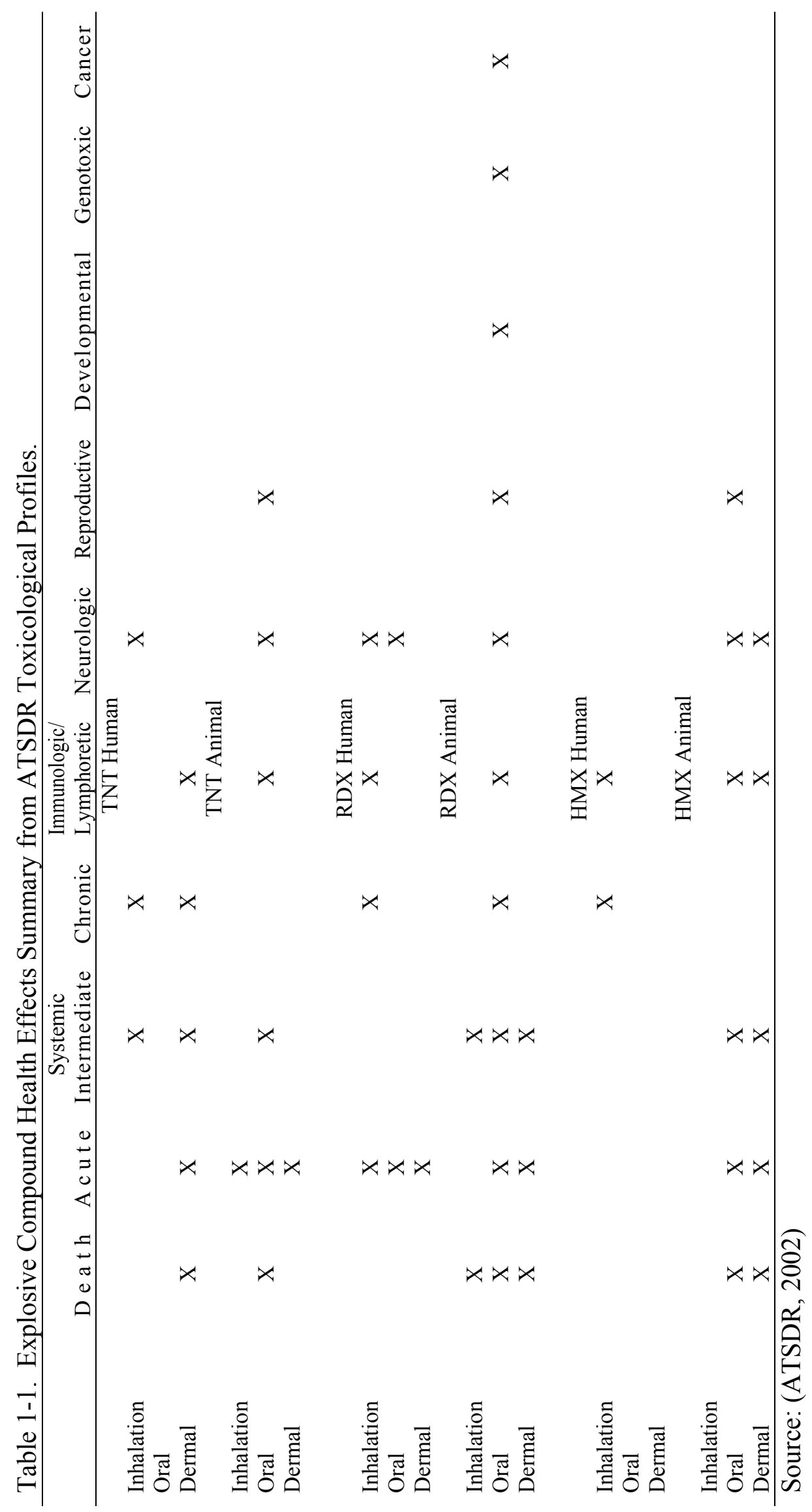


Table 1-2. Explosive Compound Regulations and Advisories Summary from ATSDR Toxicological Profiles.

\begin{tabular}{|c|c|c|c|c|}
\hline Area & Description & TNT & RDX & HMX \\
\hline Air - OSHA & PEL TWA & $0.5 \mathrm{mg} / \mathrm{m} 3$ & $1.5 \mathrm{mg} / \mathrm{m} 3$ & $\mathrm{n} / \mathrm{a}$ \\
\hline Air - NIOSH & $\begin{array}{l}\text { REL TWA (10 } \\
\text { hrs) }\end{array}$ & $0.5 \mathrm{mg} / \mathrm{m} 3$ & $1.5 \mathrm{mg} / \mathrm{m} 3$ & $\mathrm{n} / \mathrm{a}$ \\
\hline Water - ODW & Lifetime & $2 \mu \mathrm{g} / \mathrm{L}$ & $2 \mu \mathrm{g} / \mathrm{L}$ & $400 \mu \mathrm{g} / \mathrm{L}$ \\
\hline Other - EPA & RfD (oral) & $\begin{array}{c}5 \times 10^{-4} \\
\mathrm{mg} / \mathrm{kg} / \text { day }\end{array}$ & $\begin{array}{c}3 \times 10^{-3} \\
\mathrm{mg} / \mathrm{kg} / \text { day }\end{array}$ & $\begin{array}{c}5 \times 10^{-2} \\
\mathrm{mg} / \mathrm{kg} / \text { day }\end{array}$ \\
\hline Other - EPA & $\begin{array}{l}\text { Carcinogenic } \\
\text { Class }\end{array}$ & $\mathrm{C}$ & $\mathrm{C}$ & $\mathrm{D}$ \\
\hline
\end{tabular}

Source: (ATSDR, 2002)

Note: PEL = permissive exposure limit, REL = recommended exposure limit, TWA = time weighted average, $\mathrm{RfD}=$ reference dose, $\mathrm{C}=$ possible human carcinogen, $\mathrm{D}=$ not classifiable as to human carcinogenicity 
produced nuclear weapons and research laboratories like the Los Alamos National Laboratory.

A demilitarization site is another type of location where explosive compounds can be released into the environment. The common method of managing excess or malfunctioned munitions, historically, was by open burn and open detonation (OB/OD). As was the acceptable practice of the times, the pits where OB/OD took place were often unlined, exposing any explosive compound residue remaining from incomplete detonation to the environment. These sites are required to be remediated by RCRA.

The number and types of explosive contaminated sites requiring attention may have unintentionally increased as a result of the congressionally mandated Base Realignment and Closure (BRAC) and closure of other Formerly Used Defense Sites (FUDS). The intent of both BRAC and FUDS was to reduce Department of Defense operational costs for maintaining facilities in excess of existing requirements. These lands could then be transferred to citizens for commercial, government, or private use. This should have been a positive situation for all interested parties. Problems arose though in bringing these areas to standards acceptable for transfer. One area of concern was those locations that had been used for weapons training and testing. With approximately $10 \%$ of munitions failing to function as designed, these areas were contaminated with unexploded ordnance (UXO) and explosive residue. Like the present concern over landmines, these UXO and explosive residues presented safety hazards and prohibited the transfer of the properties without first removing these hazardous substances. 
A more subtle concern was the health effects posed by the explosive compounds in these munitions. Those areas where military testing and training with explosive compounds were actively being conducted were exempt under RCRA from regulation. Once no longer active, this exemption became less definitive. With the withdrawal of a proposed Department of Defense Range Rule (with which the Environmental Protection Agency (EPA) did not agree), this issue has yet to be resolved (Macdonald, 2001).

Incidents surrounding training activities at the National Guard's Massachusetts Military Reservation (MMR) at Camp Edwards, Cape Cod, Massachusetts ushered in new issues involving explosive compounds and their release into the environment. Among other contaminant constituents, RDX was found in quantities above the recommended lifetime exposure limit in the groundwater. The Massachusetts Military Reservation is the first location that the EPA required action be taken for environmental reasons because of UXOs. Citing justification under emergency provisions in the Safe Drinking Water Act (SDWA), EPA ordered training activities on the installation to cease because of the potential risk these activities posed to the environment and the sole source drinking water aquifer under the installation (Williams, 2000).

This EPA order provides additional support to organizations already arguing against active military installations where live fire training is conducted. The primary "not in my backyard" arguments include safety issues from stray bombs falling outside the range, to fire and noise complaints, to survival of endangered species (Schafer, 2001). Potential health hazards to people and the environment are the latest additions to this list. A prominent example of a bombing range now closed is the Navy bombing range on the island of Viesques, Puerto Rico (Scarborough, 2002). Another is the Army's live fire 
training range, Makua Military Reservation in the Makua Valley on the Hawaiian island of Oahu (Stone, 2001). Those military-civilian conflicts over land-use could affect the combat readiness of the military service.

These series of events, some supported by suggestive evidence, while others are backed by public opinion and rhetoric, mandated that research must support decisions that need to be made based on scientifically drawn conclusions. Assessments need to be based on the ecological as well as physical setting where explosive compound contamination is found (Houston et al., 2001). In the final report by the Keystone Center, National Policy Dialogue on Military Munitions, the lack of information concerning munitions constituents was highlighted. The report stated, "this knowledge base needs significant expansion" (Keystone Center, 2000). To effectively address explosive compound persistence and subsequent migration, fate, concentration, and risk, the source term needs to be better characterized. Of particular interest is how these explosives compounds dissolve in an aqueous environment.

\section{Objectives}

The objectives of this study are to characterize the aqueous dissolution of three explosive compounds TNT, RDX, and HMX, and three explosive formulations that incorporate these compounds: octol, Composition B, and LX-14. Specifically, this study was designed to

1. Identify the major variables affecting dissolution rate

2. Develop correlation equations that predict dissolution rates given a set of environmental conditions for each of these explosives

3. Develop correlation equations that predict the solubility of each of these explosives as a function of temperature 
4. Determine the effect of $\mathrm{pH}$ (within the limits found in acid rain) on the dissolution rate and solubility equations

5. Determine interactive effects of more than one explosive compound in solution at a time on compound dissolution rates or solubility

6. Determine if the explosive formulations octol, Composition B, and LX-14 adhere to the dissolution rate equations developed for each explosive compound in that particular formulation

7. Determine if the explosive formulations octol, Composition B, and LX-14, adhere to the solubility equations developed for each explosive compound in that particular formulation

8. Model the flux load resulting from a dissolving solid explosive source and assess the persistence of this source using three different modeling approaches

The laboratory phase of this study was conducted at the U.S. Army Engineer

Research and Development Center, Environmental Laboratory, Vicksburg, Mississippi over two summer periods. Objectives 1 though 4 were accomplished during 2000 and Objectives 5 through 7 were completed in 2001. Data analysis and Objective 8 were completed at the University of Florida in the Department of Environmental Engineering Sciences. Results for the study objectives are presented in the chapters as indicated in Table 1-3.

Table 1-3. Study Objectives and Chapter Affiliation.

\begin{tabular}{cc}
\hline Study Objective(s) & Dissertation Chapter \\
\hline 1,2 & 2 \\
3,4 & 3 \\
$5,6,7$ & 4 \\
8 & 5 \\
\hline
\end{tabular}




\section{CHAPTER 2 \\ DISSOLUTION RATES OF THREE HIGH EXPLOSIVE COMPOUNDS: TNT, RDX, AND HMX}

\section{Introduction}

High explosives (compounds that rapidly detonate when initiated by a blow or shock) (Van Deuren et al., 1997) can enter the environment from sites where they are manufactured, stored, disposed, or used in military training (Best et al., 1999). Besides causing possible physical injury and property damage by detonation, several high explosive compounds have been found to have detrimental health effects as well. Human exposure can occur by drinking contaminated water, breathing contaminated air, or coming in contact with contaminated soil.

Health effects associated with exposure to high explosive compounds vary by explosive type. TNT has been associated with liver and blood damage, anorexia, and anemia. RDX and HMX have been associated with systemic poisoning usually affecting bone marrow and the liver. Both TNT and RDX have been classified as possible human carcinogens, while HMX has not yet been classified as to its human carcinogenicity (Agency for Toxic Substances and Disease Registry (ATSDR), 1996 [TNT, RDX], 1997 $[\mathrm{HMX}])$. To help safeguard people against these detrimental effects, the EPA lifetime exposure drinking water health advisory limits for TNT, RDX, and HMX are 2, 2, and $400 \mu \mathrm{g} \mathrm{L}{ }^{-1}$, respectively (Crockett et al., 1999).

Risk assessments should adequately link a contaminant source, transmission pathways, and exposure potential. The degree of risk that a source poses to a population 
is a function of the amount and frequency of contaminant uptake (Daniels and Knezovich, 1994). Dissolution into water is the primary method by which nonvolatile explosives migrate away from their initial source. Yet, information on dissolution rates of high explosives is limited (Brannon et al., 1999). The purpose of this study was to develop equations describing aqueous dissolution rates for these three explosives as a function of temperature, solid-liquid interfacial surface area, and energy input. Of interest are explosive compounds used by the military and their resulting presence in the environment.

\section{Materials}

Three military grade explosives selected for this study were 2,4,6-trinitrotoluene (TNT), hexahydro-1,3,5-trinitro-1,3,5-triazine (RDX), and octahydro-1,3,5,7-tetranitro1,3,5,7-tetrazocine (HMX). TNT is a nitroaromatic explosive while RDX and HMX are classified as nitroamines (Figure 2-1). The TNT used in this study is identified as Type I flake; the RDX is Type II, Class 3 crystals; and the HMX is Grade B, Class 2 crystals. Military grade high explosives were used to replicate the nature of explosives expected in a field environment (i.e., age, composition) and were deemed more representative than pure individual compounds.

\section{Environmental Variables}

The choice of experimental variables was based on key terms in Fick's First Law:

$$
V \frac{d C}{d t}=\frac{D}{h} a\left(C_{s}-C_{b}\right)
$$

where $d C / d t$ is the change in concentration over time $\left(\mathrm{mg} \mathrm{s}^{-1} \mathrm{~L}^{-1}\right), V=$ volume of solvent (L), $D=$ diffusion coefficient $\left(\mathrm{cm}^{2} \mathrm{~s}^{-1}\right) ; a=$ surface area $\left(\mathrm{cm}^{2}\right) ; C_{s}=$ solubility $\left(\mathrm{mg} \mathrm{cm}^{-3}\right)$; $C_{b}=$ concentration in bulk liquid $\left(\mathrm{mg} \mathrm{cm}^{-3}\right)$; and $h=$ stagnant layer thickness $(\mathrm{cm})$. 
This expression can be reduced to a zero order equation where the approximation of the $D / h$ term under different environmental conditions is possible. To approximate a zero order equation, several of the variables in Eq. (2-1) had to be assumed as constant. In dilute solutions, $C_{b}$ is small with respect to $C_{s}$ and can be assumed to be negligible. Sampling intervals were therefore arranged to be complete before the predicted $C_{b} / C_{s}$ ratio reached 0.2. Experiments were also controlled so that changes in solvent volume (averaging a 1\% loss from total sampling) and explosive compound surface areas (averaging a 5\% loss from dissolution) would be negligible. The need to maintain a dilute solution affected run times, ranging from 4.3 minutes for $\mathrm{HMX}$ at $30^{\circ} \mathrm{C}$ (solubility less than $3 \mathrm{mg} \mathrm{L}^{-1}$ ) to 120 minutes for TNT at $10^{\circ} \mathrm{C}$ (solubility greater than $70 \mathrm{mg} \mathrm{L}^{-1}$ ).

The three temperatures selected for this study $\left(10^{\circ} \mathrm{C}, 20^{\circ} \mathrm{C}, 30^{\circ} \mathrm{C}\right)$ are representative of the range of ambient conditions where unexploded explosive compounds might be found in the environment.

Approximation of explosive surface areas was necessary because of the heterogeneity of particle sizes and shapes (ranging from less than $0.04 \mathrm{~mm}$ in diameter for HMX crystals to greater than $4 \mathrm{~mm}$ in length for TNT flakes). Surface areas for RDX and HMX were estimated using mass to surface area ratios for each explosive based on military specifications for acceptable granulation distribution. These nominal surface areas do not account for surface roughness that was seen microscopically on the explosives. Based on a desired separation of approximately $20 \%$ among the three sample 


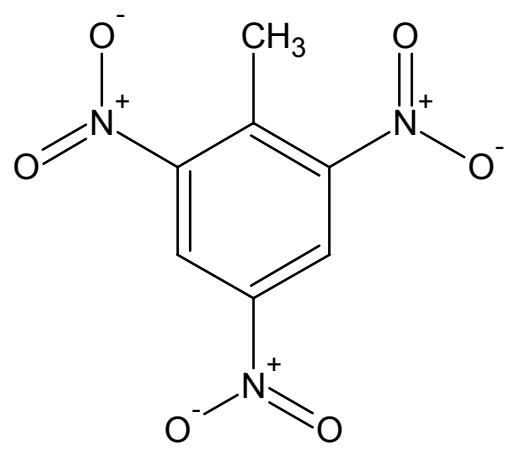

2,4,6-trinitrotoluene (TNT)<smiles>O=[N+]([O-])N1CN([N+](=O)[O-])CN([N+](=O)[O-])C1</smiles>

hexahydro-1,3,5-trinitro-1,3,5-triazine (RDX)<smiles>O=[N+]([O-])N1CN([N+](=O)[O-])CN([N+](=O)[O-])CN([N+](=O)[O-])C1</smiles>

octahydro-1,3,5,7-tetranitro-1,3,5,7-tetrazocine (HMX)

Figure 2-1. TNT, RDX, and HMX Molecular Structures 
surface areas (to provide sufficient separation yet fit within the conditions of this study), RDX quantities that produced sample surface areas of approximately 8,10 , and $12 \mathrm{~cm}^{2}$ were measured out using an estimated RDX surface area to mass ratio of $100.4 \mathrm{~cm}^{2} \mathrm{~g}^{-1}$. Similarly, sufficient HMX was used to produce sample surface areas of approximately 5, 6, and $7 \mathrm{~cm}^{2}$ based on a HMX surface area to mass ratio estimate of $598.5 \mathrm{~cm}^{2} \mathrm{~g}^{-1}$.

For TNT, measuring TNT flake areas under a microscope and then weighing these sets of flakes on a balance yielded a reproducible surface area to mass ratio. This method yielded a surface area to mass estimate of $23.28 \mathrm{~cm}^{2} \mathrm{~g}^{-1}$. Sufficient TNT was used to produce sample surface areas of approximately $5.8 \mathrm{~cm}^{2}, 7.3 \mathrm{~cm}^{2}$, and $8.7 \mathrm{~cm}^{2}$.

The stagnant layer thickness represents the gradient zone in the solution between the surface of the solid explosive (where the solution concentration is at the solubility limit) to a point in the solution where the concentration equals that of the rest of the bulk solution. Since dissolution is affected by the rate of transport from the explosive compound's surface to the bulk solution, rates would increase if the layer were thinner and the gradient steeper (Stumm and Morgan, 1996). This condition can be achieved by energy input in the form of agitation or stirring. Mixing rates of 90, 150, and $250 \mathrm{rpm}$ were selected to determine the effects of mixing rate on dissolution rate.

\section{Methods}

\section{Experimental Design}

To determine each variable's impact on dissolution rate, duplicate experiments were performed where one of the identified variables was changed while the other two variables were held constant. To limit TNT photolysis (Townsend and Myers, 1996), all experiments were performed under limited light conditions and samples stored in the 
dark. The experimental design is based on dissolution test protocols described in the United States Pharmacopeia (1990).

Five hundred $\mathrm{mL}$ of demineralized (reverse osmosis) water in $600 \mathrm{~mL}$ beakers were covered with aluminum foil and allowed to equilibrate to temperature for 15 hours in a water bath. The water temperature was regulated using a Fisher Scientific Isotemp Refrigerated Circulator and was insulated from the air temperature by a floating layer of $20 \mathrm{~mm}$ hollow plastic balls.

Stirring propellers from an overhead mounted Yamato Scientific StedFast Digital Lab Stirrer were centered and lowered into each beaker, raised to a height of $2.5 \mathrm{~cm}$ above the beaker bottom, and adjusted to the desired rpm. Once these conditions were achieved, the desired amount of dry explosive compound was added to each beaker and a timer simultaneously started. While continuing to stir, five one-mL samples were periodically withdrawn by pipet from a zone midway between the surface of the solution and the top of the stirring propeller and midway between the beaker wall and the propeller shaft.

\section{Analytical Methodology}

The one $\mathrm{mL}$ samples were immediately filtered using a disposable $3 \mathrm{~mL}$ Luer-Lok syringe with attached $0.45 \mu \mathrm{m}$ pore size Millex Millipore Filter. The filtrates were combined with an equal volume of $0.45 \mu \mathrm{m}$-filtered acetonitrile, and capped in a $4 \mathrm{~mL}$ vial. The vial was vortexed for five seconds and then stored quiescently for at least 25 minutes. Samples were then analyzed using a Waters High Performance Liquid Chromatograph (HPLC) with a model 486 tunable UV detector $(\lambda=245 \mathrm{~nm})$ and auto sampler running a Millennium Software package using Method 8330 (USEPA, 1994). 


\section{Results and Discussion}

Analysis of the dissolution data showed that linear regression adequately described the observed explosives dissolution. The experimental methodology selected (i.e. sampling period and intervals, amounts of explosive compounds used) to obtain a zero order representation of Eq. (2-1) worked well for TNT and RDX and was satisfactory for HMX. The mean value \pm one standard deviation of all the $\mathrm{r}^{2}$ values for each explosive compound regression, including all experimental runs, was $0.986 \pm 0.008$ for TNT, $0.989 \pm 0.014$ for RDX and $0.746 \pm 0.096$ for HMX.

If the surface area approximation methodologies were reproducible, then explosive compound dissolution rates recorded in units of $\mathrm{mg} \mathrm{min}^{-1} \mathrm{~cm}^{-2}$ would be equivalent given that the amount of surface area exposed was the only difference among experiments. To check this premise, the dissolution rates for the three explosive compounds were plotted versus surface area (Figure 2-2). Using the individual data, the average percent differences from the means were $3.8 \%$ for TNT, $5.7 \%$ for RDX and $6.6 \%$ for HMX. These results indicate that the surface area estimation procedures were reproducible. Correlations of dissolution rates and surface area determined at $150 \mathrm{rpm}$ and $10^{\circ} \mathrm{C}, 20^{\circ} \mathrm{C}$, and $30^{\circ} \mathrm{C}$ are summarized in Table $2-1$.

Correlations of dissolution rate and temperature measured at a mixing rate of 150 rpm and at the specified explosive compound surface areas are summarized in Table 2-2. Temperature effects on dissolution rate are best represented using an exponential trend line. Changes in temperature have the greatest effect on TNT and the smallest effect on RDX dissolution rates. Dissolution rate increases with increases in temperature, suggesting that dissolution of these explosive compounds is an endothermic process. 


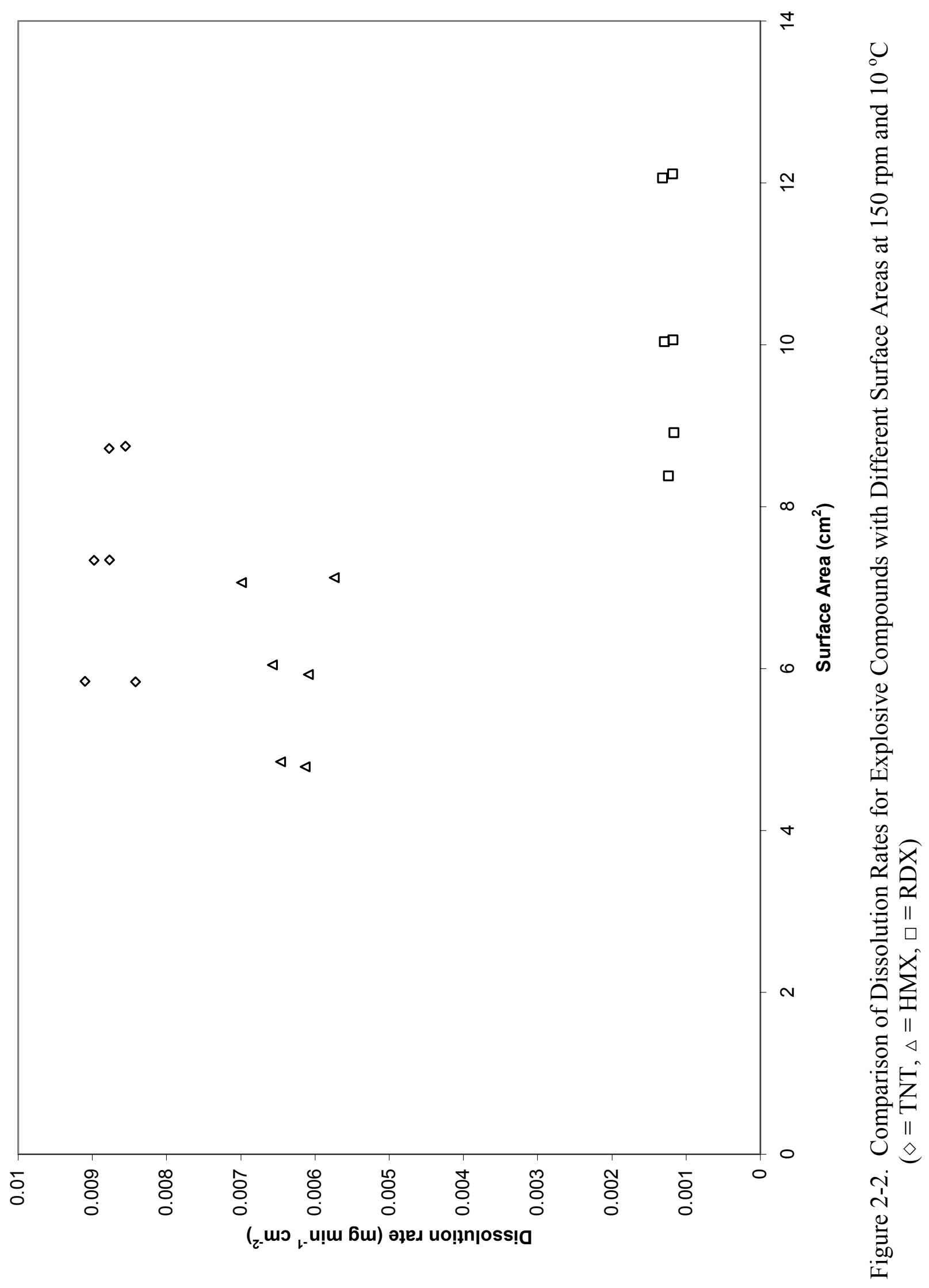


Table 2-1. Correlation of Explosive Compound Dissolution Rates, $r\left(\mathrm{mg} \mathrm{min}^{-1}\right)$ and Surface Area, $a\left(\mathrm{~cm}^{2}\right)$, at $150 \mathrm{rpm}$ and Specified Temperatures $10^{\circ} \mathrm{C} \quad 20^{\circ} \mathrm{C} \quad 30^{\circ} \mathrm{C}$

$\begin{array}{lrrrrrr}\text { Compound } & r= & \mathrm{r}^{2} & r= & \mathrm{r}^{2} & r= & \mathrm{r}^{2} \\ \text { TNT } & 9.0 \times 10^{-3} a & 0.99 & 1.4 \times 10^{-2} a & 0.91 & 4.1 \times 10^{-2} a & 0.96 \\ \text { RDX } & 1.0 \times 10^{-3} a & 0.98 & 3.0 \times 10^{-3} a & 0.72 & 6.0 \times 10^{-3} a & 0.99 \\ \text { HMX } & 6.0 \times 10^{-3} a & 0.99 & 1.3 \times 10^{-2} a & 0.99 & 2.0 \times 10^{-2} a & 0.99\end{array}$


Table 2-2. Correlation of Explosive Compound Dissolution Rates, $r\left(\mathrm{mg} \mathrm{min}^{-1}\right)$ and Temperature, $T\left({ }^{\circ} \mathrm{C}\right)$, at $150 \mathrm{rpm}$ and Specified Explosive Surface Areas

\begin{tabular}{lcccccccccc}
\hline & $\mathrm{cm}^{2}$ & $r=$ & $\mathrm{r}^{2}$ & $\mathrm{~cm}^{2}$ & $r=$ & $\mathrm{r}^{2}$ & $\mathrm{~cm}^{2}$ & $r=$ & $\mathrm{r}^{2}$ \\
\hline TNT & 5.8 & $8.0 \times 10^{-3} T$ & 0.96 & 7.3 & $9.0 \times 10^{-3} T$ & 0.96 & 8.7 & $1.2 \times 10^{-2} T$ & 0.95 \\
RDX & 8.0 & $1.5 \times 10^{-3} T$ & 0.96 & 10.0 & $1.8 \times 10^{-3} T$ & 0.96 & 12.0 & $2.3 \times 10^{-3} T$ & 0.96 \\
HMX & 4.8 & $3.0 \times 10^{-3} T$ & 0.99 & 6.0 & $4.0 \times 10^{-3} T$ & 0.99 & 7.1 & $5.0 \times 10^{-3} T$ & 0.99 \\
\hline
\end{tabular}


The activation energies of dissolution were calculated using a form of the Arrhenius equation (Henry and Heinke, 1996):

$$
\mathrm{E}_{\mathrm{a}}=\frac{\mathrm{R} \ln \left(\mathrm{k}_{2} / \mathrm{k}_{1}\right)}{\left(1 / \mathrm{T}_{1}-1 / \mathrm{T}_{2}\right)}
$$

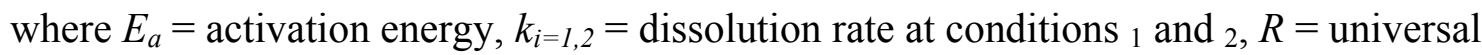
gas constant, $T_{i=1,2}=$ temperature in $\mathrm{K}$ at conditions ${ }_{1}$ and ${ }_{2}$. Activation energies for TNT, RDX, and HMX were calculated to be 55.6, 55.4, and $40.7 \mathrm{~kJ} \mathrm{~mol}^{-1}$, respectively. In agreement with the Arrhenius prediction that dissolution rate will double with a $10^{\circ} \mathrm{C}$ increase in temperature, the experimental dissolution rates increased by approximately 2.2 times for TNT and RDX and 1.8 times for HMX.

Dissolution rates vs. mixing rpm at $10^{\circ} \mathrm{C}$ and $30^{\circ} \mathrm{C}$ and explosive compound surface areas equal to $7.3 \mathrm{~cm}^{2}$ for TNT, $10 \mathrm{~cm}^{2}$ for RDX and $6 \mathrm{~cm}^{2}$ for HMX are shown in Figure 2-3. Correlations of dissolution rate and mixing rate are presented in Table 2-3. Given that zero agitation equates to a diffusion process, linear regression trend lines of the data were not forced through zero. The terms in the correlation equations that are not a function of rpm in Table 2-3 allow comparison of the "relative" (relative because this study was not designed to determine diffusion and actual rates cannot be negative) diffusion rates of the three explosive compounds. TNT had the apparent slowest diffusion rate followed by RDX, and HMX with the highest diffusion rate. Changes in stirring rate have the greatest effect on TNT and the smallest effect on HMX dissolution rates.

A linear regression trend line with an $\mathrm{r}^{2}$ of only 0.58 was obtained using the mixing rates of 90,150 , and $210 \mathrm{rpm}$ for $\mathrm{HMX}$ at $30^{\circ} \mathrm{C}$ (Figure 2-3). Experiments for 


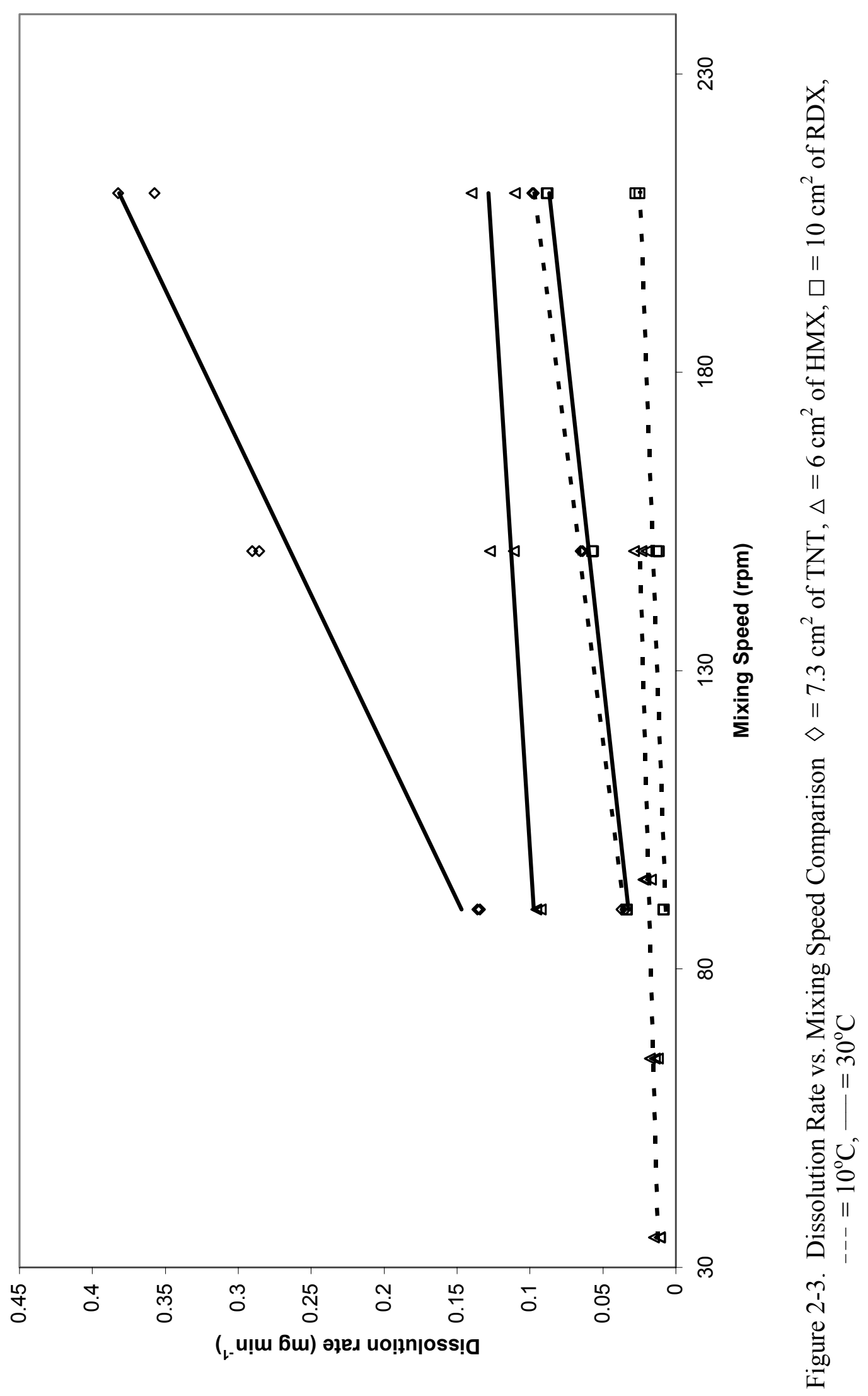


Table 2-3. Correlation of Explosive Compound Dissolution Rates, $r\left(\mathrm{mg} \mathrm{min}^{-1}\right)$ and Mixing Rate, $m$ (rpm), Using Surface Areas as Given in the Text and Specified Temperatures.

\begin{tabular}{|c|c|c|c|c|}
\hline & $10^{\circ} \mathrm{C}$ & & $30^{\circ} \mathrm{C}$ & \\
\hline & $r=$ & $\mathrm{r}^{2}$ & $r=$ & $r^{2}$ \\
\hline TNT & $5.0 \times 10^{-4} m-1.1 \times 10^{-2}$ & 0.99 & $2.0 \times 10^{-3} m-2.9 \times 10^{-2}$ & 0.96 \\
\hline RDX & $1.0 \times 10^{-4} m-6.7 \times 10^{-3}$ & 0.89 & $5.0 \times 10^{-4} m-8.5 \times 10^{-3}$ & 0.99 \\
\hline HMX & $1.0 \times 10^{-4} \mathrm{~m}+8.7 \times 10^{-3}$ & 0.97 & $3.0 \times 10^{-4} \mathrm{~m}+7.4 \times 10^{-2}$ & 0.58 \\
\hline
\end{tabular}

Note HMX correlations at $10^{\circ} \mathrm{C}$ and $30^{\circ} \mathrm{C}$ were not performed using the same range of mixing rates. 
HMX conducted at $10^{\circ} \mathrm{C}$ yielded similar results. These reduced values suggested that increases in mixing speed over the experimental range had increasingly smaller effects on enhancing HMX dissolution rate. In theory, there should be a limit to how much the stagnant layer thickness can be decreased as a result of increased energy input. A second set of experiments using mixing rates of $35,65,95$, and $150 \mathrm{rpm}$ at $10^{\circ} \mathrm{C}$ and a surface area of $6 \mathrm{~cm}^{2}$ for HMX were performed to test this theory. The resulting $\mathrm{r}^{2}$ for this correlation improved to 0.97 and this set of data is included on Figure 2-3. These results indicate that a stirring rate exists for each explosive compound above which the use of these correlation equations is invalid. For HMX, this rate appears to be above $150 \mathrm{rpm}$.

To be able to relate rpm-based dissolution rates in a beaker to terms that are used in an engineered process or in the environment, mixing speed was correlated to two different terms. The first is the $\varepsilon$ term (a mass normalized energy dissipation rate) in the Levins- Glastonbury (1972a) correlation:

$$
\varepsilon \approx \frac{N^{3} D_{s}^{5}}{D_{T}^{2} H}
$$

where $N=$ stirrer speed, $D_{s}=$ stirrer diameter, $D_{T}=$ tank diameter, and $H=$ height of liquid. This term has been used in tank reactors and is relevant in an equation to be presented later (Eq. (2-8)) when comparing TNT dissolution rate results of this study to those of Gilcrease et al. (1996).

The second correlation relates the power-driven mixing rate to the " $R$ " term (rainfall erosivity index) in the Revised Universal Soil Loss Equation (RUSLE) (USDA, 2001). The reason for pursuing this relationship was to relate rainfall energy impinging on explosives residue in the field to the energy input variable in the experimental design. This would permit the calculation of dissolution rates and contaminant persistence 
resulting from rain falling on explosive compounds exposed on the soil surface. The $R$ term, a yearly average, is in units of hundreds foot tons-force inch acre $^{-1}$ hour $^{-1}$ year $^{-1}$, or energy times a rainfall rate over an area (Simanton, 2000). The experimental design has similar units with power input (energy/time) over an area (beaker area) in a certain depth (height of liquid in beaker). Mixing power requirements assuming turbulent flow were estimated using the equation (Tchobanoglous and Schroeder, 1987):

$$
p=k \rho n^{3} d_{i}^{5}
$$

where $p=$ power requirement, $k=$ arbitrary constant estimated as 1 (Borsella, 2000), $\rho=$ liquid density, $n=$ rotational speed, and $d_{i}=$ diameter of mixer impeller

After equating units, $R$-values in the RUSLE program (ranging in the U.S.A. from the 20s in Nevada to the 350s in Florida) were similar to the experimental energy input values selected for this study. For example, an $R$-value of 250 hundred foot tons-force inch acre ${ }^{-1}$ hour $^{-1}$ year $^{-1}$ (representative for Tennessee, U.S.A.) from the RUSLE compares well to a mixing speed of approximately $120 \mathrm{rpm}$ in the experimental design using the equation:

$$
\mathrm{rpm}=60\left(\mathrm{R} \frac{1.182 \times 10^{-6} \Pi_{\mathrm{T}}{ }^{2}}{\mathrm{kpd}_{\mathrm{i}}{ }^{5} \mathrm{H}}\right)^{1 / 3}
$$

with units for $R=100$ foot-ton-force inch acre $^{-1}$ hour $^{-1}$ year $^{-1}, D_{T}=\mathrm{cm}, d_{i}=\mathrm{m}$, $\rho=\mathrm{kg} \mathrm{m}^{-3}$, and $H=\mathrm{cm}$

Besides evaluating individual variable effects on explosive compound dissolution rates, the combination of temperature, surface area, and mixing speed into a single correlation was investigated using three different approaches. The first approach built on the individual variable dissolution rate approach and involved a series of linear 
regressions incorporating an additional variable into the rate term at each regression, ultimately yielding an expression for dissolution rate with units of $\mathrm{mg} \mathrm{min}^{-1} \mathrm{~cm}^{-2} \mathrm{rpm}^{-1}$ ${ }^{\circ} \mathrm{C}^{-1}$. Of the possible combinations, the sequence of variable additions and regressions used in this study was from dissolution rate expressed as $\mathrm{mg} \mathrm{min}^{-1}$ to $\mathrm{mg} \mathrm{min}^{-1} \mathrm{~cm}^{-2}$ to $\mathrm{mg} \mathrm{min}{ }^{-1} \mathrm{~cm}^{-2} \mathrm{rpm}^{-1}$ to $\mathrm{mg} \min ^{-1} \mathrm{~cm}^{-2} \mathrm{rpm}^{-1}{ }^{\circ} \mathrm{C}^{-1}$. All regressions except the last one forced the trend line through zero. Other sequences for variable addition did not yield a multi-variable trend line that closely fit the experimental data. With respect to the variables employed in this study, ranking from greatest to least impact on dissolution rate, temperature $\left({ }^{\circ} \mathrm{C}\right)$ was first, followed by surface area $\left(\mathrm{cm}^{2}\right)$, and then mixing speed (rpm). The multi-regression, multivariable correlations, the solutions to which yield a dissolution rate in units of $\mathrm{mg} \mathrm{min}^{-1}$, are presented below. The average percent difference between raw data dissolution rates expressed as $\mathrm{mg} \mathrm{min}^{-1}$ and those calculated by the multivariable correlations averaged less than $10 \%$ for TNT and RDX and less than $15 \%$ for HMX.

TNT

$$
\frac{\mathrm{dm}}{\mathrm{dt}}=\left(1.0 \times 10^{-5} \mathrm{~T}-4.3 \times 10^{-5}\right) \mathrm{am}
$$

HMX

$$
\begin{gathered}
\frac{\mathrm{dm}}{\mathrm{dt}}=\left(4.75 \times 10^{-6} \mathrm{~T}-2.4 \times 10^{-6}\right) \mathrm{am} \\
R D X \\
\frac{\mathrm{dm}}{\mathrm{dt}}=\left(1.49 \times 10^{-6} \mathrm{~T}-6.5 \times 10^{-6}\right) \mathrm{am}
\end{gathered}
$$

where $T=$ temperature in ${ }^{\circ} \mathrm{C}, a=$ surface area in $\mathrm{cm}^{2}$ and $m=$ mixing rate in $\mathrm{rpm}$ 
A second approach avoided the series of regressions in favor of a single linear regression. Dissolution rates were normalized by dividing each run's initial $\mathrm{mg} \mathrm{min}^{-1}$ rate by two of the variables used in that particular run (for example surface area and rpm). These normalized rates were then regressed against the remaining variable (in this case temperature). These single linear regressions were not forced through zero. This process was then repeated two more times, once for rpm as the independent variable and again using surface area as the independent variable. The means of the average percent differences between the resulting correlation for each explosive compound and the experimental data for each of the independent variables were: temperature, $10 \%$; surface area, $15 \%$; mixing speed, $450 \%$. This indicates that temperature has the greatest impact on dissolution rate as compared to the other variables. Those correlation equations where temperature served as the independent variable are presented below.

$$
\begin{gathered}
\text { TNT } \\
\frac{\mathrm{dm}}{\mathrm{dt}}=\left(9.82 \times 10^{-6} \mathrm{~T}-4.0 \times 10^{-5}\right) \mathrm{am} \\
\mathrm{HMX} \\
\frac{\mathrm{dm}}{\mathrm{dt}}=\left(4.46 \times 10^{-6} \mathrm{~T}-7.8 \times 10^{-7}\right) \mathrm{am} \\
\mathrm{RDX} \\
\frac{\mathrm{dm}}{\mathrm{dt}}=\left(1.49 \times 10^{-6} \mathrm{~T}-6.1 \times 10^{-6}\right) \mathrm{am}
\end{gathered}
$$

Results from the multiple linear regression methodology for determining a correlation with multiple variables are very similar to the single linear regression approach. Two validation runs were performed for each explosive compound using different temperatures $\left(15^{\circ} \mathrm{C}\right.$ and $\left.25^{\circ} \mathrm{C}\right)$, surface area $\left(6 \mathrm{~cm}^{2}\right)$, and mixing rate values 
(120 rpm and $180 \mathrm{rpm}$ ) from those generating the correlations. The single regression correlation line is included with the multiple regression correlation line for comparison with experimental HMX data in Figure 2-4 as are the validation data points. All TNT (not shown) and HMX data and validation points fell within the $99 \%$ confidence interval while all RDX data (not shown) and validation points fell within the 95\% confidence interval.

The last method for determining a multivariable dissolution rate expression used a correlation developed by Levins and Glastonbury (1972b) describing spherical particleliquid hydrodynamics and mass transfer in a stirred vessel:

$$
\frac{k d_{p}}{D_{v}}=2+0.47\left(\frac{d_{p}^{4 / 3} \varepsilon^{1 / 3}}{v}\right)^{0.62}\left(\frac{D_{S}}{D_{T}}\right)^{0.17}\left(\frac{v}{D_{v}}\right)^{0.36}
$$

where $k=$ mass transfer coefficient, $d_{p}=$ particle diameter, $D_{v}=$ diffusivity, $\varepsilon=$ energy dissipation rate/unit mass, $v=$ kinematic viscosity, $D_{S}=$ stirrer diameter, and $D_{T}=\operatorname{tank}$ diameter. Gilcrease et al. (1996) used this method in their evaluation of TNT dissolution in reactors containing either water or a water/Teflon bead slurry.

Comparisons between the Levins and Glastonbury (1972b) correlation and the experimental data obtained in this study can be made by expressing the " $k$ " term (Eq. (2-8)) in milligrams dissolved per minute and comparing it to the rate determined from the data of each run. The dissolution rates from this study, rates predicted by the multivariable equation derived in this study, and rates predicted by the Levins and Glastonbury (1972b) correlation for TNT mixed at $150 \mathrm{rpm}$ and $10^{\circ} \mathrm{C}$ (lower set of data) and $30^{\circ} \mathrm{C}$ (upper set of data), are presented in Figure 2-5. The average percent difference 


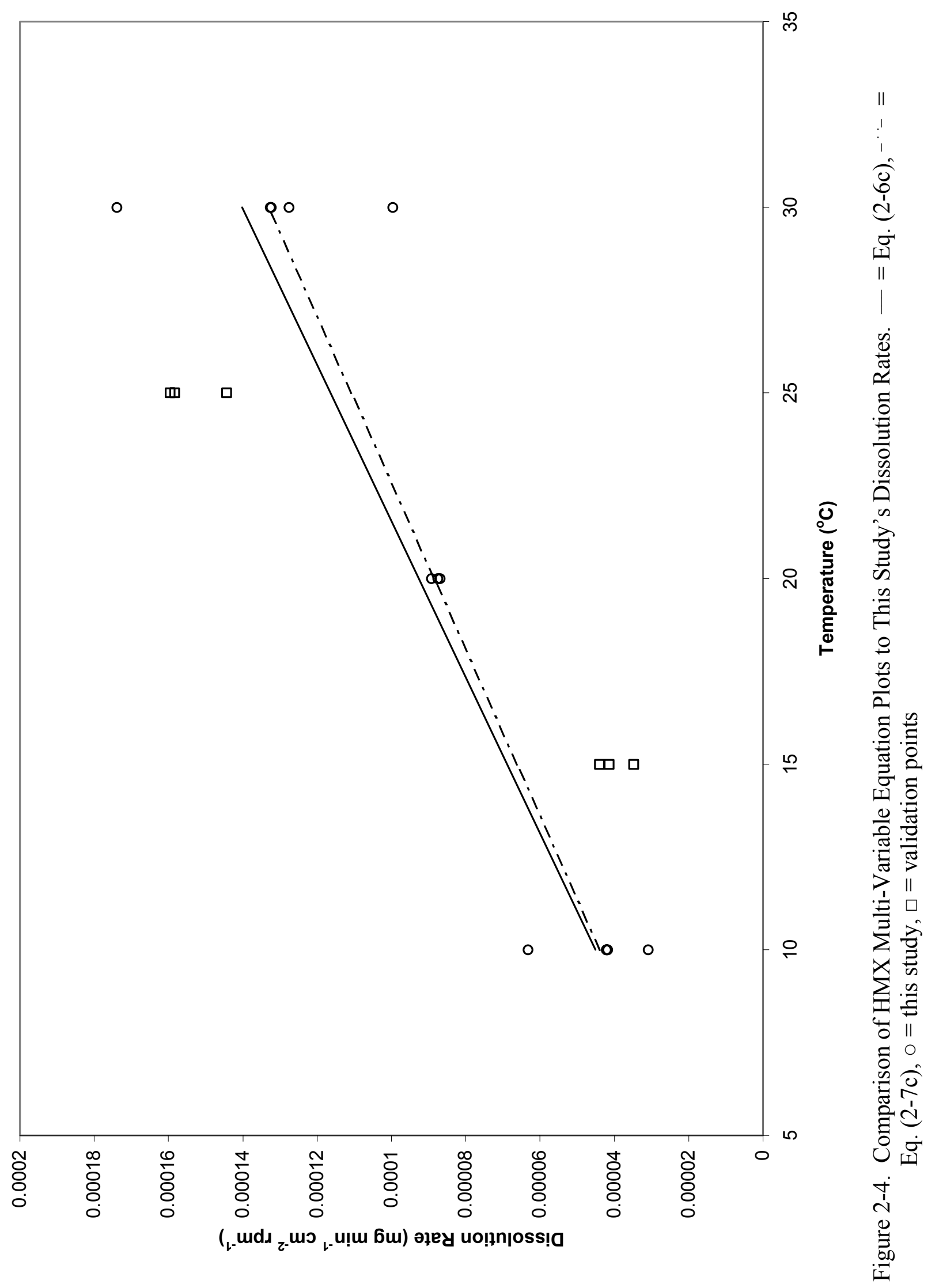


between actual rates and those predicted using the Levins and Glastonbury (1972a) correlation are slightly greater than those based on the multivariable equation.

Gilcrease et al. (2001) noted that the effectiveness of the $\mathrm{k}$ term in Eq. (2-8) depended on selecting an appropriate effective diffusivity value. Gilcrease et al. (1996) successfully used the Levins and Glastonbury (1972b) approach in describing the dissolution of solid TNT in both deionized water and in a Teflon chip/water slurry. For the best fit to their experimental design, Gilcrease et al. (1996) selected a TNT diffusivity of $7.4 \times 10^{-6} \mathrm{~cm}^{2} \mathrm{~s}^{-1}$ at $25^{\circ} \mathrm{C}$. For our study, a diffusivity of $6.71 \times 10^{-6} \mathrm{~cm}^{2} \mathrm{~s}^{-1}$ at $25^{\circ} \mathrm{C}$ (Townsend and Meyers, 1996) was used.

The Levins and Glastonbury (1972b) correlation did not prove as accurate in predicting dissolution rates for either RDX or HMX compared to the multivariable equations developed in this study. Average percent differences between results of their correlation and actual rates in this present study exceeded $20 \%$ for each explosive compound, even after modifying diffusivity values from those reported in the literature. Best-fit diffusivity values at $25^{\circ} \mathrm{C}$ were $2.2 \times 10^{-6} \mathrm{~cm}^{2} \mathrm{~s}^{-1}$ and $1.5 \times 10^{-4} \mathrm{~cm}^{2} \mathrm{~s}^{-1}$ for RDX and HMX, respectively (vs. $7.15 \times 10^{-6}$ and $6.02 \times 10^{-6} \mathrm{~cm}^{2} \mathrm{~s}^{-1}$, reported by Townsend and Meyers, 1996 at $25^{\circ} \mathrm{C}$ ). It is interesting to note that the "relative diffusivities" in Figure 2-3 show similar orders of separation among explosives as those presented here.

Estimating a single particle diameter for RDX and HMX from a heterogeneous mix of crystal sizes may have had a major impact on the applicability of the Levins and Glastonbury (1972b) correlation. A comparison of RDX dissolution rates based on the data from our study, Eq. (2-6c), Eq. (2-7c), and the $k$ term from Eq. (2-8) is shown in 


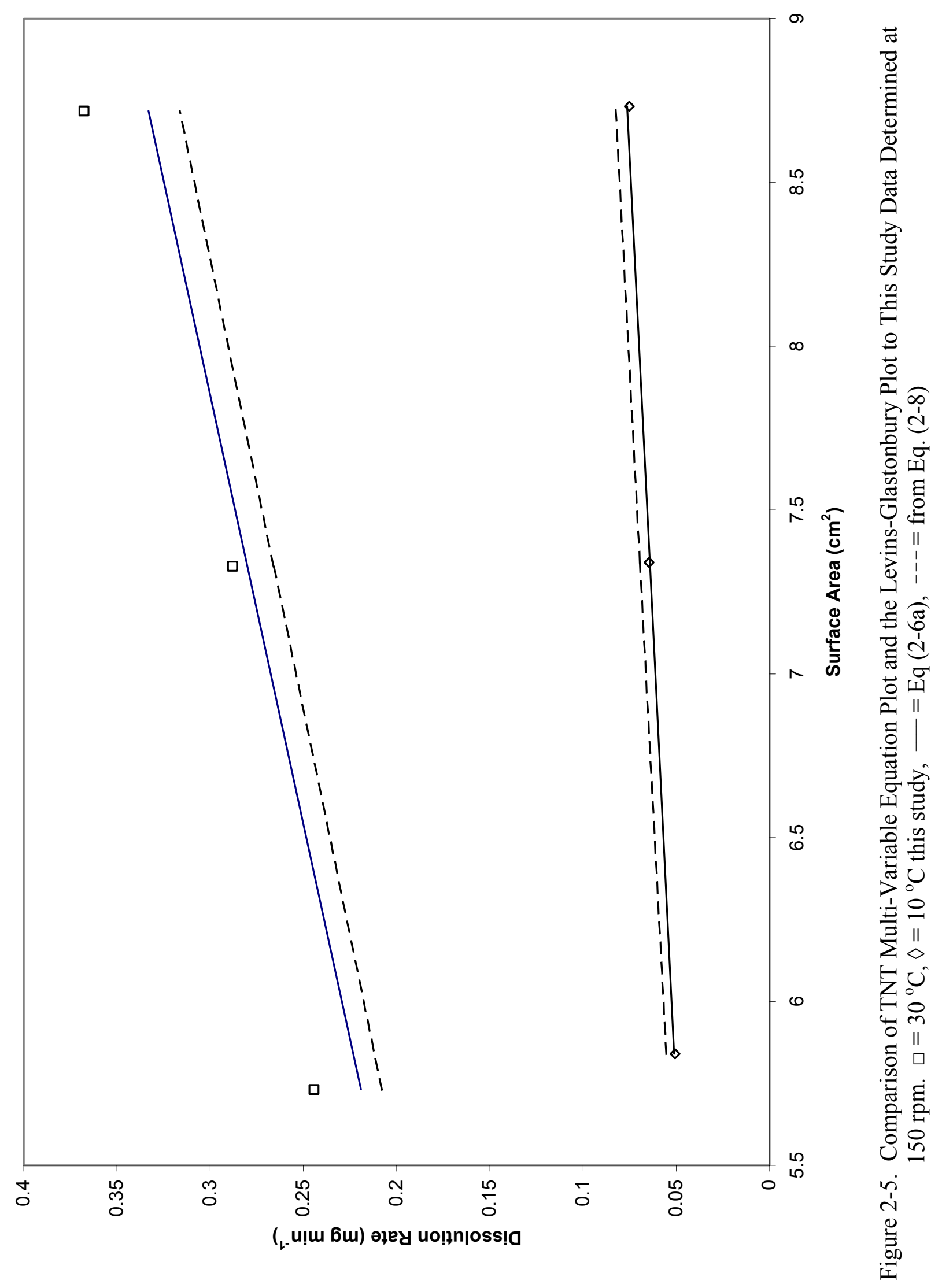


Table 2-4. Use of an estimated single particle size may also account for the discrepancies in the best-fit diffusivities.

Dissolution rates for TNT, RDX, and HMX as a function of temperature, surface area, and power input are best represented by Eqs. (2-7a, 2-7b, 2-7c) where temperature was the final variable in correlation determination. These correlations provide insight to expected changes in explosive dissolution rates given changing seasonal temperatures

and remaining explosive surface area. To predict rainfall effects on expected dissolution rates, use Eq. (2-5) which relates the RUSLE "R" term to mixing rpm. Eq. (2-3) can be used to relate the mixing rpm to processes in stirred reactors.

Limits exist for the use of these correlations, however. First, dissolution rates cannot exceed the solubility limit of the explosive compound. Second, extrapolation outside the limits of the study boundaries may not yield valid results. Third, as demonstrated by the HMX results, there is a point where increased power input results in only minimal changes in dissolution rate.

\section{Summary and Conclusions}

Dissolution rates of explosive compounds increase as surface area, temperature, and mixing rate increase. Under the same conditions, the order from fastest to slowest dissolution rate among the compounds studied was TNT, HMX, and RDX. Dissolution rates observed in this study support attainment of concentrations in water above the established health advisory limits for explosive compounds. Calculated activation energies for dissolution of TNT, RDX, and HMX in $\mathrm{kJ} \mathrm{mol}^{-1}$ are 55.6, 55.4, and 40.7, respectively. Dissolution rates approximately double with every $10^{\circ} \mathrm{C}$ increase in temperature. Based on this study, surface area estimates were reproducible and the 
Table 2-4. Average Percent Difference Comparisons Among Dissolution Rates, $r$ $\left(\mathrm{mg} \mathrm{min}{ }^{-1}\right.$ ) from this Study, the Multiple Regression Multiple Variable Equation, the Single Regression Multiple Variable Equation, and the Levins and Glastonbury (1972a) Correlation for RDX

\begin{tabular}{ccccccccc}
\hline Run & Description & $r$, This & $r$, Eq & Avg $\%$ & $r$, Eq & Avg $\%$ & $k$, Eq & Avg \% \\
ID & $\mathrm{cm}^{2} / \mathrm{rpm} /{ }^{\circ} \mathrm{C}$ & Study & $(6 \mathrm{c})$ & Diff & $(7 \mathrm{c})$ & Diff & $(8)$ & Diff \\
\hline $\mathrm{M}$ & $8 / 150 / 10$ & 0.010 & 0.011 & -6.3 & 0.011 & -10.5 & 0.014 & -29.2 \\
$\mathrm{O}$ & $10 / 150 / 10$ & 0.012 & 0.013 & -3.5 & 0.013 & -7.6 & 0.016 & -26.4 \\
$\mathrm{P}$ & $12 / 150 / 10$ & 0.015 & 0.015 & -2.1 & 0.016 & -6.2 & 0.019 & -25.16 \\
$\mathrm{R}$ & $10 / 90 / 10$ & 0.008 & 0.008 & 9.1 & 0.008 & 4.9 & 0.012 & -34.0 \\
$\mathrm{~S}$ & $10 / 210 / 10$ & 0.026 & 0.018 & 38.4 & 0.019 & 34.3 & 0.020 & 28.8 \\
$\mathrm{R} 1$ & $4 / 150 / 20$ & 0.015 & 0.014 & 4.0 & 0.014 & 2.5 & 0.015 & -2.5 \\
$\mathrm{R} 2$ & $5 / 150 / 20$ & 0.015 & 0.018 & -13.6 & 0.018 & -15.1 & 0.019 & -20.1 \\
$\mathrm{R} 3$ & $6 / 150 / 20$ & 0.019 & 0.021 & -8.7 & 0.021 & -10.2 & 0.023 & -15.1 \\
$\mathrm{R} 8$ & $8 / 150 / 30$ & 0.047 & 0.046 & 1.6 & 0.047 & 0.6 & 0.055 & -15.0 \\
$\mathrm{R} 6$ & $10 / 150 / 30$ & 0.057 & 0.058 & -1.0 & 0.058 & -2.0 & 0.068 & -17.6 \\
$\mathrm{R} 9$ & $12 / 150 / 30$ & 0.071 & 0.069 & 2.2 & 0.070 & 1.2 & 0.082 & -14.4 \\
$\mathrm{R} 4$ & $10 / 90 / 30$ & 0.034 & 0.035 & -2.9 & 0.035 & -3.9 & 0.050 & -39.4 \\
$\mathrm{R} 5$ & $10 / 210 / 30$ & 0.088 & 0.081 & 8.9 & 0.081 & 8.0 & 0.083 & 5.5 \\
\hline
\end{tabular}


RUSLE "R" values and experimental energy input were comparable. It is recommended that further research validate this RUSLE " $\mathrm{R}$ " factor to rpm conversion. At $25^{\circ} \mathrm{C}$ and using the Levins-Glastonbury (1972b) correlation, best-fit diffusivities from this study were $6.71 \times 10^{-6} \mathrm{~cm}^{2} \mathrm{~s}^{-1}$ for TNT, $2.2 \times 10^{-6} \mathrm{~cm}^{2} \mathrm{~s}^{-1}$ for RDX, and $1.5 \times 10^{-4} \mathrm{~cm}^{2} \mathrm{~s}^{-1}$ for HMX.

The use of combined variable equations, such as those presented in Eqs. (2-7a, 2-7b, 2-7c) and Eq. (2-5), are representative of observed dissolution rates under differing environmental conditions. There is no benefit in predicting dissolution rates by performing multiple regressions of data compared with normalizing these data into the appropriate units for dissolution rate and performing a single regression. Regressing dissolution rate in units of $\mathrm{mg} \mathrm{min}^{-1} \mathrm{~cm}^{-2} \mathrm{rpm}^{-1}$ versus temperature in ${ }^{\circ} \mathrm{C}$ provides the best multi-variable equation fit to experimental data. The Levins-Glastonbury (1972b) correlation, as evaluated in this study, is a viable method of estimating dissolution rates when diffusivities are known and explosive compounds are of uniform diameter. The relationships developed in this study can serve as initial approximations of expected dissolution rates under field conditions. The effects of $\mathrm{pH}$ on aqueous dissolution rate (related to acid rain and natural waters), explosive-explosive interaction effects on dissolution and solubility, and interactions resulting from explosive formulations using desensitizers and binders have been reported separately (Lynch et al., 2001a, Lynch et al., 2001b). 


\section{CHAPTER 3 \\ EFFECTS OF pH AND TEMPERATURE ON THE AQUEOUS SOLUBILITY AND DISSOLUTION RATE OF TNT, RDX, AND HMX}

\section{Introduction}

High explosive compounds such as 2,4,6-trinitrotoluene (TNT), hexahydro-1,3,5trinitro-1,3,5-triazine (RDX), and octahydro-1,3,5,7-tetranitro-1,3,5,7-tetrazocine (HMX) have entered the environment from sites where they were manufactured, stored, disposed, or used in military training (Best et al., 1999). TNT has been associated with liver and blood damage, anorexia, and anemia. RDX and HMX have been associated with systemic poisoning usually affecting bone marrow and the liver. Both TNT and RDX have been classified as possible human carcinogens, whereas HMX is not yet classifiable as to its human carcinogenicity (ATSDR, 1996a; ATSDR, 1996b; ATSDR, 1997). Understanding the factors that affect the environmental fate of these compounds and the possible routes for human exposure is important (Daniels and Knezovich, 1994; Arnold, 2000).

Environmental factors such as temperature and $\mathrm{pH}$ can affect solubility and therefore chemical fate and toxicity (Huang et al., 2000). If ideal conditions are assumed, solubility can be estimated using the equation (Atkins, 1982):

$$
\ln \mathrm{x}_{\mathrm{B}}=-\left(\frac{\Delta_{\text {fus }} \mathrm{H}}{\mathrm{R}}\right)\left(\frac{1}{\mathrm{~T}}-\frac{1}{\mathrm{~T}^{*}}\right)
$$

where $x_{B}=$ mole fraction of solute, $\Delta_{\text {fus }} H=$ enthalpy of fusion of solute, $R=$ ideal gas 
constant, $T=$ absolute temperature, and $T^{*}=$ solute melting temperature. Aqueous solutions of explosive compounds are not ideal, but the general equation remains similar following the form:

$$
\ln S=A-\frac{B}{T} \quad \text { or } \quad S=A * \operatorname{EXP}\left(\frac{-B}{T}\right)
$$

where $S=$ solubility, $A$ and $B=$ arbitrary constants.

Taylor and Rinkenbach (1923) conducted one of the earliest studies on TNT aqueous solubility over the temperature range $(0 \text { to } 100)^{\circ} \mathrm{C}$ but did not evaluate the effect of $\mathrm{pH}$. Spanggord et al (1983) reported expressions for TNT and RDX solubility based on measurements at $(10,20 \text {, and } 30)^{\circ} \mathrm{C}$ but also did not investigate $\mathrm{pH}$. Ro et al. (1996) reported aqueous solubilites for TNT at differing $\mathrm{pH}$ and temperatures. In their report, Ro et al. (1996) proposed a solubility correlation and found that temperature had the greater impact on solubility and that solubility varied widely at higher $\mathrm{pH}$. Phelan and Barnett (2001) reported TNT pH-independent aqueous solubility values that agree with those reported by Spanggord et al. (1983). None of the predictive solubility correlations are similar to the other (Figure 3-1). Townsend and Myers (1996) and Gibbs and Popolato (1980) list solubilities from the literature for TNT, RDX, and HMX as a function of temperature and independent of $\mathrm{pH}$. In this chapter we re-evaluate TNT solubility correlations as a function of temperature and $\mathrm{pH}$ and add evaluations of $\mathrm{RDX}$ and HMX solubility as a function of these same variables.

Dissolution is the primary mechanism allowing for transformation and transport of nonvolatile explosive compounds. An explosive's dissolution rate and solubility control the persistence of the contamination at the source and the degree of contamination 


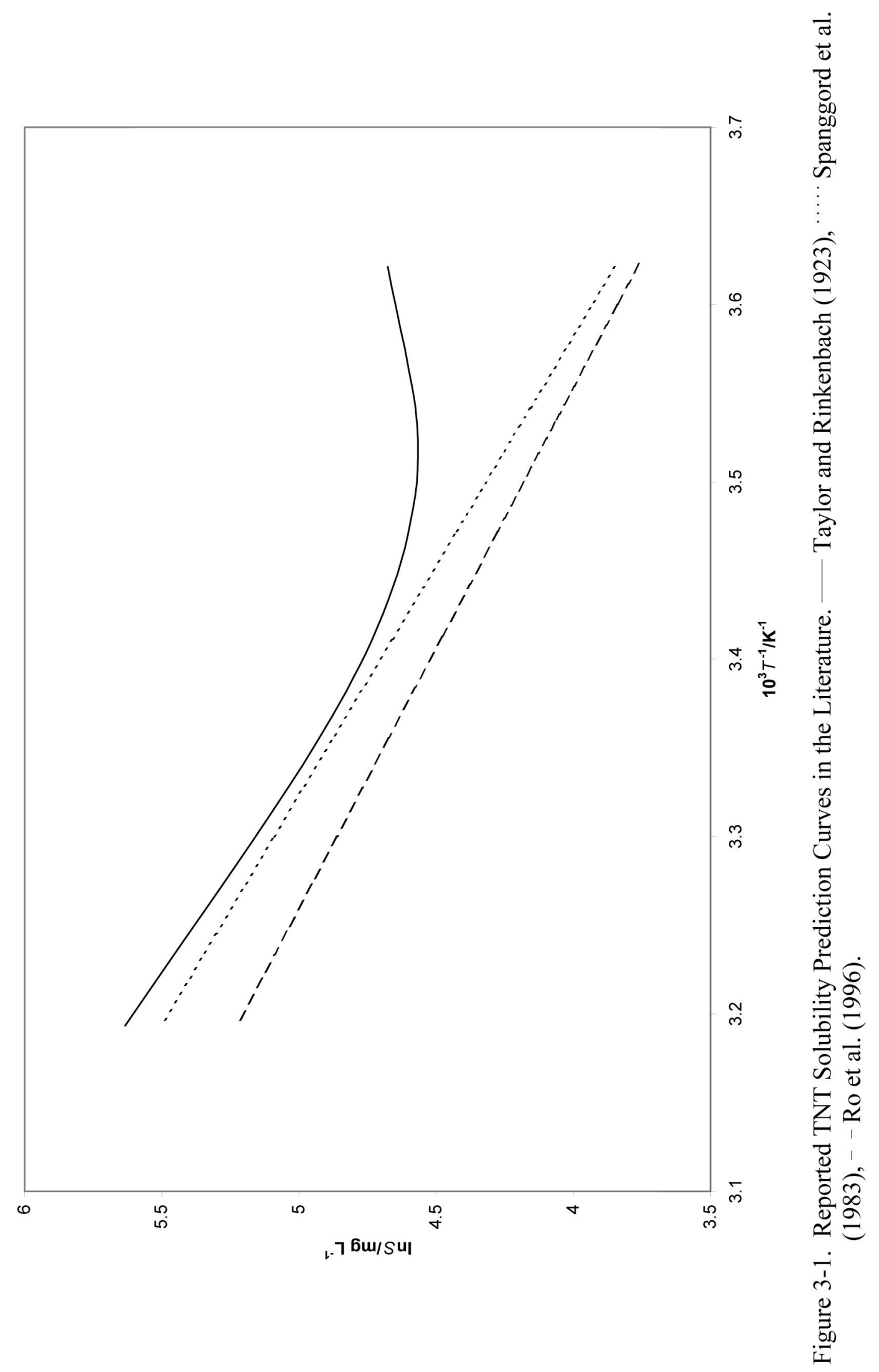


some distance away from this source. Fick's Law can be used to predict the concentration of explosive compounds dissolved in water as well as the time required to reach solubility limits:

$$
\frac{d C}{d t}=K_{L} a\left(C_{s}-C_{b}\right)
$$

where $d C / d t$ is the dissolution rate, $K_{L} a=$ overall mass transfer coefficient, $C_{s}=$ solubility; and $C_{b}=$ concentration in bulk liquid. If the dissolution rate is known, Eq. (33) can be integrated to identify the concentration, $C_{t}$, at any time, $t$ (Tchobanoglous and Schroeder, 1987):

$$
C_{t}=C_{s}\left(1-e^{\left(-K_{L} a\right) t}\right)
$$

Information on high explosive dissolution rates is sparse. Gilcrease et al. (1996) reported surface area and mixing rate effects on TNT dissolution rate. Lynch et al. (2002a) reported surface area, temperature, and mixing rate effects on the dissolution rate of TNT, RDX, and HMX. Neither of these papers addressed $\mathrm{pH}$. A general zero-order, multivariable, dissolution rate $(d C / d t)$ equation proposed by Lynchet al. (2002a) is:

$$
\frac{\mathrm{dC}}{\mathrm{dt}}=\left(\mathrm{RT}^{\wedge}-\mathrm{I}\right) \mathrm{ar}
$$

where $R=$ correlation factor with units of $\mathrm{mg} \mathrm{s}^{-1}{ }^{\circ} \mathrm{C}^{-1} \mathrm{~cm}^{-2} \mathrm{rps}^{-1}$ ( $\mathrm{rps}=$ revolutions per second) (for TNT, $R=2.75 \times 10^{-9}$, for RDX, $R=4.15 \times 10^{-10}$, and for HMX, $R=1.19 \times 10^{-9}$ ), $I=$ correlation factor with units of $\mathrm{mg} \mathrm{s}^{-1} \mathrm{~cm}^{-2} \mathrm{rps}^{-1}$ (for TNT, $I=1.3 \times 10^{-8}$, for RDX, $I=$ $1.7 \times 10^{-9}$, and for HMX, $\left.I=2.0 \times 10^{-10}\right), a=$ nominal surface area in $\mathrm{cm}^{2}, \mathrm{~T}^{\wedge}=$ temperature in ${ }^{\circ} \mathrm{C}$, and $r=$ rps.

Price et al. (1997) presented the effects of redox potential and $\mathrm{pH}$ on TNT transformation in soil-water slurries. Price et al. (1998) studied the effects of redox 
potential and $\mathrm{pH}$ on RDX and HMX transformation in soils but did not directly address their effects on dissolution rate. In this chapter, we examine $\mathrm{pH}$ effects on the dissolution rates of TNT, RDX, and $\mathrm{HMX}$ at $30^{\circ} \mathrm{C}$ and at a mixing rate of $2.5 \mathrm{rps}$. Surface area effects on dissolution rate were normalized by dividing the dissolution rate by the nominal explosive surface area used in a given experiment, resulting in a dissolution rate with units of $\mathrm{mg} \mathrm{s}^{-1} \mathrm{~cm}^{-2}$.

\section{Experimental Section}

\section{Chemicals}

Experimental quantities of weapons grade TNT, RDX, and HMX were provided by the Environmental Processes and Engineering Division of the Engineer Research and Development Center, US Army Corps of Engineers Waterways Experiment Station, Vicksburg, Mississippi. Demineralized water (reverse osmosis with a $\mathrm{pH}$ of $\sim 5.7$ ) was used with the $\mathrm{pH}$ adjusted lower by addition of $\mathrm{H}_{2} \mathrm{SO}_{4}$ and $\mathrm{HNO}_{3}$ or higher by the addition of $\mathrm{Na}_{2} \mathrm{CO}_{3}$ and $\mathrm{NaOH}$. These chemicals were selected to approximate acidic rain conditions expected in the natural environment.

\section{Procedure}

Solubility. Aqueous solutions with $\mathrm{pH}$ values of 4.2, 5.7, and 6.2 were used as the solvent for the solid explosive dissolution experiments. An excess amount of solid explosive was added to $200 \mathrm{~mL}$ of $\mathrm{pH}$-adjusted water in a $250 \mathrm{~mL}$ Erlenmeyer flask wrapped in aluminum foil to minimize photolysis (Townsend and Myers, 1996).

A magnetic stir bar was added to the flask, which was then sealed with Parafilm, and the solution stirred on a magnetic stirrer at a rate sufficient to maintain a deep vortex. 
Experiments were performed in duplicate and at temperatures of $(3.1 \pm 0.8)^{\circ} \mathrm{C},(21.1 \pm$ $1.4)^{\circ} \mathrm{C}$, and $(33.3 \pm 3.0)^{\circ} \mathrm{C}$. Replicate sample aliquots were taken 7 and 14 days after agitation began. Samples were immediately passed through a $0.45 \mu \mathrm{m}$ pore size membrane filter and combined with an equal volume of $0.45 \mu \mathrm{m}$-filtered acetonitrile in preparation for high-performance liquid chromatographic (HPLC) analysis.

Dissolution rate. The experimental design is based on the dissolution test described in the United States Pharmacopeia (1990). Five hundred milliliters of pHregulated demineralized water was maintained overnight at $30^{\circ} \mathrm{C}$ using a Fisher Scientific Isotemp Refrigerated Circulator combined with a LabLine Aquabath in duplicate $600 \mathrm{~mL}$ beakers. A three-blade propeller rotated by an overhead Yamato Scientific StedFast Digital Lab Stirrer set at $2.5 \mathrm{rps}$ was centered and lowered into the beaker and raised to a height of $2.5 \mathrm{~cm}$ above the beaker bottom. Dry explosive was then added to these beakers, and $1 \mathrm{~mL}$ samples were periodically pipetted from a zone midway between the surface of the solution and the top of the stirring propeller and midway between the beaker wall and the propeller shaft while the solution continued to be stirred. Five samples were taken during each experimental run and immediately passed through a 0.45 $\mu \mathrm{m}$ Millipore filter and combined with equal amount of $0.45 \mu \mathrm{m}$-filtered acetonitrile in preparation for HPLC analysis.

Equipment. Vials containing the sample and acetonitrile were sealed with a Teflon faced silicone rubber cap, mixed using a vortex mixer for $5 \mathrm{~s}$, and then stored quiescently in the dark for at least 25 min before analysis. Analyses were performed using a Waters HPLC running a Millennium Software package with a model 486 tunable detector $(\lambda=245 \mathrm{~nm})$ and auto sampler following Method 8330 (1994). A reversed 
phase eluent (50:50 methanol and water) was used in the HPLC system. The analytical column was a $25 \mathrm{~cm}$ x $4.6 \mathrm{~mm}, 5 \mu \mathrm{m}$ Supelco LC-18 reversed phase HPLC column. The HPLC was calibrated using a seven-point calibration curve. A sample replicate, a blank, and a check standard were included in each analytical run. An Accumet model 50 combination $\mathrm{pH} /$ ion/conductivity meter was used to measure the $\mathrm{pH}$ of the solutions.

\section{Results and Discussion}

\section{Solubility of High Explosive Compounds as a Function of pH and Temperature}

The temperature range studied, $(3.1 \text { to } 33.3)^{\circ} \mathrm{C}$, is representative of ambient conditions at which explosives residues are typically found, whereas the $\mathrm{pH}$ range was selected on the basis of maximum and minimum $\mathrm{pH}$ values reported for rainfall in the Continental United States (National Atmospheric Deposition Program, 1998). The experimental solubility data for the three high explosives at three $\mathrm{pH}$ values and temperature are summarized in Table 3-1. To conform to the format in Eq. (3-2), data were plotted as $\ln [\mathrm{S}]$ versus $1 / \mathrm{K}$ and linearly regressed.

Evaluation based on the mean solubility values at each $\mathrm{pH}$ suggested a trend that solubilities increase as $\mathrm{pH}$ and temperature increase. This trend is much less apparent when viewed on the basis of the solubility range plus or minus one standard deviation around the mean. From this perspective the $\mathrm{pH}$-specific solubility range bars tend to overlap one another. The average percent difference found between replicate samples at one $\mathrm{pH}$ and temperature was comparable with those between the low-end value at $\mathrm{pH} 4.2$ and the high-end value at $\mathrm{pH} 6.2$ evaluated at the same temperature. No statistically 
ํ. ํ. जि

II

Iu

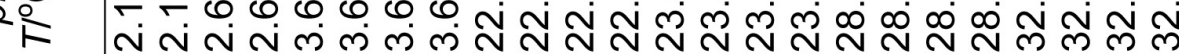

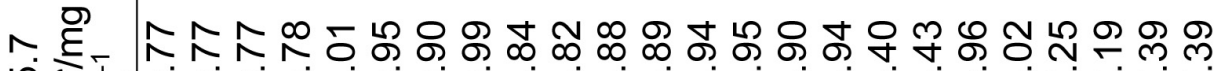

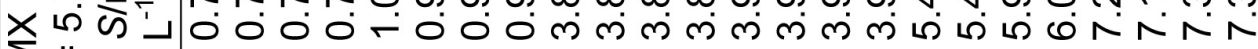
III

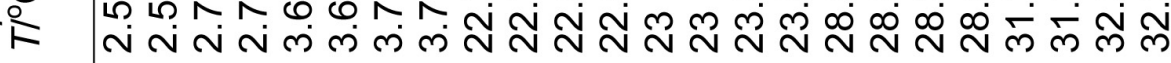

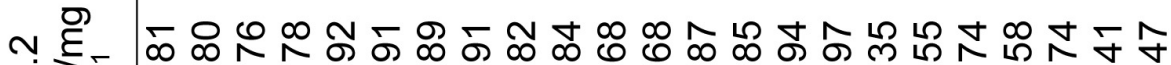

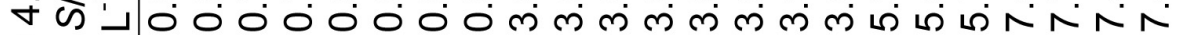
II

Io hatr.

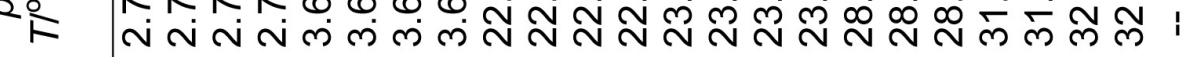

ᄂ ঢ II

Ju F

人 एம

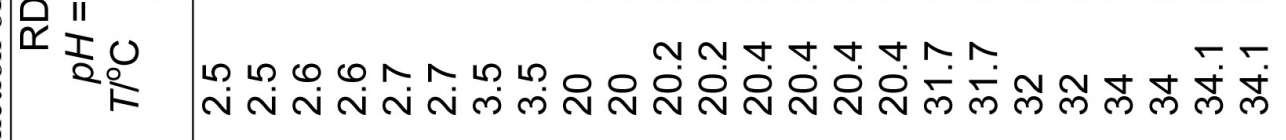

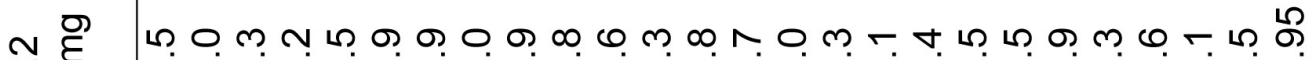
†ं II

Iu NNNN

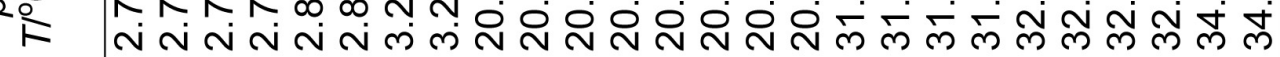

พ ह

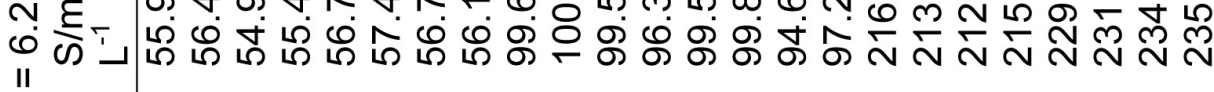

长员

R $\quad$ N

ค 一 एक z

Iu mmmmF N 서

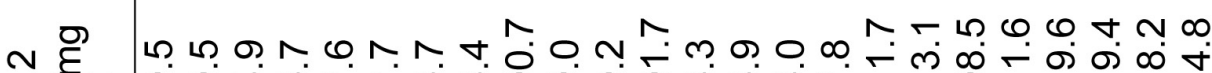
的 II Io

m m 0 ก N N N F $\quad$ N 
significant difference in solubility for TNT, RDX, or HMX based on different $\mathrm{pH}$ values can be drawn within the range of conditions used in this study.

Solubilities for TNT compare favorably with those reported by Spanggord et al. (1983) and Phelan and Barnett 2001) (Figure 3-2). Solubilities for TNT were found to be less than those reported by Taylor and Rinkenbach (1923) but higher than those reported by Ro et al. (1996). Solubilities for RDX (Figure 3-3) again compare favorably with those of Spanggord et al. (1983) although they are generally less than those values reported in the literature. Solubilities for HMX agree well with those values reported by Townsend and Meyers (1996) (Figure 3-4). A correlation was made for solubilities reported by Spanggord as cited by Townsend and Meyers (1996) and plotted in Figure 3-4 for comparative purposes. Composite correlations that use all TNT, RDX, and HMX data from this study to predict solubility are shown in Figure 3-5 together with the experimental data upon which they are based.

\section{High Explosives Dissolution Rate as a Function of pH and Temperature}

Evaluation of $\mathrm{pH}$ effects on dissolution rate was conducted at $30^{\circ} \mathrm{C}$ because of the higher solubility values for each explosive. Samples were taken at a frequency and over a time period so that sample concentrations would be well below solubility maxima, hence keeping the solution dilute (Table 3-2). The effects of $\mathrm{pH}$ on dissolution rates for TNT, RDX, and HMX were not statistically different (Figure 3-6), falling within each other's one standard deviation confidence bars. In general, TNT has the fastest

dissolution rate, followed by HMX and RDX. Composite dissolution rates incorporating all $\mathrm{pH}$ data from this study for TNT, HMX, and RDX (Table 3-3) compared well to those predicted by Eq. (3-5) (Lynch et al., 2002a). 


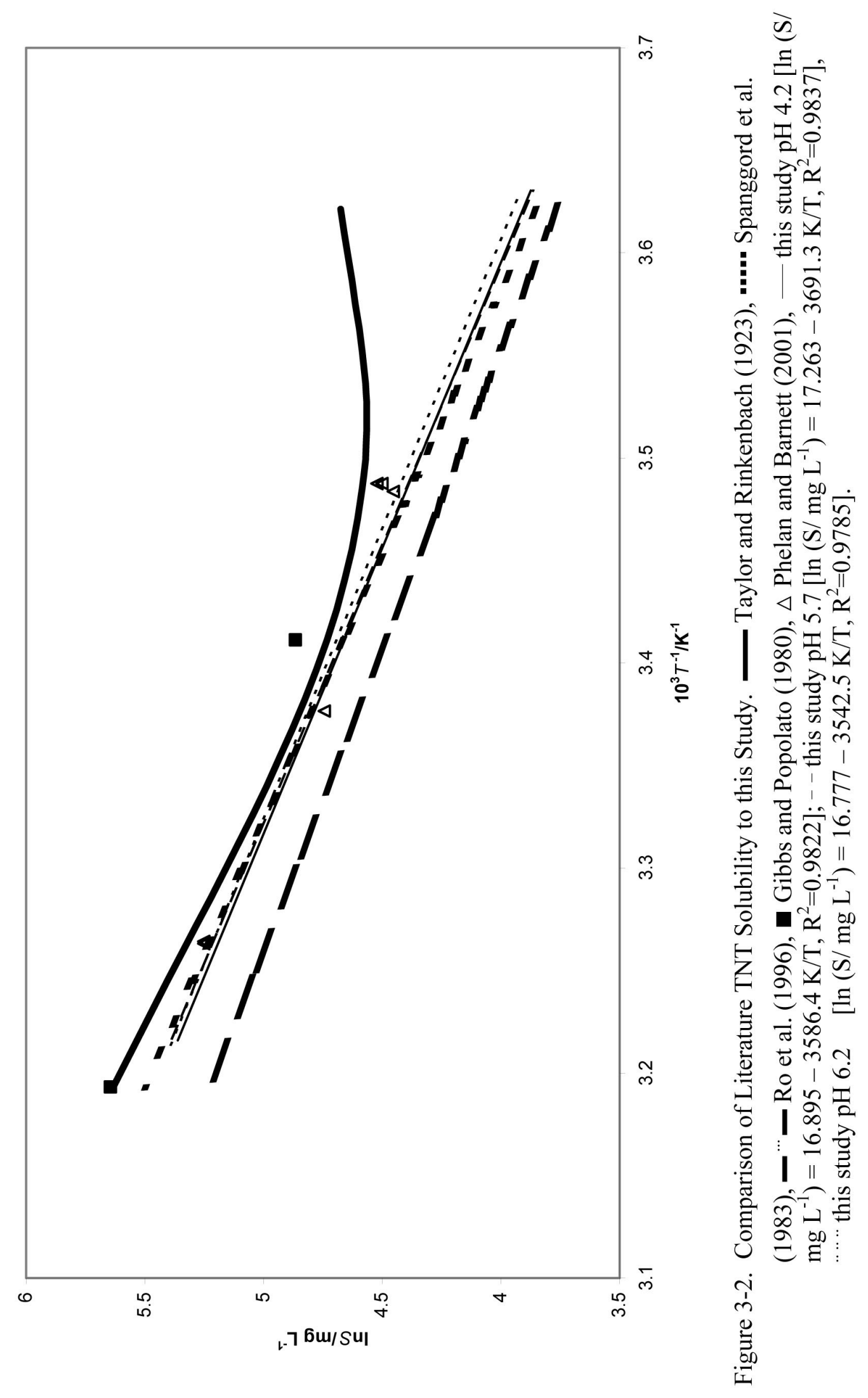




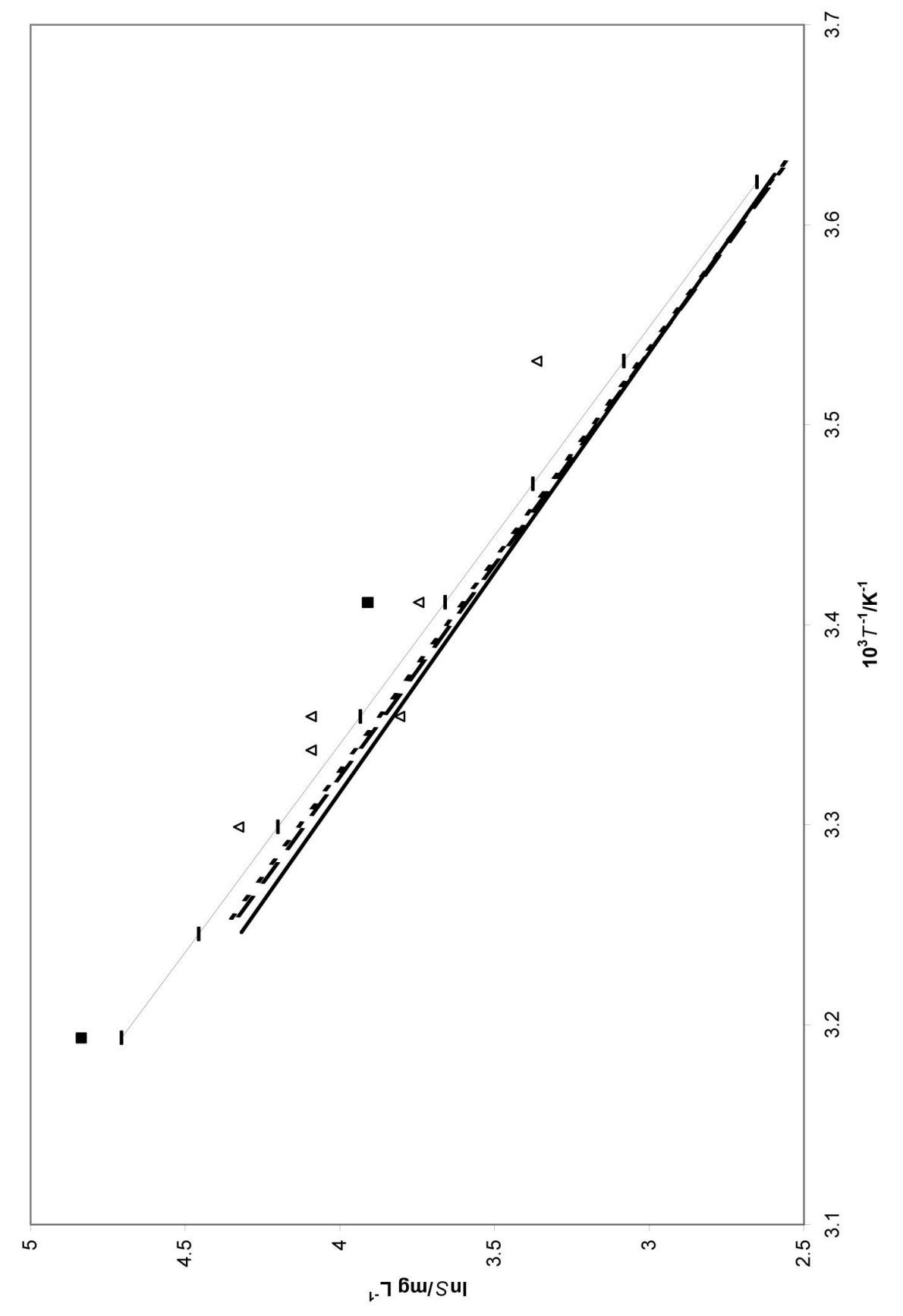

$\triangleleft \overline{7}$

요은

站

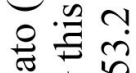

।

त.

च $\infty$

क 0

ป⿻

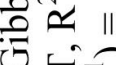

ㅁำ

(ิ드미

के के

$\beth \forall$

- 1 E

$\div \infty$

명

on $\|$

구ㄴㅠㅠ

( )

这:

흘

ㄴ.

ง

를

웅주

氙㤩占

을

N

年

ลิ

은

$E_{0}$

बे $خ$

: $\sum_{2}^{0}$

पु

ธี ส

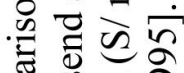

जै

ㅎํ엥

Uำ

官 


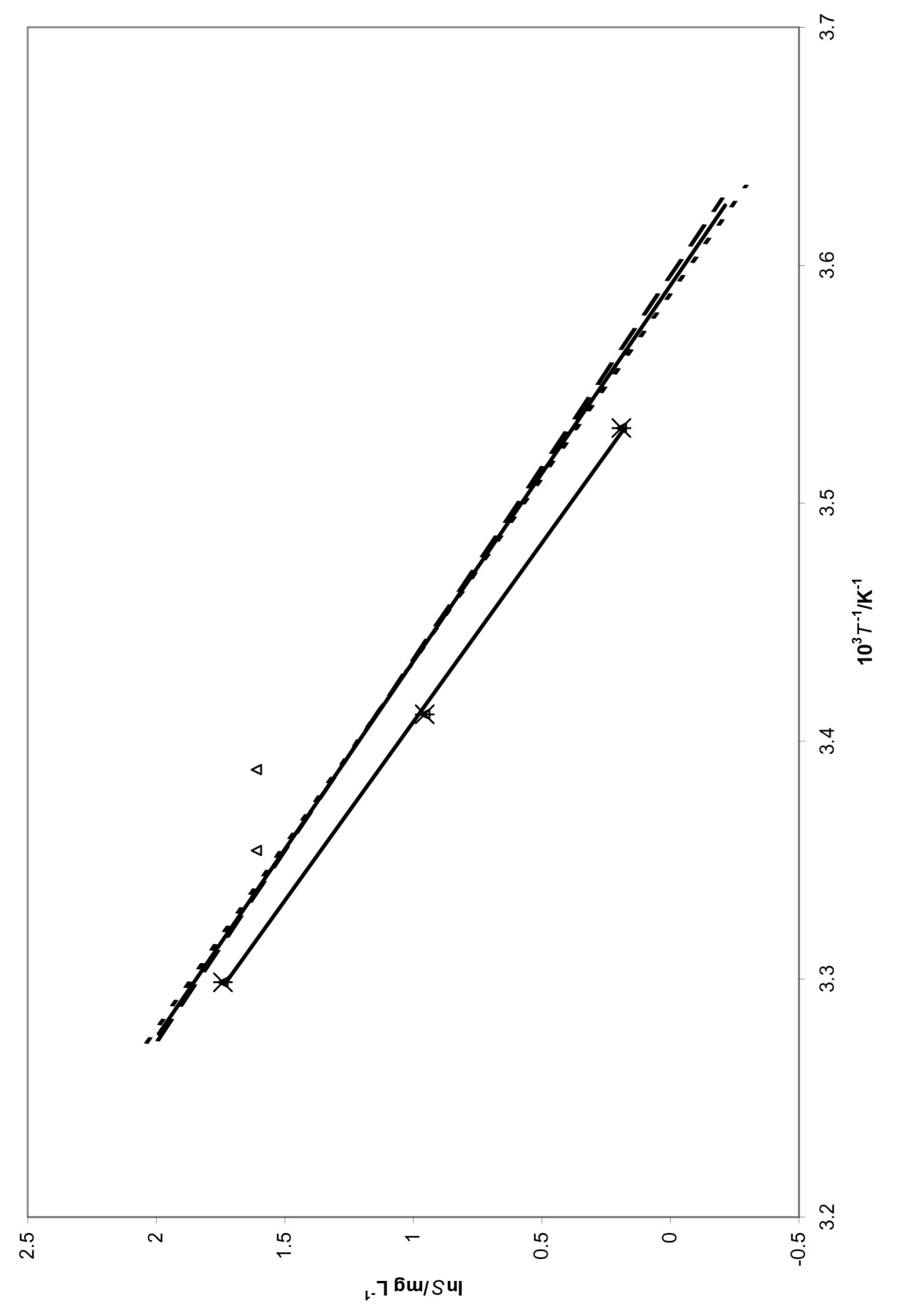

$\triangleleft I$

क

을

$\infty$

$\overline{0} \equiv$

ङ 1 हु

可।

సे शे

वृ

पू 1

幽

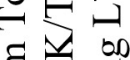

ฮ

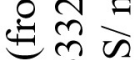

ส 1 =

吉

ㄷำ

क $\mathrm{N}$

空

का ह

* E. ⿷匚⿳丨コ丨

运:

完寻

婇

步 풀

에

를 $\simeq$

흘

릉

次

¿ $\hat{0}$

० बे

है N

के

.

470

ะ สี

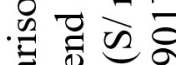

त

छิ

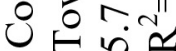

官

苟 


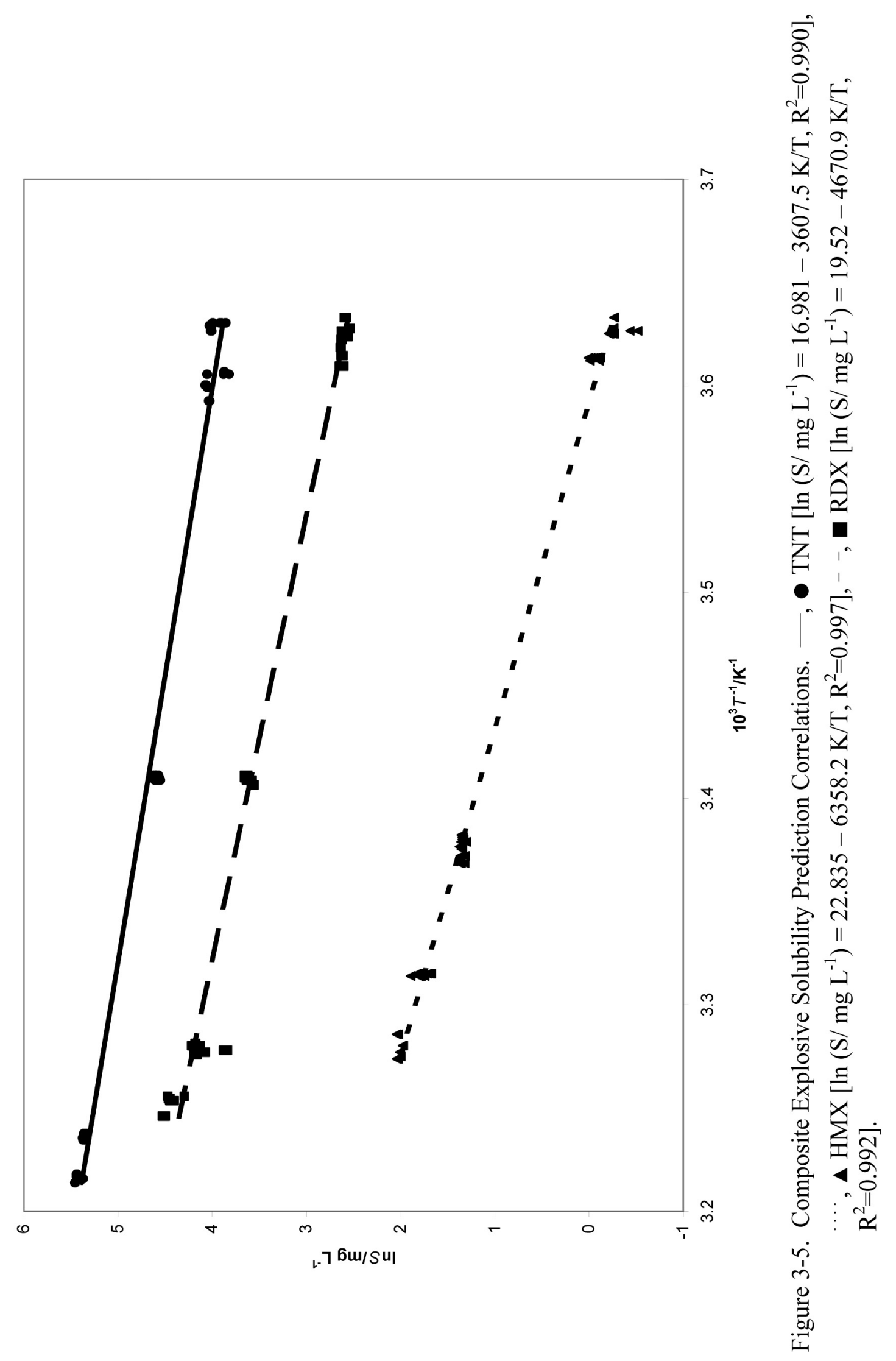


Table 3-2. Summary of Mass of High Explosive Dissolved at Specified Sampling Times and $\mathrm{pH}$ Normalized for Solid Explosive Surface Area (Experiments performed twice at each $\mathrm{pH}$ )

\begin{tabular}{|c|c|c|c|c|c|c|}
\hline \multirow[b]{2}{*}{$\mathrm{t} / \mathrm{sec}$} & \multicolumn{2}{|c|}{ pH 4.2} & \multicolumn{2}{|c|}{ pH 5.7} & \multicolumn{2}{|c|}{ pH 6.2} \\
\hline & $\mathrm{c} / \mathrm{mg} \mathrm{cm}^{-2}$ & $\mathrm{c} / \mathrm{mg} \mathrm{cm}^{-2}$ & $\mathrm{c} / \mathrm{mg} \mathrm{cm}^{-2}$ & $\mathrm{c} / \mathrm{mg} \mathrm{cm}^{-2}$ & $\mathrm{c} / \mathrm{mg} \mathrm{cm}^{-2}$ & $\mathrm{c} / \mathrm{mg} \mathrm{cm}^{-2}$ \\
\hline \multicolumn{7}{|c|}{ TNT } \\
\hline 240 & 0.19 & 0.20 & 0.18 & 0.18 & 0.18 & 0.20 \\
\hline 600 & 0.45 & 0.48 & 0.44 & 0.44 & 0.45 & 0.46 \\
\hline 1200 & 0.89 & 0.89 & 0.81 & 0.84 & 0.84 & 0.96 \\
\hline 1800 & 1.25 & 1.28 & 1.20 & 1.14 & 1.18 & 1.43 \\
\hline 2400 & 1.63 & 1.71 & 1.52 & 1.60 & 1.56 & 1.72 \\
\hline $\mathrm{r} / \mathrm{mg} \mathrm{cm}^{-2} \mathrm{~s}^{-1}$ & 0.00070 & 0.00072 & 0.00065 & 0.00066 & 0.00066 & 0.00075 \\
\hline \multicolumn{7}{|c|}{$\mathrm{RDX}$} \\
\hline 240 & 0.03 & 0.03 & 0.03 & 0.03 & 0.03 & 0.03 \\
\hline 600 & 0.06 & 0.06 & 0.06 & 0.07 & 0.07 & 0.06 \\
\hline 1200 & 0.12 & 0.12 & 0.12 & 0.12 & 0.12 & 0.12 \\
\hline 1800 & 0.16 & 0.18 & 0.17 & 0.17 & 0.17 & 0.18 \\
\hline 2400 & 0.23 & 0.23 & 0.22 & 0.23 & 0.22 & 0.24 \\
\hline $\mathrm{r} / \mathrm{mg} \mathrm{cm}^{-2} \mathrm{~s}^{-1}$ & 0.000095 & 0.000098 & 0.000094 & 0.000097 & 0.000095 & 0.0001 \\
\hline \multicolumn{7}{|c|}{ HMX } \\
\hline 60 & 0.023 & 0.023 & 0.033 & 0.030 & 0.030 & 0.023 \\
\hline 110 & 0.035 & 0.035 & 0.050 & 0.044 & 0.043 & 0.035 \\
\hline 160 & 0.043 & 0.044 & 0.063 & 0.055 & 0.057 & 0.046 \\
\hline 210 & 0.053 & 0.055 & 0.073 & 0.062 & 0.066 & 0.054 \\
\hline 260 & 0.059 & 0.059 & 0.083 & 0.072 & 0.074 & 0.061 \\
\hline $\mathrm{r} / \mathrm{mg} \mathrm{cm}^{-2} \mathrm{~s}^{-1}$ & 0.00025 & 0.00026 & 0.00036 & 0.00031 & 0.00032 & 0.00026 \\
\hline
\end{tabular}




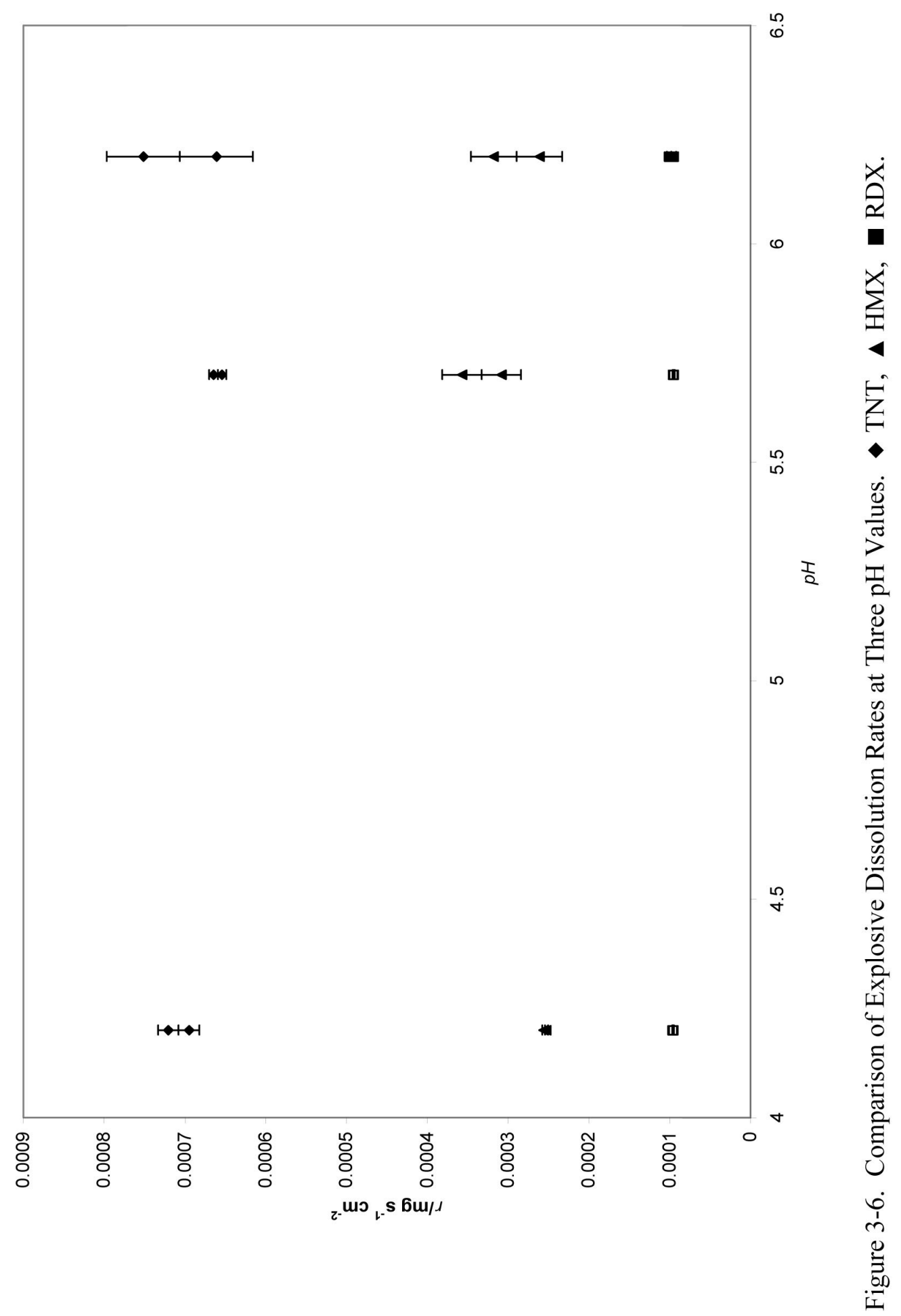


Table 3-3. Zero-Order pH-Related Explosive Dissolution Rates Measured at $30^{\circ} \mathrm{C}, 2.5$ rps Mixing, and Normalized Solid Explosive Surface Area

\begin{tabular}{lclc}
\hline \multicolumn{1}{c}{ Method } & \multicolumn{1}{c}{ Dissolution Rate/ $\mathrm{mg} \mathrm{cm}^{-2} \mathrm{~s}^{-1}$} & \multicolumn{1}{c}{$\mathrm{R}^{2}$} & Avg \% Diff \\
\hline Eq. (3-5) & $\mathrm{TNT}$ & & \\
Composite & $=0.00063$ & $\mathrm{n} / \mathrm{a}$ & \\
& $=0.00069$ & 0.984 & \\
Eq. (3-5) & $\mathrm{HMX}$ & & \\
Composite & $=0.00032$ & $\mathrm{n} / \mathrm{a}$ & \\
& $=0.00029$ & 0.628 & \\
Eq. (3-5) & $\mathrm{RDX}$ & & 1.0 \\
Composite & $=0.000097$ & $\mathrm{n} / \mathrm{a}$ & \\
\hline
\end{tabular}

Note: Average percent difference for equations from data is $10 \%$ for TNT and RDX and $15 \%$ for HMX (Lynch, et al., 2002a) 
The effect of $\mathrm{pH}$ on dissolution rate was found to be minimal within the range of this study. Nevertheless, $\mathrm{pH}$ does appear to play a role in explosive compound transformations. For example, Brannon et al. (1998) found that the abiotic reduction of TNT was $\mathrm{pH}$ sensitive, with rates increasing as $\mathrm{pH}$ increased under anaerobic conditions.

The ability to predict both solubility and dissolution rate at a given temperature permits the prediction of solution concentration at any given time using Eq. (3-4). This equation was used in this study to confirm that solubility had been reached prior to the seventh day of stirring. Using a conservative mixing rate of $3.5 \mathrm{rps}$ and $30^{\circ} \mathrm{C}, \mathrm{HMX}$ attained saturation in $<0.5$ day, RDX had attained saturation in $<5$ days, and TNT reached $99.996 \%$ of saturation in 7 days.

\section{Conclusions}

Solubilities and dissolution rates of TNT, RDX, and HMX were not significantly affected by $\mathrm{pH}$ over the range $4.2-6.2$ but were significantly affected by temperature over the temperature range $(3.1-33.3)^{\circ} \mathrm{C}$. TNT was the most soluble and had the highest dissolution rate, whereas RDX had the second highest solubility but exhibited the slowest dissolution rate. Composite correlations incorporating all study $\mathrm{pH}$ data are presented in Figure 3-5 to predict explosive solubility as a function of temperature and in Eq.(3-5) to predict dissolution rates using specified variables. These equations can be used in predicting the solubility of TNT, RDX, and HMX, their dissolution rates, and, with Eq. (3-4), solution concentrations over time. 


\section{CHAPTER 4 \\ EFFECTS OF COMPONENT INTERACTIONS ON THE AQUEOUS SOLUBILITIES AND DISSOLUTION RATES OF THE EXPLOSIVE FORMULATIONS OCTOL, COMPOSITION B, AND LX-14}

\section{Introduction}

Exposure to certain explosive compounds has the potential of causing detrimental human health effects. The Environmental Protection Agency (EPA) established lifetime exposure drinking water health advisory limits for 2,4,6-trinitrotoluene (TNT), hexahydro-1,3,5-trinitro-1,3,5-triazine (RDX), and octahydro-1,3,5,7-tetranitro-1,3,5,7tetrazocine (HMX) at 2, 2, and $400 \mu \mathrm{g} / \mathrm{L}$, respectively (Crockett et al., 1999). A key word search of active Superfund sites on the EPA web page for TNT, RDX and/or HMX identified twenty-two National Priority List (NPL) locations (Superfund Hazardous Waste Site, 2001). Other potential sources of explosive compound contamination are places where explosives have been manufactured, stored, disposed, or used (Best et al., 1999). Of recent interest are unexploded ordnance (UXO) containing explosive compounds on formerly used defense sites that are raising both safety and environmental concerns (MacDonald, 2001). There are between 1500 and 7500 possible sites that could contain UXO. Dissolution is the primary method by which solid explosive compounds are made available for transport in the environment, yet information on dissolution kinetics has been limited (Brannon et al., 1999). Characterizing an explosive compound source with respect to its aqueous dissolution rate and solubility will contribute to 
environmental models useful for predicting source persistence, conducting risk assessments, and comparing remediation alternatives.

The limited number of correlations describing the aqueous dissolution rates of explosives has, to date, focused on individual compounds without any explosive-toexplosive interactions. Gilcrease et al. (1996), for example, reported the effects of surface area and mixing rate on TNT dissolution rates. We have reported on the effects of surface area, temperature, mixing rate, and $\mathrm{pH}$ on the separate aqueous dissolution rates of TNT, RDX and HMX (Lynch et al., 2002a; Lynch et al., 2001). Using the Lynch et al. (2002a) data and a mixing rate of $2.5 \mathrm{rps}$, correlations predicting dissolution rates for TNT, RDX, and HMX as a function of temperature were developed:

$$
\begin{aligned}
& \text { TNT: } \frac{1}{\mathrm{a}}\left(\frac{\mathrm{dm}}{\mathrm{dt}}\right)=7 \times 10^{-5} \mathrm{e}^{(0.0779 \theta)} \\
& \text { RDX: } \frac{1}{\mathrm{a}}\left(\frac{\mathrm{dm}}{\mathrm{dt}}\right)=1 \times 10^{-5} \mathrm{e}^{(0.0779 \theta)} \\
& \text { HMX: } \frac{1}{\mathrm{a}}\left(\frac{\mathrm{dm}}{\mathrm{dt}}\right)=6 \times 10^{-5} \mathrm{e}^{(0.0568 \theta)}
\end{aligned}
$$

where the left sides of the equations represent the mass $(m)$ in $\mathrm{mg}$ of solid explosive dissolved per second $(t)$ per $\mathrm{cm}^{2}$ solid surface area $(a)$ and where $\theta$ is temperature in ${ }^{\circ} \mathrm{C}$.

With the exception of a column test performed by Spanggord et al. (1983) containing both TNT and RDX, explosive compound aqueous solubilities have been studied separately without consideration of explosive-to-explosive interactions. Examples of recently proposed correlations for independently determined explosive compound solubilities as a function of temperature include Ro et al. (1996) for TNT and Lynch et al. (2001) for TNT, RDX, and HMX. The Lynch et al. (2001) temperaturebased solubility $(S)$ correlations for TNT, RDX, and HMX are 


$$
\begin{array}{ll}
\text { TNT: } & \ln \left(\mathrm{S} / \mathrm{mg} \cdot \mathrm{L}^{-1}\right)=16.981-\frac{3607.5 \mathrm{~K}}{\mathrm{~T}} \\
\text { RDX: } & \ln \left(\mathrm{S} / \mathrm{mg} \cdot \mathrm{L}^{-1}\right)=19.52-\frac{4670.9 \mathrm{~K}}{\mathrm{~T}} \\
\text { HMX: } & \ln \left(\mathrm{S} / \mathrm{mg} \cdot \mathrm{L}^{-1}\right)=22.835-\frac{6358.2 \mathrm{~K}}{\mathrm{~T}}
\end{array}
$$

Independent explosive compounds, though, are generally not expected in a field environment. Of the twenty-two NPL sites previously mentioned, at least ten sites contain two or more of the three explosive compounds. In addition, high explosives are not often used in their pure form but rather in explosive formulations. Multiple types of ordnance, containing differing formulations, have been used on training ranges. Explosive formulations are varying blends of explosive compounds with additives such as binders and desensitizers tailored for specific applications. The processes by which formulations are made and/or the presence of more than one explosive compound in the formulation may result in dissolution rates or solubilities different than those predicted by studies using separate explosive compounds. In this chapter we determine the dissolution rates and solubilities of the primary explosive compounds in the formulations known as octol, Composition B, and LX-14 and evaluate the applicability of explosive compound dissolution rate and solubility correlations (Eqs. (4-1) throughout (4-6)) to these formulations. Also evaluated are the dissolution rates and solubilities of military grade RDX and HMX crystals and TNT flakes in seven different non-bound mixture combinations. 


\section{Experimental Section}

\section{Chemicals}

The Holston Army Ammunition Plant, Kingsport, Tennessee, provided experimental quantities of TNT and the explosive formulations octol and Composition B. Picatinny Arsenal, Picatinny, New Jersey, provided experimental quantities of LX-14. Three samples of TNT and eight samples, each, of Composition B and octol were meltcast into $5.5 \mathrm{~cm}$ diameter disk-shaped molds with an average thickness of $(0.88 \pm 0.08)$ $\mathrm{cm}$ at the Holston plant. Octol is the formulation name given to a bound mixture of HMX and TNT (Gibbs and Popolato, 1980). The octol used here consisted of $70 \%$ by mass HMX and $30 \%$ by mass TNT. Composition B is a bound mixture of TNT and RDX that might also include a wax desensitizer (Gibbs and Popolato, 1980). Composition B consisted of $59.5 \%$ by mass RDX, $39.5 \%$ by mass TNT, and $1 \%$ by mass wax. Both octol and Composition B are prepared by stirring into melted TNT the other components of the formulation and, after mixing, allowing the resulting formulation to solidify. LX-14 is a plastic bonded explosive consisting of $95.5 \%$ by mass HMX and $4.5 \%$ by mass polyurethane that is trademarked as Estane. LX-14 is prepared by mixing the polyurethane (which has been dissolved in a solvent) with a slurry of HMX and water, removing the water and solvent, and allowing the polyurethane to lacquer coat the HMX in granule shapes.

Experimental quantities of weapons grade RDX and HMX crystals and TNT flakes were provided by the Environmental Processes and Engineering Division of the Engineer Research and Development Center, US Army Corps of Engineers Waterways Experiment Station, Vicksburg, Mississippi. These explosive compounds were used 
separately and in the preparation of the non-bound explosive mixtures to compare with the explosive compounds in the formulations. Though quantities of explosive compounds used in this study were small, health precautions to protect against inhalation and electrical grounding to protect from detonation by electrostatic charge were taken. Demineralized water (reverse osmosis) served as the experimental solvent.

\section{Procedure}

Solubility. The experimental procedure for solubility is outlined in Lynch, et al. (2001). A non-bound mixture of individual explosive compounds was prepared by adding together excess (quantities greater than the expected solubility) amounts of RDX and HMX crystals and TNT flakes. Solubility tests for each formulation were run separately using sufficient formulation to assure excess amounts of each explosive component. The solvent used for all experiments was $200 \mathrm{~mL}$ of demineralized water in a 250 Erlenmeyer flask. The first experiment, conducted at a temperature of $(29.0 \pm$ $2.2)^{\circ} \mathrm{C}$, compared the solubility of each explosive compound in a formulation to that of each explosive compound run independently. A second experiment, conducted at a temperature of $(26.3 \pm 0.2)^{\circ} \mathrm{C}$, compared solubilities of the three explosive compounds in the mixture to those of each explosive compound run independently. Formulation and mixture experiments were performed in triplicate.

Dissolution rate. The procedure for the dissolution rate experiments is outlined in Lynch et al. (2001), with one modification. The width of the formulation disks required that the mold be added first to the beaker and the $500 \mathrm{~mL}$ of water subsequently added at time zero while the stirring propellers were turning. For the runs involving mixtures, sufficient mass of RDX, HMX, and TNT to provide six $\mathrm{cm}^{2}$ of surface area 
each were added together according to the particular experimental run mixture requirement. The binders, Indramic wax and polyurethane Estane $\left(1.5 \mathrm{~cm}^{2}\right.$ each $)$, were also added to selected mixtures, mimicking the components of Composition B and LX14 , respectively, as well as both to one mixture containing all three explosive compounds. Each experimental run was performed in triplicate.

Equipment. Samples ( $1 \mathrm{~mL}$ each) were immediately passed through a $0.45 \mu \mathrm{m}$ Millipore filter and combined with an equal amount of $0.45 \mu \mathrm{m}$-filtered acetonitrile in preparation for HPLC analysis. Vials containing the sample and acetonitrile were sealed with a Teflon faced silicone rubber cap and mixed using a vortex mixer for five seconds and then stored quiescently in the dark for at least $25 \mathrm{~min}$ before analysis. Analyses were performed using a Waters HPLC running a Millennium Software package with a model 486 tunable detector $(\lambda=245 \mathrm{~nm})$ and auto sampler, in accordance with Method 8330 (EPA, 1994). A reverse phase eluent (50:50 methanol and water) was used in the HPLC system. The analytical column was a $25 \mathrm{~cm}$ x $4.6 \mathrm{~mm}, 5 \mu \mathrm{m}$ Supelco LC-18 reverse phase HPLC column. The HPLC was calibrated using a seven-point calibration curve. A sample replicate, blank, and check standard were included in each analytical run. Percent recoveries were $99.1,99.5$, and 99.0 for TNT, RDX, and HMX, respectively. The average percent differences between replicate analyses for TNT, RDX, and HMX were $5.1 \%$ (standard deviation of 3.7, 92 samples), $7.0 \%$ (standard deviation of 5.3, 71 samples), and 3.8\% (standard deviation of 3.1, 89 samples), respectively. 


\section{Results and Discussion}

\section{Dissolution Rates of High Explosive Compounds}

The dissolution rates for all analytical runs were recorded in units of $\mathrm{mg} \mathrm{s}^{-1} \mathrm{~cm}^{-2}$ to normalize for the variations in solid surface area. TNT, RDX, and HMX were run independently, in addition to the formulations and mixtures, to serve as a basis for dissolution rate comparison. The dissolution rates for the various mixtures and separate compounds at $2.5 \mathrm{rps}$ and three temperatures are summarized in Table 4-1. The dissolution rates for the formulations in the form of molds at $2.5 \mathrm{rps}$ and three temperatures are summarized in Table 4-2.

Dissolution rates for each explosive compound in a specific mixture compared well with the dissolution rates of that particular explosive compound run separately. Overall, RDX showed the smallest variance in dissolution rate between highest and lowest values of the three runs with a difference averaging less than $0.000017 \mathrm{mg} \mathrm{s}^{-1}$ $\mathrm{cm}^{-2}$. This was followed by HMX with an average difference less than $0.000083 \mathrm{mg} \mathrm{s}^{-1}$ $\mathrm{cm}^{-2}$ and TNT with an average difference less than $0.00017 \mathrm{mg} \mathrm{s}^{-1} \mathrm{~cm}^{-2}$. TNT consistently exhibited the fastest dissolution rates at each temperature, followed sequentially by HMX and RDX. Dissolution rates among explosive compounds determined at one temperature did not extend over each other regardless of the mixing conditions.

The dissolution rates for a specific explosive compound across the different mixtures were similar. Though relatively small, the greatest difference in dissolution rates existed between runs of an explosive compound run independently and in the two mixtures containing all three explosive compounds. Of the three explosive compounds, 
Table 4-1. Dissolution Rates, $r$, of Explosive Compounds Measured Separately and in Mixtures $\left(\mathrm{mg} \mathrm{s}^{-1} \mathrm{~cm}^{-2}\right)$ Stirred at $2.5 \mathrm{rps}$ and Measured at Temperatures Shown.

\begin{tabular}{|c|c|c|c|c|c|c|c|c|c|}
\hline \multirow{3}{*}{$\begin{array}{c}\text { Runs } \\
\text { Constituent }\end{array}$} & \multirow{2}{*}{\multicolumn{3}{|c|}{$\theta=10^{\circ} \mathrm{C}$}} & \multicolumn{3}{|c|}{$10^{5} \mathrm{r} / \mathrm{mg} \mathrm{s}^{-1} \mathrm{~cm}^{-2}$} & \multirow{2}{*}{\multicolumn{3}{|c|}{$\theta=30^{\circ} \mathrm{C}$}} \\
\hline & & & & & $\theta=20^{\circ}$ & & & & \\
\hline & TNT & RDX & HMX & TNT & RDX & HMX & TNT & RDX & HMX \\
\hline Pure & 15 & & & 27 & & & 60 & & \\
\hline Pure & 16 & & & 25 & & & 52 & & \\
\hline Pure & 14 & & & 18 & & & 60 & & \\
\hline Pure & & 2.8 & & & 5.3 & & & 10 & \\
\hline Pure & & 2.4 & & & 5.6 & & & 11 & \\
\hline Pure & & 2.4 & & & 5.2 & & & 10 & \\
\hline Pure & & & 5.6 & & & 14 & & & 37 \\
\hline Pure & & & 8.0 & & & 14 & & & 32 \\
\hline Pure & & & 6.6 & & & 18 & & & 38 \\
\hline Mix & 14 & 2.4 & & 28 & 5.0 & & 69 & 9.6 & \\
\hline Mix & 13 & 2.3 & & 33 & 5.0 & & 57 & 11 & \\
\hline Mix & 14 & 2.6 & & 21 & 5.6 & & 57 & 10 & \\
\hline Mix & & 2.4 & 7.0 & & 4.9 & 17 & & 11 & 51 \\
\hline Mix & & 2.6 & 8.2 & & 5.3 & 15 & & 10 & 33 \\
\hline Mix & & 2.4 & 7.6 & & 5.3 & 12 & & 11 & 37 \\
\hline Mix & 16 & & 7.6 & 31 & & 18 & 57 & & 45 \\
\hline Mix & 16 & & 7.2 & 29 & & 16 & 58 & & 34 \\
\hline Mix & 15 & & 7.7 & 31 & & 14 & 61 & & 36 \\
\hline Mix & 16 & 2.4 & 8.4 & 31 & 5.3 & 24 & 73 & 9.1 & 50 \\
\hline Mix & 16 & 2.4 & 8.3 & 31 & 5.4 & 16 & 62 & 8.1 & 37 \\
\hline Mix & 14 & 2.3 & 8.3 & 33 & 4.8 & 19 & 63 & 9.6 & 38 \\
\hline $\mathrm{Mix}+\mathrm{W}$ & 18 & 2.5 & & 32 & 5.5 & & 63 & 9.4 & \\
\hline $\mathrm{Mix}+\mathrm{W}$ & 15 & 2.7 & & 31 & 5.6 & & 67 & 11 & \\
\hline $\mathrm{Mix}+\mathrm{W}$ & 16 & 2.4 & & 34 & 6.3 & & 65 & 11 & \\
\hline Pure+P & & & 10 & & & 20 & & & 33 \\
\hline Pure $+\mathrm{P}$ & & & 8.3 & & & 14 & & & 32 \\
\hline Pure $+\mathrm{P}$ & & & 9.1 & & & 17 & & & 49 \\
\hline $\mathrm{Mix}+\mathrm{W}+\mathrm{P}$ & 16 & 2.2 & 12 & 32 & 4.4 & 20 & 67 & 9.8 & 37 \\
\hline $\mathrm{Mix}+\mathrm{W}+\mathrm{P}$ & 15 & 2.2 & 9.3 & 29 & 5.4 & 17 & 67 & 9.2 & 46 \\
\hline $\mathrm{Mix}+\mathrm{W}+\mathrm{P}$ & 17 & 2.2 & 11 & 34 & 4.7 & 19 & 68 & 9.8 & 50 \\
\hline
\end{tabular}

Note: $\mathrm{W}$ and $\mathrm{P}$ indicate addition of wax and polyurethane, respectively, to the explosive compounds. 
Table 4-2. Dissolution Rates, $r$, of Explosive Compounds Found in Formulations and TNT Mold Measured at Temperature Indicated and Mixed at $2.5 \mathrm{rps}$

\begin{tabular}{|c|c|c|c|c|c|c|c|c|}
\hline \multirow[b]{3}{*}{ TNT } & \multirow{2}{*}{\multicolumn{2}{|c|}{$\theta=10^{\circ} \mathrm{C}$}} & \multicolumn{3}{|c|}{$10^{5} \mathrm{r} / \mathrm{mg} \mathrm{s}^{-1} \mathrm{~cm}^{-2}$} & \multirow[b]{3}{*}{ TNT } & \multirow{2}{*}{\multicolumn{2}{|c|}{$\theta=30^{\circ} \mathrm{C}$}} \\
\hline & & & & $\theta=20$ & & & & \\
\hline & RDX & HMX & TNT & RDX & HMX & & $\mathrm{RDX}$ & HMX \\
\hline \multicolumn{9}{|c|}{ TNT Mold } \\
\hline 7.4 & & 0.092 & 19 & & 0.47 & 36 & & 0.24 \\
\hline 7.6 & & 0.093 & 21 & & 0.52 & 43 & & 0.35 \\
\hline 8.5 & & 0.071 & 23 & & 0.50 & 43 & & 0.19 \\
\hline \multicolumn{9}{|c|}{ LX-14 Mold } \\
\hline & & 0.48 & & & 0.91 & & & 2.8 \\
\hline & & 0.46 & & & 0.94 & & & 2.8 \\
\hline & & 0.41 & & & 0.93 & & & 2.7 \\
\hline \multicolumn{9}{|c|}{ Octol Mold } \\
\hline 6.4 & & 0.22 & 16 & & 0.48 & 30 & & 0.81 \\
\hline 7.2 & & 0.22 & 16 & & 0.48 & 34 & & 1.0 \\
\hline 7.4 & & 0.24 & 15 & & 0.48 & 34 & & 1.1 \\
\hline \multicolumn{9}{|c|}{ Composition B Mold } \\
\hline 5.1 & 1.1 & 0.19 & 9.9 & 2.1 & 0.37 & 18 & 2.8 & 0.40 \\
\hline 5.3 & 1.3 & 0.21 & 13 & 2.6 & 0.48 & 20 & 4.3 & 0.75 \\
\hline 4.9 & 1.3 & 0.20 & 12 & 2.7 & 0.49 & 23 & 4.6 & 0.82 \\
\hline
\end{tabular}




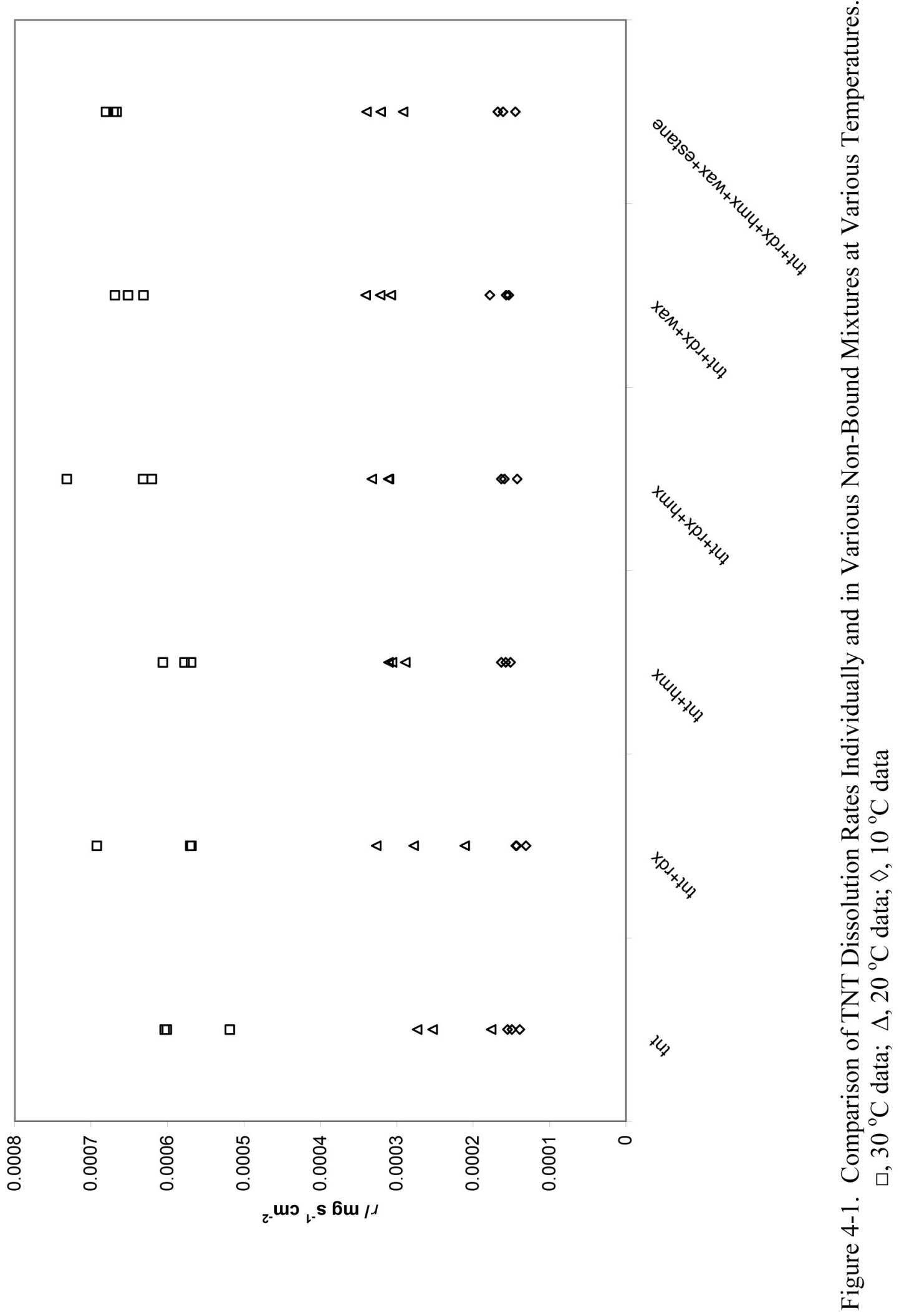


TNT exhibited the largest variation in dissolution rate among the various runs (Figure 4-1). In general, the dissolution rates for TNT and HMX in the two mixtures containing all three explosive compounds were somewhat higher than for these respective compounds run separately while for RDX the dissolution rates were somewhat lower than those measured for RDX run separately.

The deviations in dissolution rates of the explosive compounds in these three explosive compound mixtures from those run individually might be partially explained by physical interactions taking place in the reaction beaker. The increased mass of explosive compounds in a fixed volume of water resulted in increased solid-to-solid frictional contact. This friction might have increased the dissolution rates for TNT and HMX by exposing more surface area. RDX crystal dissolution rates, however, were slightly suppressed (Table 4-1). This suppression may be partially explained by the observation that RDX crystals routinely converged to the beaker's bottom center and were shielded by the TNT flakes.

Taking the physical interactions among explosives into account, experimental results indicated that the presence of more than one independent explosive compound in a single solution did not significantly affect individual compound dissolution rates.

Dissolution rate data from the experiments where the explosive compounds were run independently are combined with earlier data ${ }^{7}$ to update the accuracy of the correlations presented in Eqs. (4-1) throughout (4- 3).

$$
\begin{aligned}
& \text { TNT: } \frac{1}{\mathrm{a}}\left(\frac{\mathrm{dm}}{\mathrm{dt}}\right)=7 \times 10^{-5} \mathrm{e}^{(0.0755 \theta)} \\
& \text { RDX: } \frac{1}{\mathrm{a}}\left(\frac{\mathrm{dm}}{\mathrm{dt}}\right)=1 \times 10^{-5} \mathrm{e}^{(0.0762 \theta)}
\end{aligned}
$$




$$
\text { HMX: } \frac{1}{\mathrm{a}}\left(\frac{\mathrm{dm}}{\mathrm{dt}}\right)=5 \times 10^{-5} \mathrm{e}^{(0.0635 \theta)}
$$

To determine if the formulations had any effect on the dissolution rates, surface areas were back calculated from the multi-variable dissolution rate equations presented in Lynch et al. (2001) and compared to the actual formulation surface area available. The three TNT molds served as a second standard for comparison since the surface areas for the military grade flakes and crystals are estimated values (Lynch et al., 2002a). HPLC analysis of the TNT molds, though, revealed that they were contaminated with small amounts of HMX, most likely occurring during the melt-pour process. This contamination was considered in the overall surface area analysis.

Based on dissolution rate results from the prepared molds, the formulation constituents appear to be relatively well mixed. Using the results from the three molds analyzed at each temperature for octol and LX-14, the average percent difference between the high and low dissolution rates was mostly below $20 \%$ while for Composition B the average percent difference was 30\% (Table 4-2). The use of an average of the three dissolution rates for each formulation in these experiments would yield representative dissolution rates applicable to other samples containing these formulations.

The processes used in the preparation of octol, Composition B, and LX-14 appear to have affected certain explosive compound dissolution rates. A comparison of TNT dissolution rates is presented in Figure 4-2. The separately determined TNT dissolution rates (TNT flakes) proceeded the fastest followed sequentially by TNT in the TNT molds, TNT in the octol molds, and TNT in the Composition B molds. The comparison of HMX dissolution rates is presented in Figure 4-3. The separately determined crystalline HMX dissolution rates greatly exceeded those in the formulations (i.e., at $30^{\circ} \mathrm{C}$ having a mean 


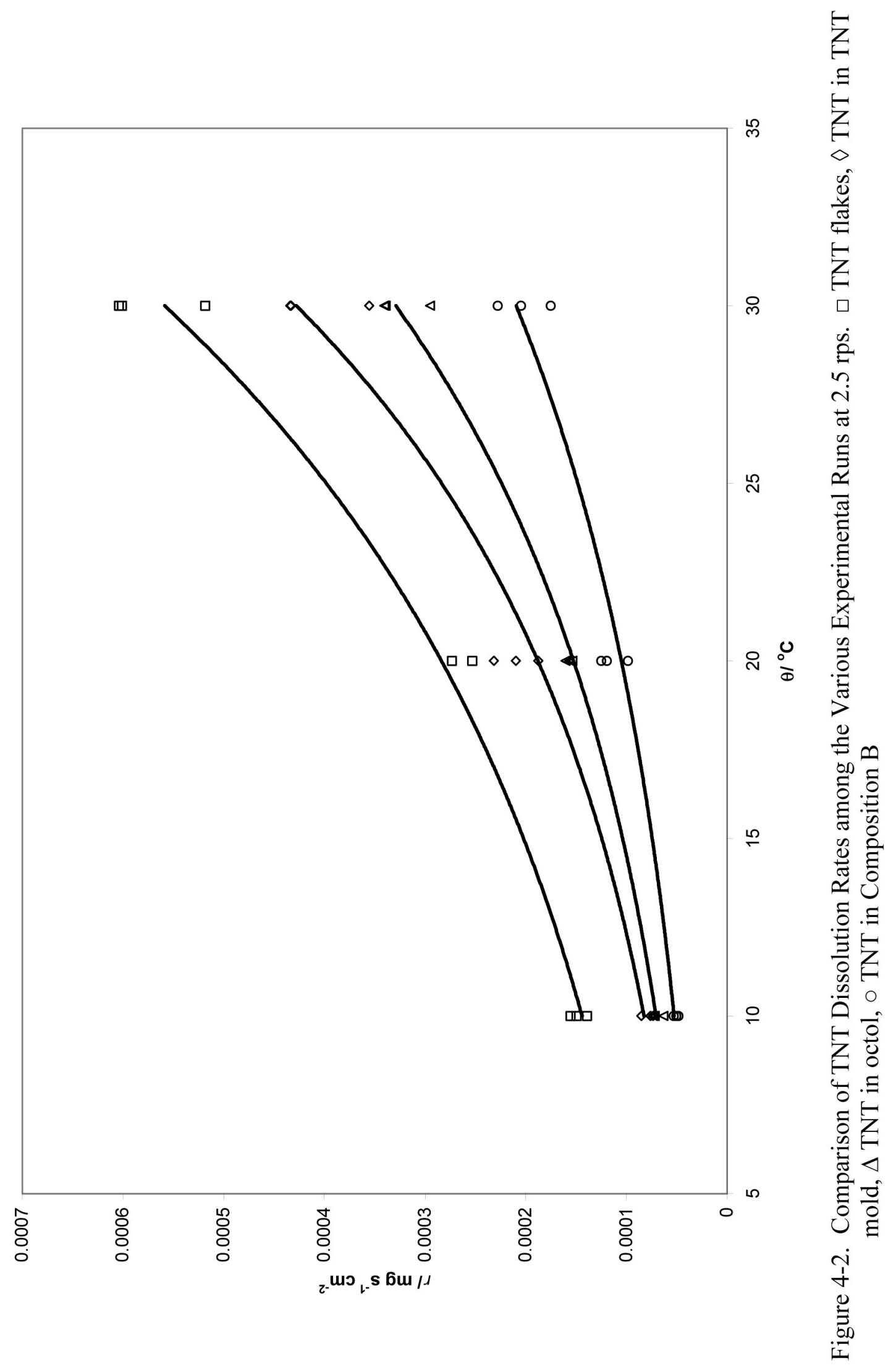




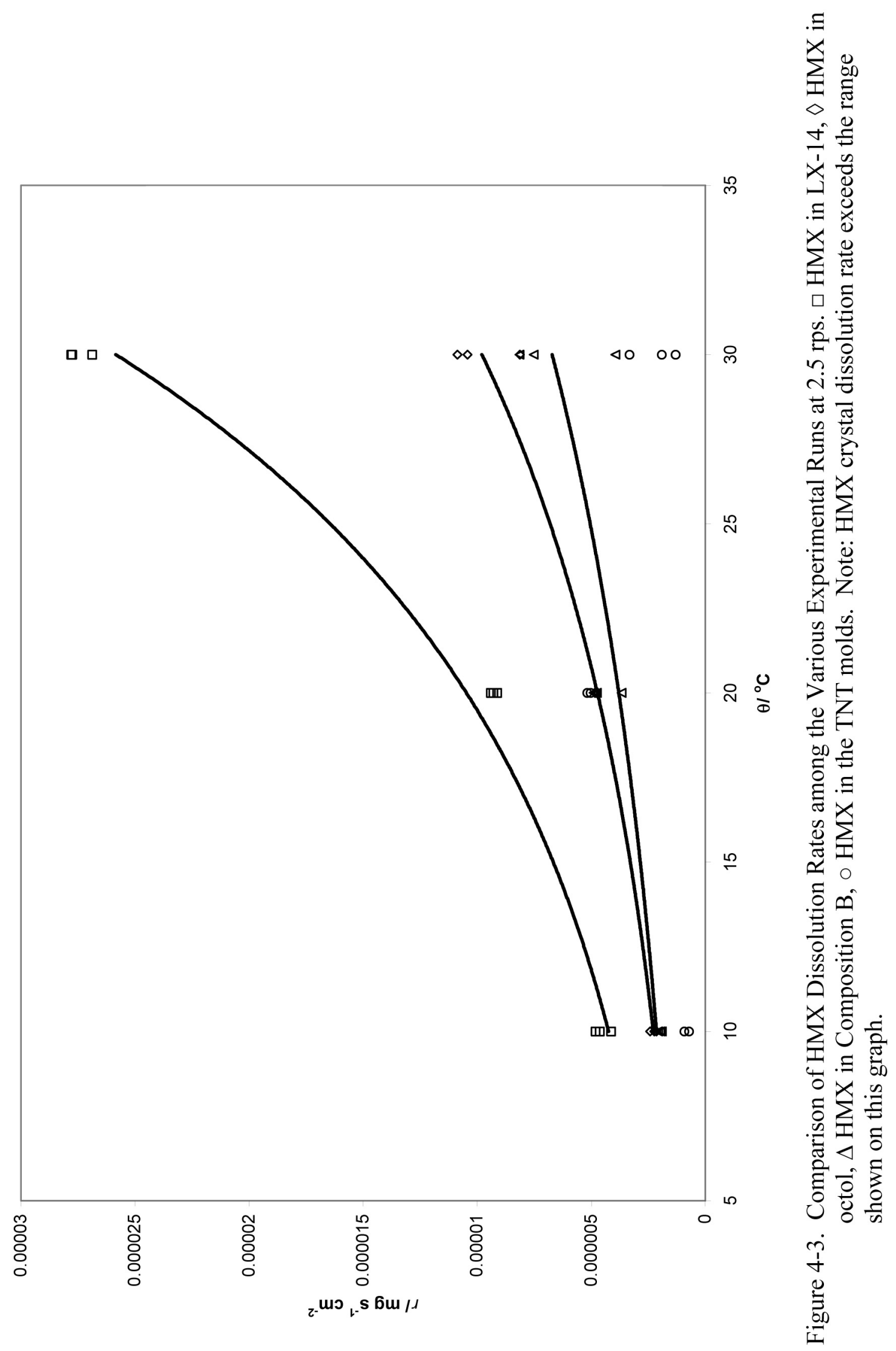


dissolution rate of $0.000354 \mathrm{mg} \mathrm{s}^{-1} \mathrm{~cm}^{-2}$ which is more than an order of magnitude higher than the highest HMX rate reported for the formulations) and are above the range presented in Figure 4-3. The HMX crystalline dissolution rates are sequentially followed by HMX in the LX-14 granules, HMX in the octol molds, and HMX in the Composition B molds. It should be noted that the TNT molds were re-used to determine dissolution rates at each temperature starting with the $20^{\circ} \mathrm{C}$ experiment. $\mathrm{HMX}$ dissolution rates from these molds at $30^{\circ} \mathrm{C}$ are lower than those seen at $20^{\circ} \mathrm{C}$, indicating that $\mathrm{HMX}$ availability was decreasing as experimentation progressed. A comparison of RDX dissolution rates is presented in Figure 4-4. The separately determined crystalline RDX dissolution rates were greater than RDX in the Composition B molds. Initial dissolution rate correlations for the explosive compounds in the formulations are presented in Table 4-3.

Using surface area comparisons, both the TNT and HMX dissolution rates in octol were suppressed with calculated surface areas totaling less than that actually available on the molds. Though comprising only $30 \%$ of the total mass of octol, TNT accounted for more mold surface area than did HMX. In the Composition B molds, RDX accounted for most of the predicted total formulation surface area followed by TNT and then HMX. The $5 \mathrm{~cm}^{2}$ of LX-14 yielded a dissolution rate similar to that of $0.3 \mathrm{~cm}^{2}$ of HMX crystals under similar conditions.

Estimations of the activation energies for dissolution based on the Arrhenius equation were made for each explosive compound (as a formulation component and separately). The calculated activation energies are lower for all explosive compounds in Composition B (49 $\mathrm{kJ} \mathrm{mol}^{-1}$ for TNT, $41 \mathrm{~kJ} \mathrm{~mol}^{-1}$ for RDX, and $41 \mathrm{~kJ} \mathrm{~mol}^{-1}$ for HMX) 


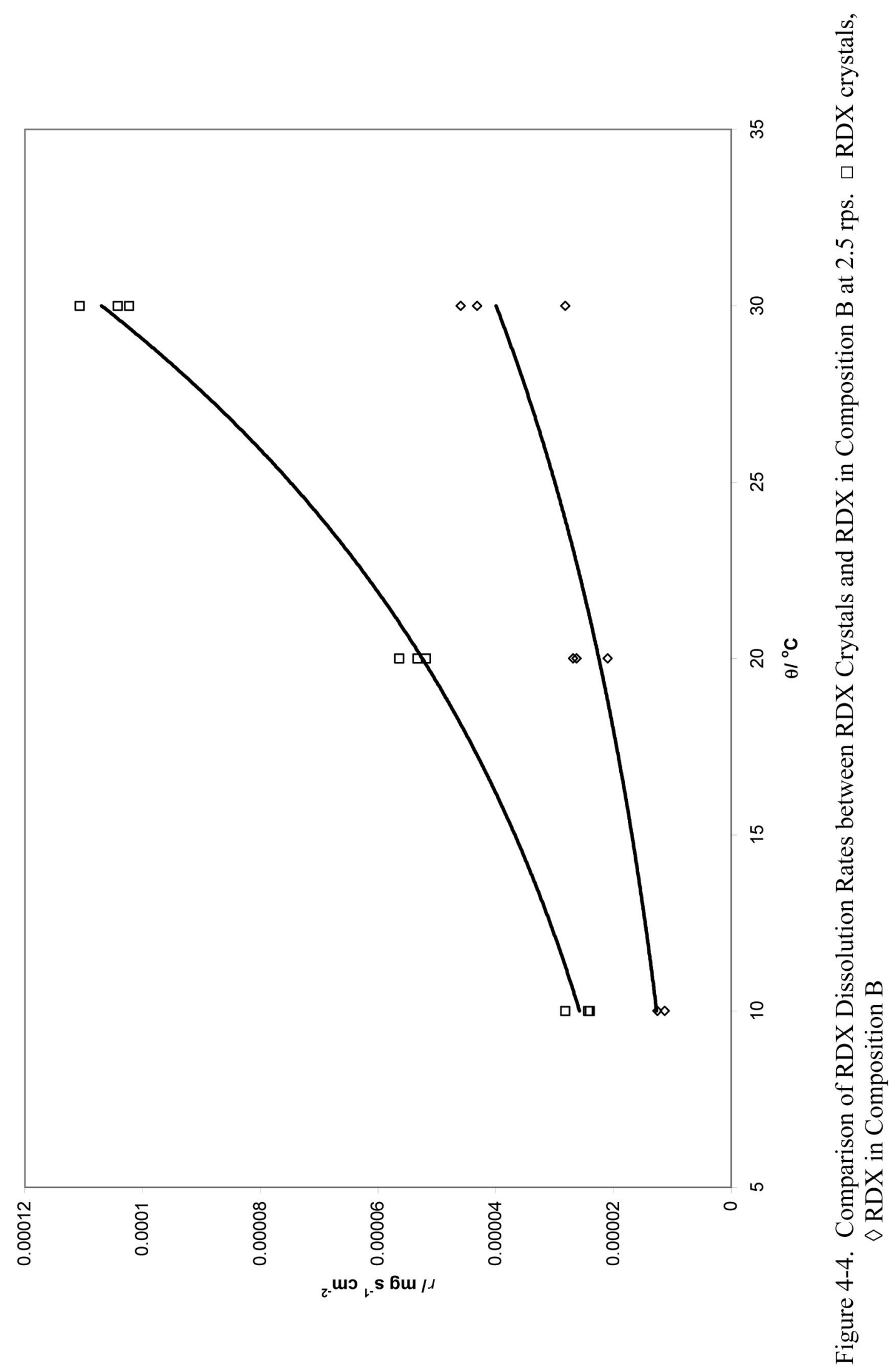


Table 4-3. Formulation Dissolution Rate $\left(\mathrm{mg} \mathrm{s}^{-1} \mathrm{~cm}^{-2}\right)$ Correlations and $\mathrm{r}^{2}$ Values for Explosive Compounds Mixed at $2.5 \mathrm{rps}$ as a Function of Temperature Over $(10-30)^{\circ} \mathrm{C}$.

\begin{tabular}{ccc}
\hline Compound & Formulation/Correlation & $\mathrm{r}^{2}$ \\
TNT & Octol & 0.99 \\
HMX & $3 \times 10^{-5} \mathrm{e}^{(0.0769 \theta)}$ & 0.98 \\
& $1 \times 10^{-6} \mathrm{e}^{(0.0728 \theta)}$ & \\
Composition B & $3 \times 10^{-5} \mathrm{e}^{(0.069 \theta)}$ & 0.97 \\
RDX & $7 \times 10^{-6} \mathrm{e}^{(0.0574 \theta)}$ & 0.90 \\
& $\mathrm{LX}-14$ & \\
HMX & $2 \times 10^{-6} \mathrm{e}^{(0.0903 \theta)}$ & 0.98 \\
\hline
\end{tabular}


than those calculated for these compounds determined independently $\left(51 \mathrm{~kJ} \mathrm{~mol}^{-1}\right.$ for TNT, $53 \mathrm{~kJ} \mathrm{~mol}^{-1}$ for RDX, and $52 \mathrm{~kJ} \mathrm{~mol}^{-1}$ for HMX). Calculated activation energies for HMX in LX-14 $\left(64 \mathrm{~kJ} \mathrm{~mol}^{-1}\right)$ and TNT in octol $\left(55 \mathrm{~kJ} \mathrm{~mol}^{-1}\right)$ are higher than those determined independently.

\section{Solubility of High Explosive Compounds}

A mixture of the three explosive compounds was prepared to investigate explosive-to-explosive interactions, if any, when there was more than one independent compound in a solution. The solubility data for the explosive compounds studied independently and in the mixture are summarized in Table 4-4. As described in the Chemicals section, the formulations provided unique opportunities to explore the formulation processes, explosive-to-explosive binding, and explosive-to-binder binding effects on solubility. The solubility data for the explosive compounds in each formulation are summarized in Table 4-5.

None of the combinations studied, either in the formulations or as a mixture, resulted in significant changes in explosive compound solubility compared with those of the separate explosive compounds. In addition, the experimental solubility values compared well to those predicted by Eqs. (4-4) throughout (4-6) (Tables 4-4, 4-5 and Figure 4-5). Independently run solubility results from this current study were combined with the original correlation data (Lynch et al., 2002a) to produce new correlations based on a larger data set. The revised solubility correlations as a function of temperature for TNT, RDX, and HMX are presented below:

$$
\text { TNT: } \quad \ln \left(S / m g \cdot L^{-1}\right)=16.793-\frac{3556.3 K}{T}
$$


Table 4-4. Solubilities of Explosive Compounds Determined Independently and in a Non-Bound Mixture with Correlation Predictions and the Average Percent Difference (APD) between Measurements and Predictions.

\begin{tabular}{|c|c|c|c|c|c|c|c|c|c|}
\hline \multirow[b]{2}{*}{$\theta /{ }^{\circ} \mathrm{C}$} & \multicolumn{3}{|c|}{ TNT } & \multicolumn{3}{|c|}{ RDX } & \multicolumn{3}{|c|}{ HMX } \\
\hline & $\begin{array}{c}\text { Predicted } \\
S / \mathrm{mg} \mathrm{l}^{-1}\end{array}$ & $\begin{array}{l}\text { Actual } \\
S / \mathrm{mg} \mathrm{l}^{-1}\end{array}$ & $\begin{array}{c}\text { APD } \\
\%\end{array}$ & $\begin{array}{l}\text { Predicted } \\
S / \mathrm{mg} \mathrm{l}^{-1}\end{array}$ & $\begin{array}{l}\text { Actual } \\
S / \mathrm{mg} \mathrm{l}^{-1}\end{array}$ & $\begin{array}{c}\text { APD } \\
\%\end{array}$ & $\begin{array}{c}\text { Predicted } \\
S / \mathrm{mg} \mathrm{l}^{-1}\end{array}$ & $\begin{array}{l}\text { Actual } \\
S / \mathrm{mg} \mathrm{l}^{-1}\end{array}$ & $\begin{array}{c}\text { APD } \\
\%\end{array}$ \\
\hline & \multicolumn{9}{|c|}{ Explosive Compounds Run Independently } \\
\hline 26.3 & 136.07 & 128.87 & 5.44 & & & & & & \\
\hline 26.3 & 136.07 & 127.06 & 6.85 & & & & & & \\
\hline 26.3 & 136.07 & 126.34 & 7.42 & & & & & & \\
\hline 26.3 & 136.07 & 127.02 & 6.88 & & & & & & \\
\hline 26.5 & & & & 50.32 & 52.74 & -4.69 & 4.99 & 4.52 & 9.94 \\
\hline 26.6 & & & & 50.60 & 52.52 & -3.73 & 5.03 & 4.50 & 11.06 \\
\hline 26.6 & & & & 50.60 & 51.68 & -2.10 & 5.03 & 4.46 & 12.03 \\
\hline 26.3 & & & & 49.77 & 53.47 & -7.18 & 4.92 & 4.56 & 7.63 \\
\hline 26.2 & & & & & & & 4.88 & 4.54 & 7.31 \\
\hline 26.3 & & & & & & & 4.92 & 4.48 & 9.31 \\
\hline 26.3 & & & & & & & 4.92 & 4.46 & 9.67 \\
\hline \multirow[t]{2}{*}{25.9} & & & & & & & 4.77 & 4.64 & 2.76 \\
\hline & \multicolumn{9}{|c|}{ Explosive Compounds Run in a Non-bound Mixture } \\
\hline 26.0 & 134.36 & 125.82 & 6.57 & 48.95 & 51.61 & -5.29 & 4.81 & 4.53 & 5.96 \\
\hline 26.2 & 135.50 & 127.51 & 6.07 & 49.49 & 51.86 & -4.67 & 4.88 & 4.57 & 6.52 \\
\hline 26.2 & 135.50 & 129.91 & 4.21 & 49.49 & 53.08 & -7.00 & 4.88 & 4.63 & 5.22 \\
\hline 26.0 & 134.36 & 129.18 & 3.93 & 48.95 & 52.20 & -6.43 & 4.81 & 4.51 & 6.32 \\
\hline
\end{tabular}


Table 4-5. Solubilities of Explosive Compounds in Formulations Compared to Correlation Predictions with Average Percent Difference.

\begin{tabular}{|c|c|c|c|c|c|c|c|c|c|}
\hline \multirow[b]{2}{*}{$\theta /{ }^{\circ} \mathrm{C}$} & \multicolumn{3}{|c|}{ TNT } & \multicolumn{3}{|c|}{ RDX } & \multicolumn{3}{|c|}{ HMX } \\
\hline & $\begin{array}{l}\text { Predicted } \\
S / \mathrm{mg} \mathrm{l}^{-1}\end{array}$ & $\begin{array}{c}\text { Actual } \\
S / \mathrm{mg} \mathrm{l}^{-1}\end{array}$ & $\begin{array}{l}\text { APD } \\
\%\end{array}$ & $\begin{array}{l}\text { Predicted } \\
S / \mathrm{mg} \mathrm{l}^{-1}\end{array}$ & $\begin{array}{c}\text { Actual } \\
S / \mathrm{mg} \mathrm{l}^{-1}\end{array}$ & $\begin{array}{l}\text { APD } \\
\%\end{array}$ & $\begin{array}{l}\text { Predicted } \\
S / \mathrm{mg} \mathrm{l}^{-1}\end{array}$ & $\begin{array}{l}\text { Actual } \\
S / \mathrm{mg} \mathrm{l}^{-1}\end{array}$ & $\begin{array}{c}\text { APD } \\
\%\end{array}$ \\
\hline & \multicolumn{9}{|c|}{ Octol } \\
\hline 30.2 & 160.41 & 145.95 & 9.44 & 61.77 & 0.42 & 197.32 & 6.62 & 5.90 & 11.56 \\
\hline 30.2 & 160.41 & 146.54 & 9.04 & 61.77 & 0.38 & 197.55 & 6.62 & 5.76 & 13.88 \\
\hline 30.2 & 160.41 & 156.26 & 2.62 & 61.77 & 0.41 & 197.35 & 6.62 & 6.14 & 7.57 \\
\hline 30.4 & 161.77 & 156.65 & 3.22 & 62.46 & 0.67 & 195.77 & 6.72 & 5.94 & 12.33 \\
\hline 31.4 & 168.75 & 144.87 & 15.23 & 66.01 & 0.43 & 197.42 & 7.25 & 6.38 & 12.87 \\
\hline 31.5 & 169.46 & 156.86 & 7.72 & 66.38 & 0.43 & 197.41 & 7.31 & 6.48 & 12.02 \\
\hline 31.2 & 167.33 & 169.10 & -1.06 & 65.29 & 0.72 & 195.66 & 7.14 & 6.56 & 8.51 \\
\hline \multicolumn{10}{|c|}{ Composition B } \\
\hline 26.5 & 137.23 & 141.19 & -2.85 & 50.32 & 57.23 & -12.85 & 4.99 & 5.00 & -0.06 \\
\hline 26.3 & 136.07 & 137.83 & -1.29 & 49.77 & 54.68 & -9.41 & 4.92 & 5.04 & -2.46 \\
\hline 26.3 & 136.07 & 142.21 & -4.41 & 49.77 & 56.48 & -12.64 & 4.92 & 5.14 & -4.50 \\
\hline 26.1 & 134.93 & 134.38 & 0.40 & 49.22 & 53.50 & -8.35 & 4.84 & 4.69 & 3.25 \\
\hline 27.5 & 143.14 & 137.81 & 3.80 & 53.19 & 54.94 & -3.24 & 5.39 & 5.07 & 6.05 \\
\hline 27.5 & 143.14 & 136.75 & 4.57 & 53.19 & 54.34 & -2.14 & 5.39 & 5.08 & 5.81 \\
\hline 27.1 & 140.74 & 140.46 & 0.20 & 52.02 & 55.68 & -6.80 & 5.23 & 4.99 & 4.67 \\
\hline \multicolumn{10}{|c|}{ LX-14 } \\
\hline 30.6 & & & & 63.15 & 0.36 & 197.71 & 6.82 & 6.08 & 11.53 \\
\hline 30.2 & & & & 61.77 & 0.39 & 197.48 & 6.62 & 6.18 & 6.86 \\
\hline 30.2 & & & & 61.77 & 0.39 & 197.48 & 6.62 & 6.14 & 7.51 \\
\hline 30.3 & & & & 62.11 & 0.37 & 197.64 & 6.67 & 5.83 & 13.40 \\
\hline 31.5 & & & & 66.38 & 0.37 & 197.79 & 7.31 & 6.79 & 7.32 \\
\hline 31.2 & & & & 65.29 & 0.36 & 197.81 & 7.14 & 6.20 & 14.20 \\
\hline 31.9 & & & & 67.87 & 0.38 & 197.77 & 7.53 & 6.79 & 10.37 \\
\hline
\end{tabular}

Note: Deviations in predicted solubility and actual concentration (i.e., APD $>100 \%$ ) indicate that insufficient explosive compound in the beaker was present to reach solubility. 


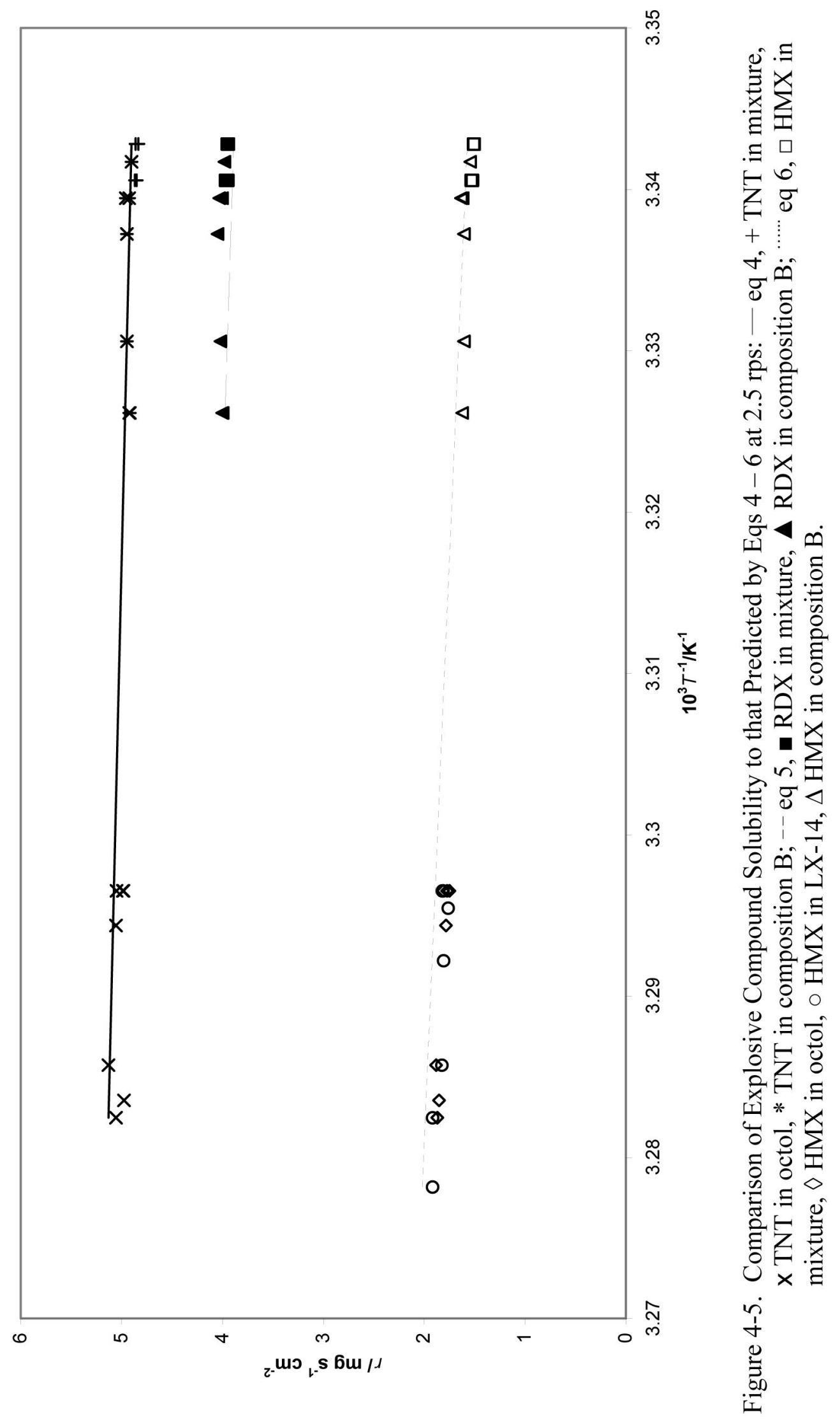




$$
\begin{array}{ll}
\text { RDX: } & \ln \left(S / m g \cdot L^{-1}\right)=19.683-\frac{4715.4 K}{T} \\
\text { HMX: } & \ln \left(S / m g \cdot L^{-1}\right)=22.399-\frac{6236.7 K}{T}
\end{array}
$$

The results of this study will aid in the modeling of fate and transport of these explosive compounds and have been included in an analysis of three models designed to predict persistence and flux (Lynch et al., 2002b). HPLC measurements identified more compounds than expected in the formulations and military grade explosives. The military grade RDX used in this study contained sufficient HMX to allow the HMX, itself, to reach its solubility in solution. TNT contained detectable quantities of its photodegradation byproduct, trinitrobenzene. LX-14 samples contained detectable quantities of RDX. Composition B contained sufficient quantities of HMX to allow the latter to reach saturation in solution and also contained detectable amounts of trinitrobenzene, dinitrobenzene, and 2,4 dinitrotoluene. Octol contained detectable quantities of RDX and trinitrobenzene. These findings are important considerations in studies of source characterization at field sites containing these explosive compounds and formulations.

\section{Conclusions}

Solubilities and dissolution rates of TNT, RDX, and HMX were not significantly affected by the presence of more than one of these separate explosive compounds in the same solution. TNT, RDX, and HMX solubilities were not significantly affected when these explosive compounds were components in explosive formulations. The formulation production process affects dissolution rates of the explosive compounds in 
the formulations. Dissolution rates are suppressed in LX-14 and octol and are mostly unaffected in Composition B. 


\section{CHAPTER 5 \\ MODELING EXPLOSIVE COMPOUND PERSISTENCE AND FLUX USING DISSOLUTION KINETICS}

\section{Introduction}

The need to predict the persistence and concentrations of explosive compounds such as 2,4,6-trinitrotoluene (TNT), hexahydro-1,3,5-trinitro-1,3,5-triazine (RDX), and octahydro-1,3,5,7-tetranitro-1,3,5,7-tetrazocine (HMX) in the environment is predicated on their health effects and the efforts of the Departments of Defense, Energy, and other federal agencies to remediate and manage sites where they were employed or deposited. These sites include explosive compound production and assembly facilities, storage locations, and training areas. Explosive compounds can be released into the environment both in their pure form and as components of explosive formulations. Sources of explosive compounds include residues from incomplete detonations of military munitions and/or unexploded ordnance (UXO) on training ranges (MacDonald, 2001) and leakage from production and storage locations (Simini et al., 1995). The potential risk associated with the leaching of explosive compounds such TNT and RDX into groundwater for example is partially responsible for the cessation of live fire training activities at the Massachusetts Military Reservation near Martha’s Vineyard, Massachusetts (Williams, 2000).

Explosive compound modeling in the environment is still in its developmental stages. An early human health-based explosive compound risk assessment proposed 
initial guidance for source soil concentration limits at sites contaminated with TNT, RDX, and HMX (Daniels and Knezovich, 1994). This preliminary assessment was based on a paucity of data available at the time, and was specific to the central-northeastern United States. A more recent study made estimations for screening values for eight nitroaromatic explosive compounds with consideration for both human and ecological health (Talmage et al., 1999). A theoretical study of in situ phytoremediation of TNT contaminated sediments (Voudrais and Assaf, 1996) predicted fate and transport of TNT once dissolved into water from a solid source. The study used a theoretical dissolution rate and concluded that TNT particle size, TNT soil content, and Darcy velocity affected equilibrium concentrations of TNT exiting a zone of contamination.

Dissolution into water is a primary mechanism by which solid explosive compound contamination spreads through and from a region where these compounds are found. Once dissolved, the explosive compounds are available for transfer (i.e., adsorption, plant uptake) or transformation (i.e., biodegradation, photolysis) (LaGrega et al., 1994). Use of new information concerning the fate (Pennington and Brannon, 2002; Bhadra et al., 2001), transport (Selim et al., 1995), and remediation methodologies (Hawari et al., 2000, Hawthorne et al., 2000, and Boopathy and Manning, 2000) could refine existing models as well as serve as the basis for new ones. Not only would integration of explosive compound aqueous dissolution rates improve risk assessments, they have the potential of aiding the prediction of solid persistence and initial concentrations of explosive compounds in solution.

The objective of this chapter is to use published explosive compound dissolution rate descriptors in the evaluation of three different dissolution models. The resulting 
predictions of HMX and TNT persistence and flux loading will be compared among the models using these explosive compounds in their pure form and as components in the explosive formulation octol.

\section{Theoretical Basis}

Source term descriptions such as dissolution rate have lagged behind the delineation of fate and transport parameters. Properly characterizing the source is important in that it establishes the initial conditions to be used in modeling. One way to describe dissolution rate is using a first order approximation of the dissolution process (Cussler, 1997):

$$
\frac{\mathrm{dm}}{\mathrm{dt}}=-\frac{\mathrm{D}}{\mathrm{h}} \mathrm{a}(\mathrm{C} *-\mathrm{C})
$$

where $d m / d t$ is the change in solid mass over time, $D$ is the aqueous phase diffusion coefficient, $\mathrm{h}$ is the boundary layer film thickness, $a$ is the area available for mass transfer between the solid and liquid, $C^{*}$ is the solubility limit, and $C$ is the concentration in the bulk solution. From Eq. (5-1) it is apparent that dissolution rate depends on proper characterization of solubility and the ratio $D / h$.

Several different correlations exist to describe the aqueous solubility of individual explosive compounds (Taylor and Rinkenbach, 1923; Ro et al., 1996; Spanggord et al., 1983; Lynch et al., 2001) as a function of temperature. Recently, we demonstrated that our correlation equations for solubility are also applicable for these explosive compounds mixed individually in a single solution, and also, when they are present as components in the explosive formulations octol ( $70 \%$ by mass HMX and $30 \%$ by mass TNT), composition B (59.5\% by mass RDX, $39.5 \%$ by mass TNT, and $1 \%$ by mass wax), or 
LX-14 (95.5\% by mass HMX and 4.5\% by mass polyurethane) (Lynch et al., 2002b). Solubility correlation equations from Lynch et al. (2002b) for TNT and HMX are repeated here:

$$
\begin{array}{ll}
\text { TNT: } & \ln (\mathrm{S})=16.793-\frac{3556.3 \mathrm{~K}}{\mathrm{~T}} \\
\text { HMX: } & \ln (\mathrm{S})=22.399-\frac{6236.7 \mathrm{~K}}{\mathrm{~T}}
\end{array}
$$

where $S$ is solubility in units of $\mathrm{mg} \mathrm{L}^{-1}$ and $T$ is in Kelvin.

Explosive compound dissolution rates have not been as widely studied as their solubilities (Jenkins, 2000; Gilgrease et al., 1996; Thiboutot et al., 1998). We have determined dissolution rate correlations for TNT and HMX, individually and in mixtures of these compounds as a function of temperature, explosive surface area, and mixing rate (Lynch et al., 2002a; Lynch et al., 2002b). Dissolution rate correlations for TNT and HMX, determined independently at a mixing rate of $150 \mathrm{rpm}$, are given in Eqs. (5-4) and (5-5) below (Lynch et al., 2002b). The use of $150 \mathrm{rpm}$ mixing rate relates to a value of 310 in the rainfall erosivity index, R, in the Revised Universal Soil Loss Equation (Lynch et al., 2002a) representative of an area such as the southeastern United States receiving high rainfall and hence much dissolution opportunity:

$$
\begin{aligned}
& \text { TNT: } \frac{1}{\mathrm{a}}\left(\frac{\mathrm{dm}}{\mathrm{dt}}\right)=7 \times 10^{-5} \mathrm{e}^{(0.0755 \theta)} \\
& \text { HMX: } \frac{1}{\mathrm{a}}\left(\frac{\mathrm{dm}}{\mathrm{dt}}\right)=5 \times 10^{-5} \mathrm{e}^{(0.0635 \theta)}
\end{aligned}
$$

where $a$ is the solid surface area in $\mathrm{cm}^{2}, d m / d t$ is the mass $(\mathrm{mg})$ dissolved per time (second), and $\theta$ is the temperature in ${ }^{\circ}$ Celsius. 
Explosive compounds as components of explosive formulations do not demonstrate the same dissolution rates as these compounds do individually (Lynch et al., 2002b). Dissolution rate correlations for the explosive compound components of octol, composition B, and LX-14 as a function of temperature and surface area determined at a mixing rate of $150 \mathrm{rpm}$ have been proposed and the initial dissolution rate correlations for TNT and HMX in octol are repeated below (Lynch et al., 2002b):

$$
\begin{aligned}
& \text { TNT: } \frac{1}{\mathrm{a}}\left(\frac{\mathrm{dm}}{\mathrm{dt}}\right)=3 \times 10^{-5} \mathrm{e}^{(0.0769 \theta)} \\
& \text { HMX: } \frac{1}{\mathrm{a}}\left(\frac{\mathrm{dm}}{\mathrm{dt}}\right)=1 \times 10^{-6} \mathrm{e}^{(0.0728 \theta)}
\end{aligned}
$$

where $a$, unlike in Eqs. (5-4) and (5-5), represents the surface area of octol.

Equations (5-4) throughout (5-7) provide solutions for $d m / d t$ in units of $\mathrm{mg} \mathrm{s}^{-1}$ and, when related to Eq. (5-1), permit the determination of the ratio $D / h$ (but not these variables independently). Given estimated diffusion coefficients for TNT and HMX at $25^{\circ} \mathrm{C}\left(6.71 \times 10^{-6} \mathrm{~cm}^{2} \mathrm{~s}^{-1}\right.$ and $6.01 \times 10^{-6} \mathrm{~cm}^{2} \mathrm{~s}^{-1}$, respectively) (Townsend and Meyers, 1996), $D$ can be approximated at any other temperature using the Stokes-Einstein equation:

$$
\mathrm{D}=\frac{\mathrm{k}_{\mathrm{B}} \mathrm{T}}{6 \Pi \mu \mathrm{R}_{\mathrm{o}}}
$$

where $k_{B}$ is Boltzmann's constant, $R_{o}$ is the solute radius, and $\mu$ is the solvent viscosity. $R_{o}$ in Eq. (5-8) was determined first using the TNT and HMX diffusion coefficient approximations at $298 \mathrm{~K}$. Knowing $\mathrm{R}_{\mathrm{o}}$ then permitted the approximation of $D$ at any other temperature. Finally, by knowing the ratio $D / h$ and the approximation of $D, h$ could be identified for a particular set of dissolution rate conditions. 
An important factor in determining the persistence of a solid is its initial size and shape. By assuming the solid to be spherical, we can re-write $\mathrm{m}$ and a in Eq. (5-1) in terms of the sphere's radius, $r$ :

$$
\frac{4}{3} \Pi \rho \frac{\mathrm{d}\left(\mathrm{r}^{3}\right)}{\mathrm{dt}}=\frac{\mathrm{D}}{\mathrm{h}}\left(4 \Pi \mathrm{r}^{2}\right)\left(\mathrm{C}^{*}-\mathrm{C}\right)
$$

where $\rho$ is the density of the solid. If the concentration in the bulk solution, $C$, is assumed negligible, then expanding this equation with respect to $r$ yields:

$$
-\frac{\mathrm{dr}}{\mathrm{dt}}=\frac{\mathrm{D}}{\mathrm{h} \rho} \mathrm{C}^{*}
$$

\section{Model Descriptions}

Model 1 treats TNT and HMX as individual solid spheres. Equations (5-4) and (5-5) were used to determine each individual explosive compound's $D$ and $h$ values. Integrating Eq. (5-10) allows the determination of the solid radius for either explosive compound sphere at any given time, t:

$$
\mathrm{r}=\mathrm{r}^{\mathrm{o}}-\left(\frac{\mathrm{DC}}{\mathrm{h} \rho}\right) \mathrm{t}
$$

where $r^{o}$ is the initial radius prior to any dissolution. Knowing the change in radius permits both the determination of solid persistence and the interfacial surface area at any given time. The flux, $J$, of either explosive compound from the solid surface area into solution when the concentration in the bulk solution, $C$, is zero can be written as:

$$
\mathrm{J}=\frac{1}{\mathrm{a}} \frac{\mathrm{dm}}{\mathrm{dt}}=\frac{\mathrm{DC}^{*}}{\mathrm{~h}}
$$

Model 2 treats TNT and HMX as octol, a single sphere with two-components. Equations (5-6) and (5-7) were used to determine each explosive compound's $D$ and $h$ values. It is assumed that the mass fraction of each explosive compound in octol is 
proportional to the amount of interfacial surface area that each compound has on the sphere's surface. A multi-component sphere introduces a new variable into Eq. (5-11); $X_{i}$, the mass fraction of the $\mathrm{i}^{\text {th }}$ component. In octol, $d r / d t$ for the slower dissolving HMX is the same as Eq. (5-10) with the inclusion of the mass fraction of HMX in octol:

$$
-\frac{\mathrm{dr}}{\mathrm{dt}}=\frac{\mathrm{D}}{\mathrm{hX} \mathrm{X}_{\mathrm{i}} \rho_{\mathrm{b}}} \mathrm{C}^{*}
$$

where $\rho_{b}$ is the bulk density of octol.

Integrating Eq. (5-13) allows the determination of the solid radius for either explosive compound at any given time, $t$ :

$$
\begin{aligned}
& r_{\mathrm{HMX}}=r^{\mathrm{o}}{ }_{\mathrm{HMX}}-\left(\frac{\mathrm{D}_{\mathrm{HMX}} \mathrm{C}^{*}{ }_{\mathrm{HMX}}}{\mathrm{h}_{\mathrm{HMX}} \mathrm{X}_{\mathrm{HMX}} \rho_{\mathrm{b}}}\right) t \\
& r_{\mathrm{TNT}}=r^{\mathrm{o}}{ }_{\mathrm{TNT}}-\left(\frac{\mathrm{D}_{\mathrm{TNT}} \mathrm{C}^{*}{ }_{\mathrm{TNT}}}{\mathrm{h}_{\mathrm{TNT}} \mathrm{X}_{\mathrm{TNT}} \rho_{\mathrm{b}}}\right) t
\end{aligned}
$$

The flux, $J$, of either explosive compound from the solid surface area into solution when the concentration in the bulk solution, $C$, is zero can be written as:

$$
\begin{gathered}
\mathrm{J}_{\mathrm{HMX}}=\frac{\mathrm{D}_{\mathrm{HMX}} \mathrm{C}^{*}{ }_{\mathrm{HMX}}}{\mathrm{h}_{\mathrm{HMX}}} \\
\mathrm{J}_{\mathrm{TNT}}=\frac{\mathrm{D}_{\mathrm{TNT}} \mathrm{C}^{*}{ }_{\mathrm{TNT}}}{\mathrm{h}_{\mathrm{TNT}}}
\end{gathered}
$$

Model 3 also treats TNT and HMX as components in a single sphere of octol and uses Eqs. (5-6) and (5-7) to determine $D$ and $h$ for each explosive compound component. From these two equations, one can see that TNT dissolves at a rate approximately thirty times faster than that of $\mathrm{HMX}$ at $10^{\circ} \mathrm{C}$. As the explosive compounds in octol continue to dissolve, TNT regresses into the solid leaving a layer of HMX with thickness $r_{H M X}-r_{T N T}$ (the radius of HMX and TNT, respectively) at the outermost surface (Figure 5-1). For 


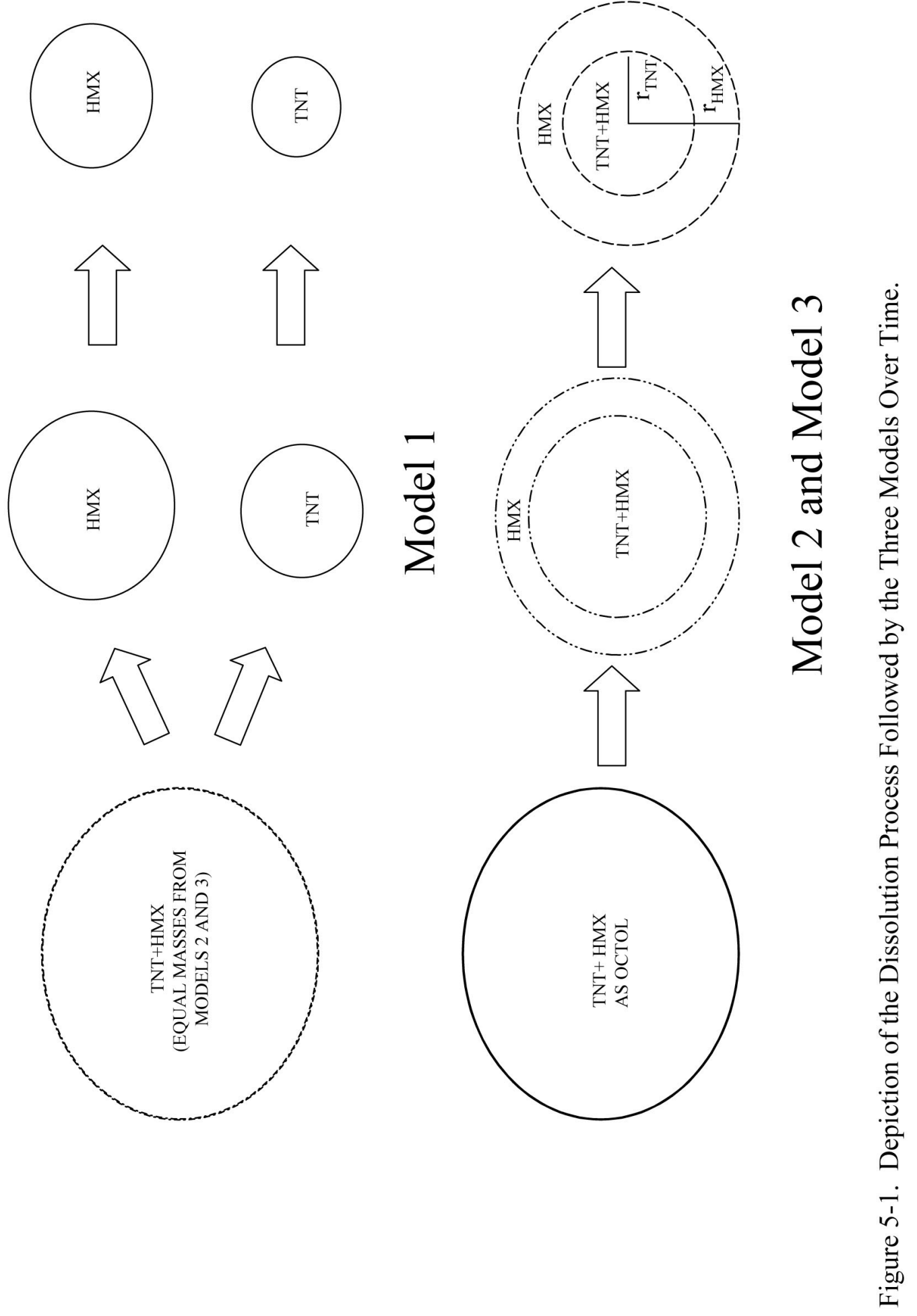


TNT (the component that has the faster dissolution rate), we need to add to $h_{T N T}$ the thickness of the HMX layer $\left(r_{H M X}-r_{T N T}\right)$ :

$$
-\frac{\mathrm{dr}_{\mathrm{TNT}}}{\mathrm{dt}}=\frac{\mathrm{D}_{\mathrm{TNT}}}{\left(\mathrm{h}_{\mathrm{TNT}}+\mathrm{r}_{\mathrm{HMX}}-\mathrm{r}_{\mathrm{TNT}}\right)} \frac{\mathrm{C}^{*}{ }_{\mathrm{TNT}}}{\mathrm{X}_{\mathrm{TNT}} \rho_{\text {octol }}}
$$

The solution for $r_{T N T}$ is dependent on first knowing the value for $r_{H M X}$. In this paper, Eqs. (5-13) and (5-16) were solved by integration with an initial condition (at $t=0, r_{H M X}=$ $r_{T N T}$ ), first solving for $r_{H M X}$ at a time $t$, and using this value in solving for $r_{T N T}$ at the same $t$ :

$$
\begin{gathered}
r_{\mathrm{HMX}}=\mathrm{r}^{\mathrm{o}}{ }_{\mathrm{HMX}}-\left(\frac{\mathrm{D}_{\mathrm{HMX}} \mathrm{C}_{\mathrm{HMX}}^{*}}{\mathrm{~h}_{\mathrm{HMX}} \mathrm{X}_{\mathrm{HMX}} \rho_{\text {octol }}}\right) \mathrm{t} \\
\mathrm{r}_{\mathrm{TNT}}=\mathrm{h}_{\mathrm{TNT}}+\mathrm{r}_{\mathrm{HMX}}-\sqrt{2\left(\frac{\mathrm{D}_{\mathrm{TNT}} \mathrm{C}_{\mathrm{TNT}}^{*}}{\mathrm{X}_{\mathrm{TNT}} \rho_{\text {octol }}}\right) \mathrm{t}+\left(\mathrm{h}_{\mathrm{TNT}}+\mathrm{r}_{\mathrm{HMX}}-\mathrm{r}^{\mathrm{o}} \mathrm{TNT}\right)^{2}}
\end{gathered}
$$

The flux, $J$, of each explosive compound into solution can be written with respect to the outer surface of octol; this being the surface area identified by $r_{H M X}$ :

$$
\begin{aligned}
& \mathrm{J}_{\mathrm{HMX}}=-\frac{\mathrm{D}_{\mathrm{HMX}} \mathrm{C}^{*}{ }_{\mathrm{HMX}}}{\mathrm{h}_{\mathrm{HMX}}} \\
& \mathrm{J}_{\mathrm{TNT}}=-\frac{\mathrm{D}_{\mathrm{TNT}} \mathrm{C}^{*} \mathrm{TNT}}{\left(\mathrm{h}_{\mathrm{TNT}}+\mathrm{r}_{\mathrm{HMX}}-\mathrm{r}_{\mathrm{TNT}}\right)}\left(\frac{\mathrm{r}_{\mathrm{TNT}}}{\mathrm{r}_{\mathrm{HMX}}}\right)^{2}
\end{aligned}
$$

Model 3 is based on a study reported by Carmichael et al. (1981) in the pharmaceutical literature. That study offered a general model for determining dissolution rates of multi drug component, non-disintegrating spheres whose components had different solubilities, diffusion coefficients, and boundary layer thickness. Several assumptions accompany the use of the theoretical dissolution modeling of a twocomponent solid:

- A homogenous mixture of components 
- Dissolution rate is diffusion controlled

- The concentration of the dissolved components in the bulk solution is negligible

- The solid shape is approximated by a sphere

- The mass fraction of the $\mathrm{i}^{\text {th }}$ component $\left(X_{i}\right)$ is not a function of time

- Porosity and tortuosity are assumed to be the same between the layers of differing composition.

\section{Example Description}

All three of these models represent the solid explosive compounds as spheres and each model will use the same masses of TNT and HMX. Models 2 and 3 assume these masses exist in a single sphere of octol having a surface area of $1 \mathrm{~cm}^{2}$. Based on an octol bulk density of $1.6 \mathrm{~g} \mathrm{~cm}^{-3}$ (Gibbs and Popolato, 1980), this equates to a sphere with a $0.5643 \mathrm{~cm}$ diameter consisting of $105.4 \mathrm{mg}$ HMX and $45.2 \mathrm{mg}$ TNT. For Model 1, these individual masses of TNT and HMX were formed into separate spheres. As such, the TNT sphere was $0.3736 \mathrm{~cm}$ in diameter with a surface area of $0.44 \mathrm{~cm}^{2}$ while that of the HMX sphere was $0.4731 \mathrm{~cm}$ in diameter with a surface area of $0.70 \mathrm{~cm}^{2}$ (TNT and HMX densities considered). A solid will be considered completely dissolved once its radius is reduced to $0.45 \mu \mathrm{m}$. The three modeling examples are outlined in Table 5-1 and depicted in Figure. 5-1.

\section{Results}

The modeling parameters for TNT and HMX as individual explosive compounds and as components of octol, determined at $10^{\circ} \mathrm{C}$ and a mixing rate of $150 \mathrm{rpm}$, are presented in Table 5-2. The initial flux loading rates, $J$, for the three models are also presented in Table 5-2. Note that for Models 1 and 2 these fluxes do not change over 
Table 5-1. Evaluation Models for the Dissolution of TNT and HMX from Correlation Equations Using a Mixing Speed of $150 \mathrm{rpm}$ and a Temperature of $10^{\circ} \mathrm{C}$

\begin{tabular}{cccc}
\hline Variable & Model 1 & Model 2 & Model 3 \\
\hline $\begin{array}{c}\text { TNT and HMX } \\
\text { depicted as: }\end{array}$ & $\begin{array}{c}\text { Individual HMX and TNT } \\
\text { spheres with same mass as } 1 \mathrm{~cm}^{2} \\
\text { of octol }\end{array}$ & $\begin{array}{c}\text { Sphere of octol with } \\
\text { surface area equal to } \\
1 \mathrm{~cm}^{2}\end{array}$ & $\begin{array}{c}\text { Same as } \\
\text { Model } 2\end{array}$ \\
HMX radius: & Eq. (11) & Eq. (14a) & Eq. (17a) \\
TNT radius: & Eq. (11) & Eq. (14b) & Eq. (17b) \\
HMX flux: & Eq. (12) & Eq. (15a) & Eq. (18a) \\
TNT flux: & Eq. (12) & Eq. (15b) & Eq. (18b) \\
\hline
\end{tabular}


Table 5-2. Explosive Compound Properties Using a Mixing Speed of $150 \mathrm{rpm}$ and $10^{\circ} \mathrm{C}$ for Model Comparison

\begin{tabular}{ccccc}
\hline & \multicolumn{2}{c}{ In Octol } & \multicolumn{2}{c}{ Individually } \\
\cline { 2 - 5 } Property & $\mathrm{TNT}$ & $\mathrm{HMX}$ & $\mathrm{TNT}$ & $\mathrm{HMX}$ \\
\hline $\mathrm{C}^{*}\left(\mathrm{~g} \mathrm{~mL}^{-1}\right)$ & $6.37 \times 10^{-5}$ & $1.46 \times 10^{-6}$ & $6.37 \times 10^{-5}$ & $1.46 \times 10^{-6}$ \\
$\mathrm{D}\left(\mathrm{cm}^{2} \mathrm{~s}^{-1}\right)$ & $4.34 \times 10^{-6}$ & $3.89 \times 10^{-6}$ & $4.34 \times 10^{-6}$ & $3.89 \times 10^{-6}$ \\
$\mathrm{~h}(\mathrm{~cm})$ & $4.27 \times 10^{-3}$ & $2.74 \times 10^{-3}$ & $1.81 \times 10^{-3}$ & $5.37 \times 10^{-5}$ \\
$\mathrm{~J}\left(\mathrm{~g} \mathrm{~s}^{-1} \mathrm{~cm}^{-2}\right)$ & $6.47 \times 10^{-8}$ & $2.07 \times 10^{-9}$ & $1.53 \times 10^{-7}$ & $1.06 \times 10^{-7}$ \\
\hline
\end{tabular}


time. For Model 3, $J_{H M X}$ does not change but $J_{T N T}$ (Eq. (5-18b)) continually slows as dissolution progresses and the distance between the TNT surface and the bulk solution increases. A comparison of the persistence of TNT at the source using the three models is shown in Figure 5-2. A comparison of the persistence of HMX at the source using the three models is shown in Figure 5-3. Note that the persistence of HMX is the same for Models 2 and 3 (Figure 5-3).

At $10^{\circ} \mathrm{C}$, HMX takes 36 times longer to dissolve completely following Models 2 and 3 as compared to Model 1 . At $10^{\circ} \mathrm{C}$, TNT takes 18.4 times longer to dissolve completely under Model 3 as compared to Model 1. The persistence of TNT under Model 2 is almost equal to, but slightly longer than, TNT following Model 1. Model predictions of the mass loading of TNT into solution based on TNT surface area and TNT flux at four different time periods are presented in Table 5-3.

\section{Discussion}

As demonstrated by the above comparisons, decisions on ways to model the dissolution of the explosive components of an explosive formulation greatly affect the predicted persistence of these compounds. A decision to consider explosive compounds separately or as components of an explosive formulation such as octol changes their predicted persistence and flux. A decision to use the variable TNT flux equation (Eq. (5-18b)) not only affects persistence, but also the concentration of TNT in water passing through the zone of contamination at any given time. The apparent dissolution of HMX takes from months to years depending on the modeling method selected.

As determined in an earlier study, the dissolution rate of each explosive compound approximately doubles for every $10^{\circ} \mathrm{C}$ decrease in temperature (Lynch et al., 


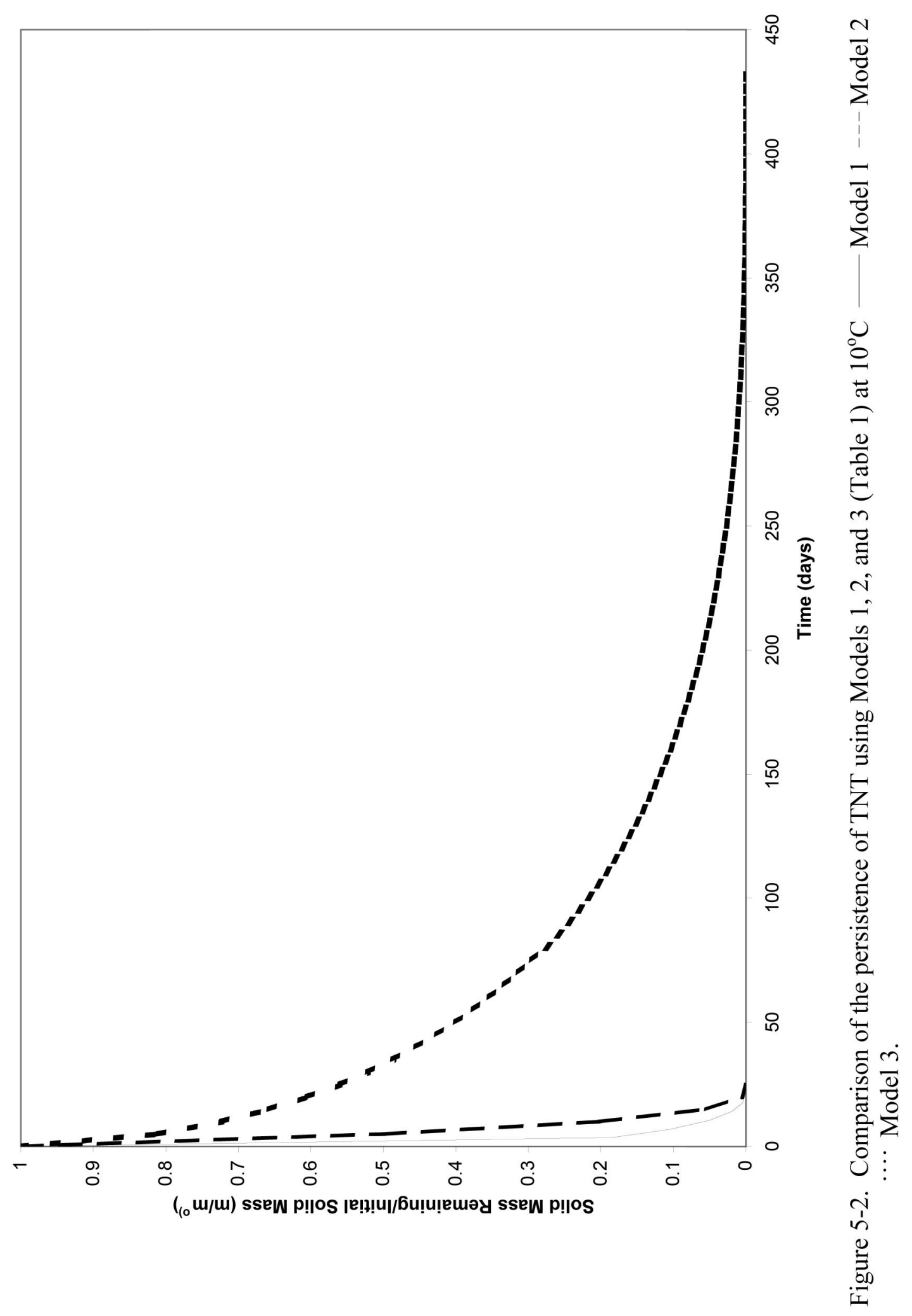




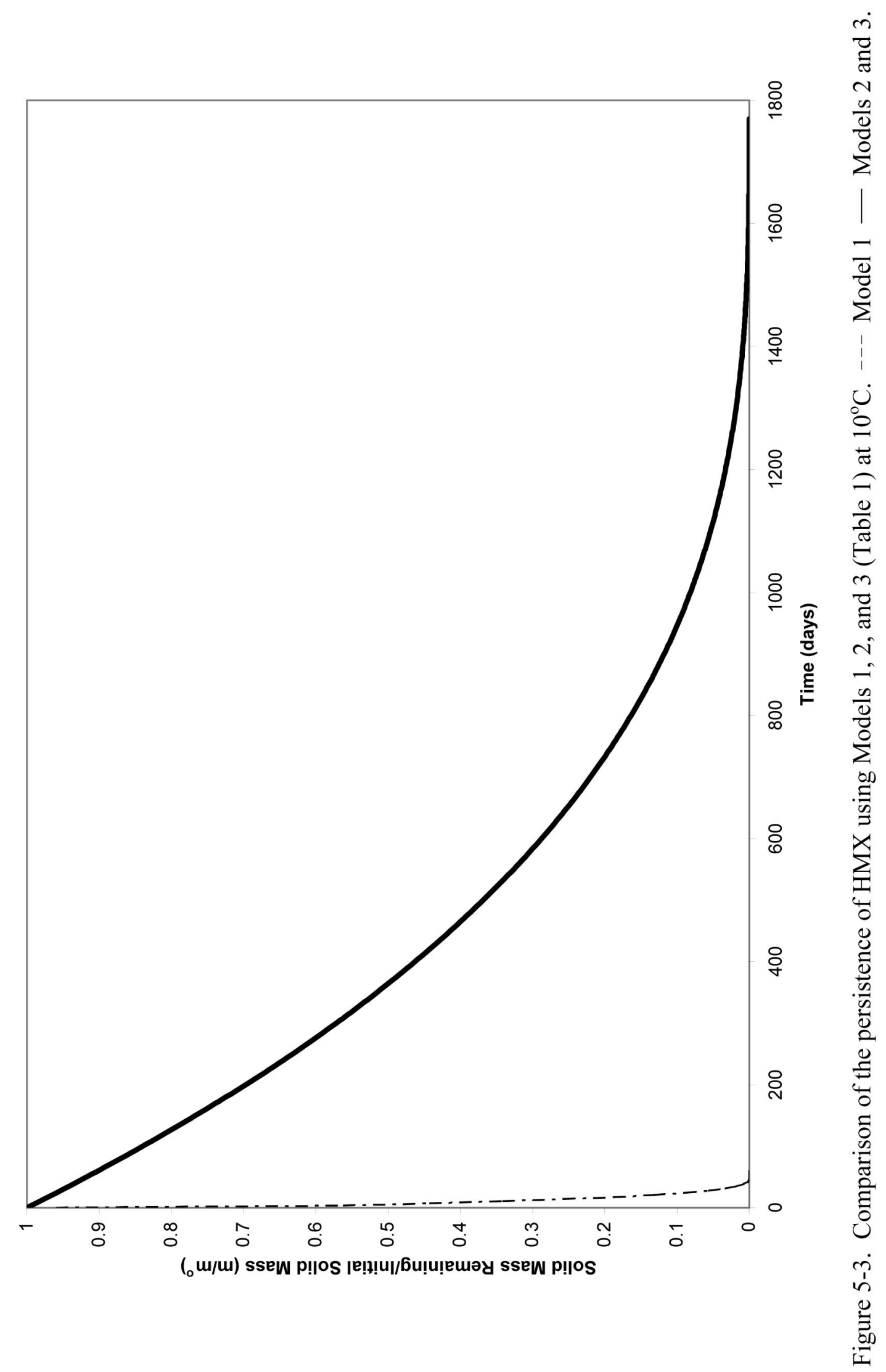


Table 5-3. Comparison of Model-Predicted TNT Loading ( $\left.\mathrm{mg} \mathrm{s}^{-1}\right)$ into Water from the Solid Explosive at $10^{\circ} \mathrm{C}$ and Determined at Four Different Times

\begin{tabular}{clll}
\hline Day & Model 1 & Model 2 & Model 3 \\
\hline 5 & $1.5 \times 10^{-4}$ & $1.5 \times 10^{-4}$ & $3.4 \times 10^{-5}$ \\
10 & $7.9 \times 10^{-5}$ & $8.0 \times 10^{-5}$ & $2.1 \times 10^{-5}$ \\
15 & $3.1 \times 10^{-5}$ & $3.4 \times 10^{-5}$ & $1.5 \times 10^{-5}$ \\
20 & $5.2 \times 10^{-6}$ & $7.1 \times 10^{-6}$ & $1.2 \times 10^{-5}$ \\
\hline
\end{tabular}


2002a). Persistence of these solid explosive contaminants will therefore also be affected by temperature related dissolution rates changes. Using Model 3 as an example, TNT persistence at $10^{\circ} \mathrm{C}$ is approximately 431 days while at $30^{\circ} \mathrm{C}$ it is expected to be approximately 100 days. Persistence of $\mathrm{HMX}$ at $10^{\circ} \mathrm{C}$ using Models 2 and 3 is approximately 1763 days; at $30^{\circ} \mathrm{C}$ it is expected to be approximately 412 days.

Unlike the pharmaceutical study using drug spheres, the mass fractions of compounds in an explosive formulation are not equal to the fraction of surface area that these compounds maintain on the formulation's surface. Production methodologies affect the distribution of formulation components on the sphere's surface area. In the production of octol, solid HMX crystals are mixed into liquid TNT and the mixture subsequently is allowed to harden. The TNT in octol is interconnected and continuous, and even though representing less mass, has a greater exposed surface area than does the encapsulated HMX. The explosive components in the formulation have different dissolution rates compared with their pure counterparts. Comparison of TNT/HMX flux ratios between individual explosives and as components of octol (Table 5-2) suggests that HMX dissolves slower in octol than it does independently. Solid explosive compounds in the variety of explosive formulations available will behave differently in the way they dissolve (Simpson and Parrott, 1983), their solid phase persistence, and the flux loading they contribute to the environment via dissolution.

In this study, the faster dissolving TNT is present in smaller quantities than the slower dissolving HMX. An important question concerns the octol sphere; does it remain intact as the TNT preferentially dissolves? Sarisuta and Jateleela (2000) describe a flaking phenomenon when a multi-component drug sphere whose components have 
largely different dissolution rates dissolves in water. If this process occurs in an explosive formulation, the critical point when flaking occurs, combined with dissolution rate changes, is an important area for future research. Using Model 3 as an example, TNT is completely dissolved within 434 days. Left behind is a "sphere" of HMX with a diameter of $0.42 \mathrm{~cm}$. Knowing that the HMX in octol is in the form of individual crystals, flaking by this point in time is likely and the HMX interfacial surface area would dramatically increase (summation of individual crystals vice the surface of the sphere), speeding HMX dissolution.

Characterizing explosive formulation dissolution rate and surface area based on the raw material specifications for each included explosive compound can lead to incorrect conclusions concerning their dissolution. Of importance for persistence and flux loading to the environment are surface area to mass ratios based on the size and distribution of solid explosives on a contaminated site (Jenkins et al., 2002; Radtke et al., 2002). Research suggests that crystalline HMX cracks during the explosive formulation production process because of mixing and applied pressure (Burnside et al., 1997). The process used to fill munitions with explosive compounds combined with the detonation side effects (i.e., pressure and heat) are likely to further change individual explosive compound characteristics. Advances in detection methods (Bart et al., 1997; Groom et al., 2001, and Goodpaster and McGuffin, 2001), combined with EPA Method 8330, may aid in characterization and distribution of these compounds from a field environment.

\section{Conclusions}

Accurate modeling of explosive compound dissolution in the field environment depends on mathematically replicating natural processes. Models are complicated by the 
need to select the correct dissolution process description and then select the correct value for each variable supporting the model. Research has identified variables and their plausible ranges of values in describing explosive compound dissolution rates. This study identifies the range in predicted solid persistence and flux loading from this solid into solution for TNT and HMX based on three dissolution models. Contaminant fate and transport at sites contaminated with multiple explosive compounds from more than one type of explosive formulation will be challenging to simulate with a model. Each specific explosive formulation is expected to dissolve differently depending on composition and manufacturing process. Actual solid persistence and flux loading in the environment likely will be somewhere between the results of Models 1 and 3 . 


\section{CHAPTER 6 \\ SUMMARY, CONCLUSIONS, AND RECOMMENDATIONS}

\section{Summary}

The need to better characterize the physical properties of explosive compounds came to the forefront when the EPA used the SDWA to stop munitions live fire training at the Massachusetts Military Reservation. This action subjected other installations with live firing training to the same possible action. If more live fire training areas were closed, the reduced ability to train as we will fight could negatively impact our overall military readiness. The actual health and environmental risks caused by live fire training and the resulting deposition of explosive compound residues and fractured unexploded ordnance needs to be clarified based on scientific analysis and conclusions rather than on assumptions and public opinion.

The primary method by which these nonvolatile compounds migrate away from the site where they were initially deposited is by dissolution into water. Dissolution is also the primary method that makes these compounds most available for transformation or sequestration. An understanding of dissolution kinetics of explosive compounds can enhance our ability to predict not only the persistence of solid explosive compounds but also the concentration available in water initially, and, when combined with fate and transport models, subsequent concentrations at locations remote from the initial source.

Because of the likely heterogeneity of munitions types used on firing ranges, it is important to determine the dissolution kinetics of individual explosive compounds and 
those of explosive formulations as well. The geographic locations of firing ranges have an impact on the ambient temperature as well as the quantity and $\mathrm{pH}$ of water where dissolution could occur. Using a methodology based on that used in the pharmaceutical industry, dissolution rates were measured in a batch reactor at various combinations of temperature $\left(10,20\right.$, and $\left.30^{\circ} \mathrm{C}\right) ; \mathrm{pH}(4.2,5.7$, and 6.2); and mixing rate (ranging from 35 to $210 \mathrm{rpm})$.

In this study, dissolution rates and solubility of three widely used explosive compounds, TNT, RDX, and HMX and three explosive formulations incorporating these compounds, octol, Composition B, and LX-14 were measured and mathematically described. Of the three explosive compounds studied, TNT demonstrated the fastest dissolution rate followed by HMX and then RDX. Composition B showed the smallest difference in component dissolution rates as compared to the individual explosive compounds followed by octol, which was slightly depressed and then LX-14, which showed the greatest suppression in dissolution rate.

The ratio $D / h$ (diffusion coefficient/boundary layer thickness) can be deduced when the dissolution rate correlation equations developed in this study are combined with a first order approximation of the dissolution process. Further, this ratio combined with approximations of the diffusion coefficients, $D$, can yield values for $h$, the boundary layer thickness. $D$ and $h$, are variables often used in process modeling. These experiments also supported estimations of the activation energies for dissolution. Last, a comparison between the study mixing rate and the "R" value from the Revised Uniform Soil Loss Equation was made in an attempt to relate study energy input to rainfall energy values used for erosion calculations. 
Knowing the rate at which explosive compounds dissolve under differing environmental conditions can give insight on both the persistence of explosive compounds at the location where they were deposited as well as the initial concentration in water as they begin transport and fate processes. Models that incorporate mathematical relationships describing the source as well as the fate and transport processes can better predict the risk that these explosive compounds pose to a population. Results from this study will aid not only in the conduct of risk assessments but in the evaluation of fate, transport, and remediation processes that are dependent on aqueous dissolution to make the explosive compounds available for interaction.

\section{Conclusions}

The following conclusions are drawn as they relate to the research performed to meet this study's objectives:

- Increases in temperature, interfacial surface area, and energy input via mixing increase the dissolution rates of the explosive compounds and explosive formulations studied.

- Single-variable and combined-variable correlation equations describing dissolution rate as a function of temperature, interfacial surface area, and mixing rate can be derived for TNT, RDX, and HMX.

- Exponential solubility correlation equations as a function of temperature can be derived for TNT, RDX, and HMX.

- Waters with a pH within the acid rain range of 4.2 to 6.2 have no effect on the dissolution rate or solubility of TNT, RDX, or HMX.

- Dissolution of more than one explosive compound (TNT, RDX, and/or HMX) at a time does not affect explosive compound dissolution rate or solubility.

- Separate dissolution rate correlation equations from those developed for individual explosive compounds are required to describe the dissolution of TNT, RDX, and/or HMX as components in the explosive formulations octol, Composition B, and LX-14. 
- Solubility correlation equations developed for TNT, RDX, and HMX are applicable to these same explosive compounds when they are components of octol, Composition $\mathrm{B}$, and LX-14.

- Selection of dissolution behavior of multi-component solids with different dissolution rates effects solid persistence and mass loading flux rates.

\section{Recommendations for Further Research}

The following recommendations are made to further the extent of knowledge

relating to explosive compound descriptions as a contaminant source:

- A surface area to mass ratio should be explored for munitions' explosives residue from incomplete detonation and for UXO.

- The mixing speed to R relationship should be verified by experimentation.

- The mass transfer coefficients of explosive formulations' components must be observed over time to determine if these coefficients vary and to determine if flaking of the slower dissolving compound occurs.

- The mixing speed to dissolution rate curve should be further expanded through experimentation to determine when an increase in mixing speed no longer causes an increase in dissolution rate for TNT and RDX.

- Risk assessment models should be improved by incorporating new information on explosive compounds, fate, and transport.

- Dissolution testing using the methodology described in this study should be performed during the development phase of new explosive compounds and explosive formulations. 
APPENDIX A

SUPPLEMENTAL INFORMATION: INDIVIDUAL EXPLOSIVE COMPOUNDS 
Table A-1. Average Percent Difference Comparisons Among Dissolution Rates, $r$ $\left(\mathrm{mg} \mathrm{min}^{-1}\right)$ from this Study, the Multiple Regression Multiple Variable Equation, the Single Regression Multiple Variable Equation, and the Levins and Glastonbury (1972a) Correlation for TNT

\begin{tabular}{|c|c|c|c|c|c|c|c|c|}
\hline $\begin{array}{l}\text { Run } \\
\text { ID }\end{array}$ & $\begin{array}{l}\text { Description } \\
\mathrm{cm}^{2} / \mathrm{rpm} /{ }^{\circ} \mathrm{C}\end{array}$ & $r$, This & $\begin{array}{l}r, \mathrm{Eq} \\
(6 \mathrm{c})\end{array}$ & $\begin{array}{l}\text { Avg \% } \\
\text { Diff }\end{array}$ & $\begin{array}{l}r, \mathrm{Eq} \\
(7 \mathrm{c})\end{array}$ & $\begin{array}{c}\text { Avg \% } \\
\text { Diff }\end{array}$ & $\begin{array}{c}k, \mathrm{Eq} \\
(8)\end{array}$ & $\begin{array}{c}\text { Avg \% } \\
\text { Diff }\end{array}$ \\
\hline $\mathrm{G}$ & $\begin{array}{l}6 / 150 / 10 \\
7 / 150 / 10\end{array}$ & 0.051 & 0.050 & 1.8 & 0.045 & 12.0 & 0.055 & -8.5 \\
\hline $\mathrm{H}$ & $9 / 150 / 10$ & 0.065 & 0.063 & 3.0 & 0.057 & 13.3 & 0.070 & -7.2 \\
\hline $\mathrm{L}$ & $7 / 90 / 10$ & 0.075 & 0.075 & 0.7 & 0.067 & 10.9 & 0.083 & -9.6 \\
\hline $\mathrm{J}$ & $7 / 210 / 10$ & 0.036 & 0.038 & -4.8 & 0.034 & 5.5 & 0.051 & -35.1 \\
\hline $\mathrm{K}$ & $0.3 / 150 / 20$ & 0.098 & 0.088 & 10.8 & 0.079 & 21.0 & 0.085 & 13.8 \\
\hline $\mathrm{T} 1$ & $0.4 / 150 / 20$ & 0.005 & 0.008 & -34.9 & 0.006 & -11.9 & 0.006 & -3.4 \\
\hline $\mathrm{T} 2$ & $0.6 / 150 / 20$ & 0.008 & 0.012 & -43.5 & 0.009 & -16.5 & 0.008 & -8.0 \\
\hline T3 & $6 / 150 / 30$ & 0.011 & 0.020 & -53.9 & 0.014 & -22.4 & 0.013 & -13.9 \\
\hline T8 & $7 / 150 / 30$ & 0.244 & 0.221 & 9.9 & 0.213 & 13.7 & 0.208 & 16.1 \\
\hline T6 & $9 / 150 / 30$ & 0.288 & 0.283 & 1.9 & 0.272 & 5.6 & 0.266 & 8.0 \\
\hline T9 & $7 / 90 / 30$ & 0.368 & 0.336 & 8.9 & 0.324 & 12.6 & 0.316 & 15.0 \\
\hline $\mathrm{T} 4$ & $7 / 210 / 30$ & 0.135 & 0.168 & -21.8 & 0.162 & -18.2 & 0.194 & -35.9 \\
\hline T5 & & 0.370 & 0.397 & -6.9 & 0.382 & -3.3 & 0.326 & 12.5 \\
\hline
\end{tabular}


Table A-2. Average Percent Difference Comparisons Among Dissolution Rates, $r$ $\left(\mathrm{mg} \min ^{-1}\right)$ from this Study, the Multiple Regression Multiple Variable Equation, the Single Regression Multiple Variable Equation, and the Levins and Glastonbury (1972a) Correlation for HMX

\begin{tabular}{|c|c|c|c|c|c|c|c|c|}
\hline $\begin{array}{l}\text { Run } \\
\text { ID }\end{array}$ & $\begin{array}{l}\text { Description } \\
\mathrm{cm}^{2} / \mathrm{rpm} /{ }^{\circ} \mathrm{C}\end{array}$ & $\begin{array}{l}r, \text { This } \\
\text { Study }\end{array}$ & $\begin{array}{l}r, \mathrm{Eq} \\
(6 \mathrm{c})\end{array}$ & $\begin{array}{l}\text { Avg \% } \\
\text { Diff }\end{array}$ & $\begin{array}{l}r, \mathrm{Eq} \\
(7 \mathrm{c})\end{array}$ & $\begin{array}{c}\text { Avg \% } \\
\text { Diff }\end{array}$ & $\begin{array}{c}k, \mathrm{Eq} \\
(8)\end{array}$ & $\begin{array}{c}\text { Avg } \% \\
\text { Diff }\end{array}$ \\
\hline & $5 / 150 / 10$ & & & & & & & \\
\hline AA & $6 / 150 / 10$ & 0.030 & 0.034 & -13.1 & 0.032 & -4.8 & 0.024 & 23.7 \\
\hline $\mathrm{BB}$ & $7 / 150 / 10$ & 0.038 & 0.043 & -12.6 & 0.039 & -4.3 & 0.030 & 24.2 \\
\hline $\mathrm{CC}$ & $6 / 90 / 10$ & 0.045 & 0.051 & -12.2 & 0.047 & -3.9 & 0.035 & 24.7 \\
\hline DD & $6 / 210 / 10$ & 0.034 & 0.026 & 28.1 & 0.023 & 36.2 & 0.025 & 28.9 \\
\hline $\mathrm{EE}$ & $5 / 150 / 20$ & 0.038 & 0.060 & -42.7 & 0.055 & -34.7 & 0.033 & 16.1 \\
\hline H1 & $6 / 150 / 20$ & 0.0649 & 0.070 & -6.4 & 0.064 & 0.9 & 0.064 & 1.8 \\
\hline $\mathrm{H} 2$ & $7 / 150 / 20$ & 0.079 & 0.086 & -8.4 & 0.079 & -1.1 & 0.079 & -0.1 \\
\hline H3 & $5 / 150 / 30$ & 0.093 & 0.102 & -9.1 & 0.094 & -1.8 & 0.094 & -0.8 \\
\hline H7 & $6 / 150 / 30$ & 0.093 & 0.104 & -11.2 & 0.097 & -4.2 & 0.122 & -27.3 \\
\hline H5 & $7 / 150 / 30$ & 0.119 & 0.129 & -7.6 & 0.120 & -0.6 & 0.152 & -23.8 \\
\hline $\mathrm{H} 8$ & $6 / 90 / 30$ & 0.143 & 0.154 & -7.3 & 0.143 & -0.4 & 0.181 & -23.6 \\
\hline $\mathrm{HV}$ & $6 / 210 / 30$ & 0.094 & 0.077 & 19.7 & 0.072 & 26.6 & 0.131 & -33.0 \\
\hline H6 & & 0.125 & 0.179 & -35.5 & 0.167 & -28.7 & 0.168 & -29.1 \\
\hline
\end{tabular}




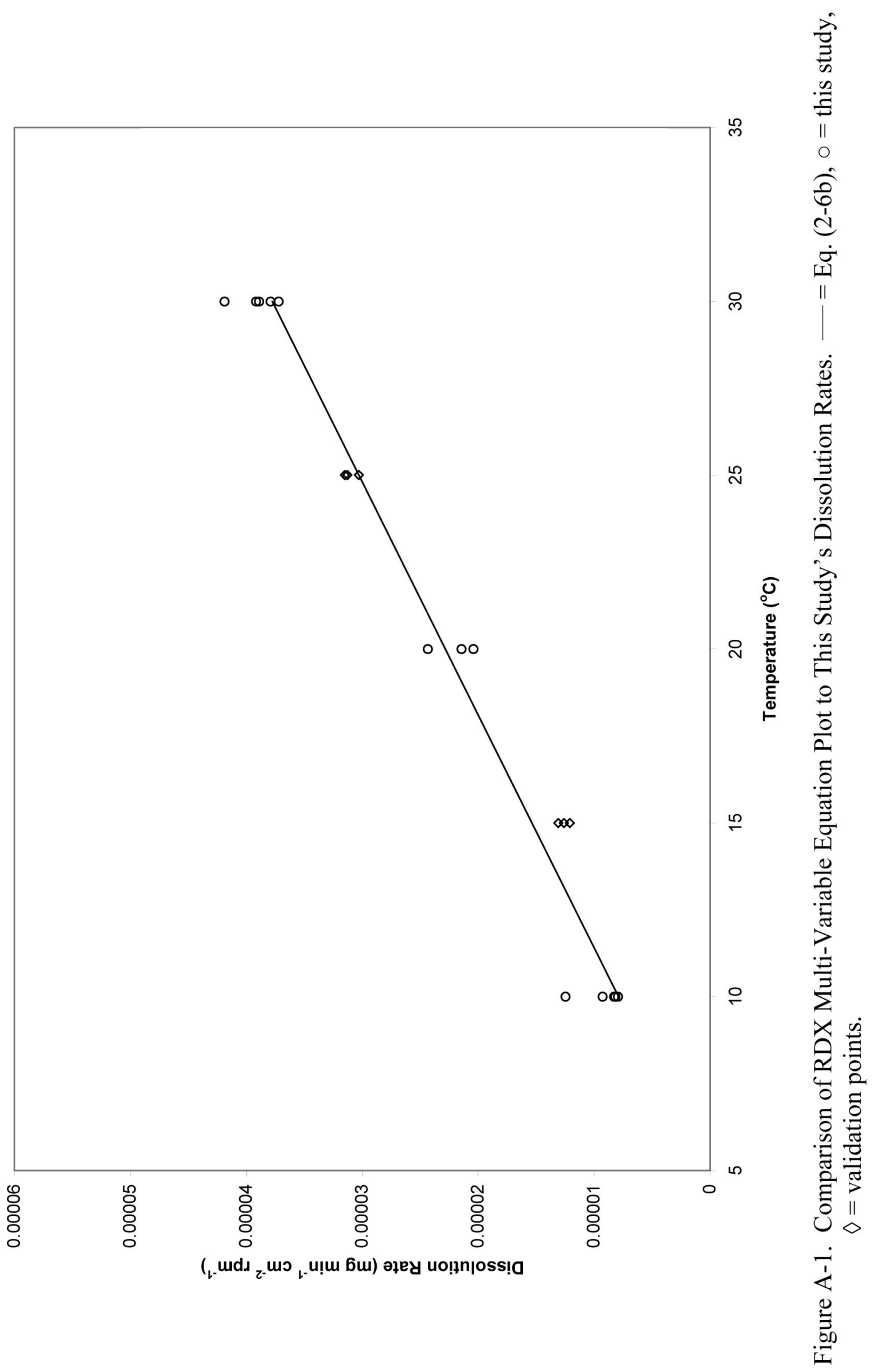



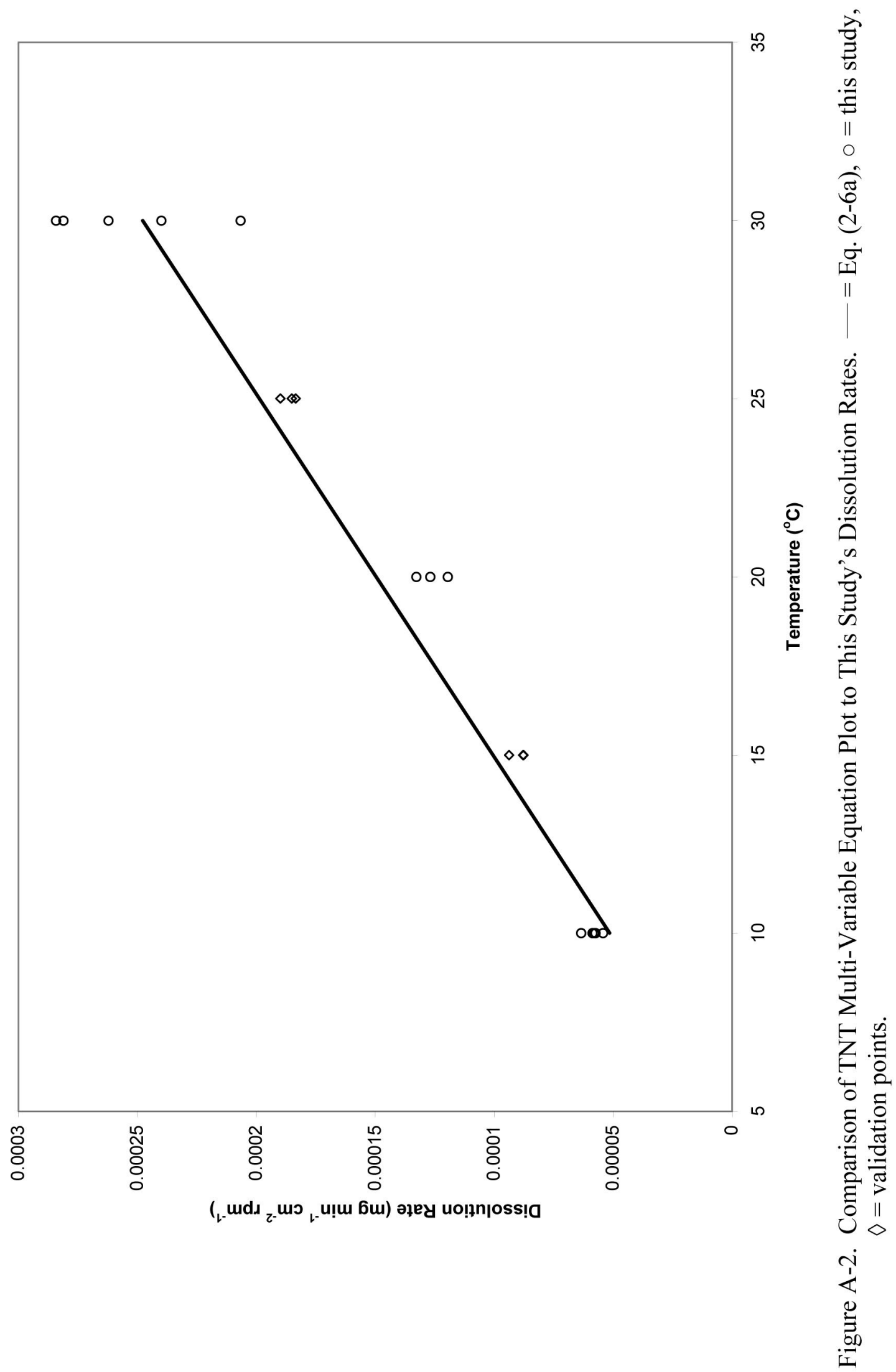
APPENDIX B

SUPPLEMENTAL INFORMATION: EXPLOSIVE COMPOUND COMPOSITES 


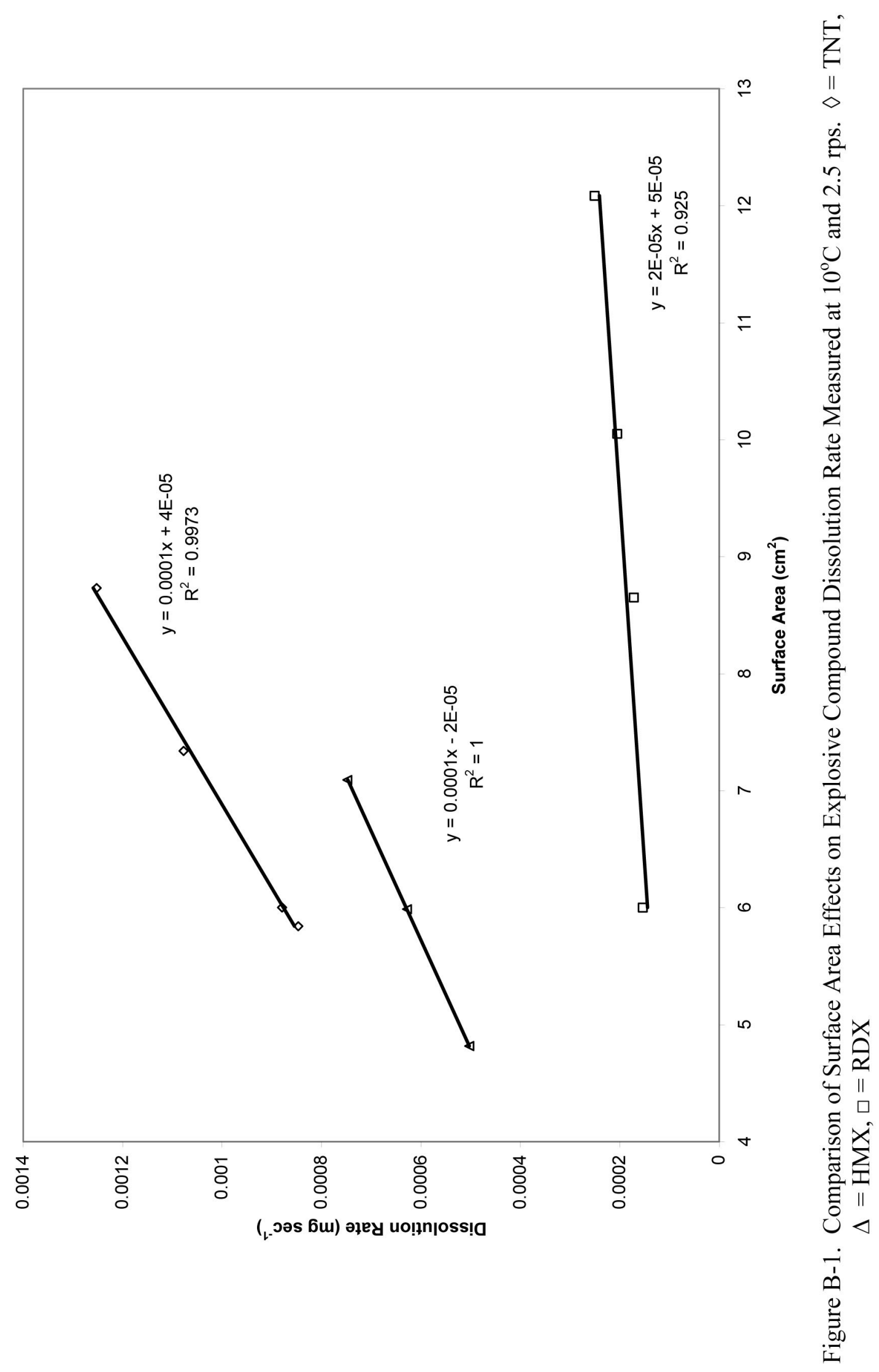




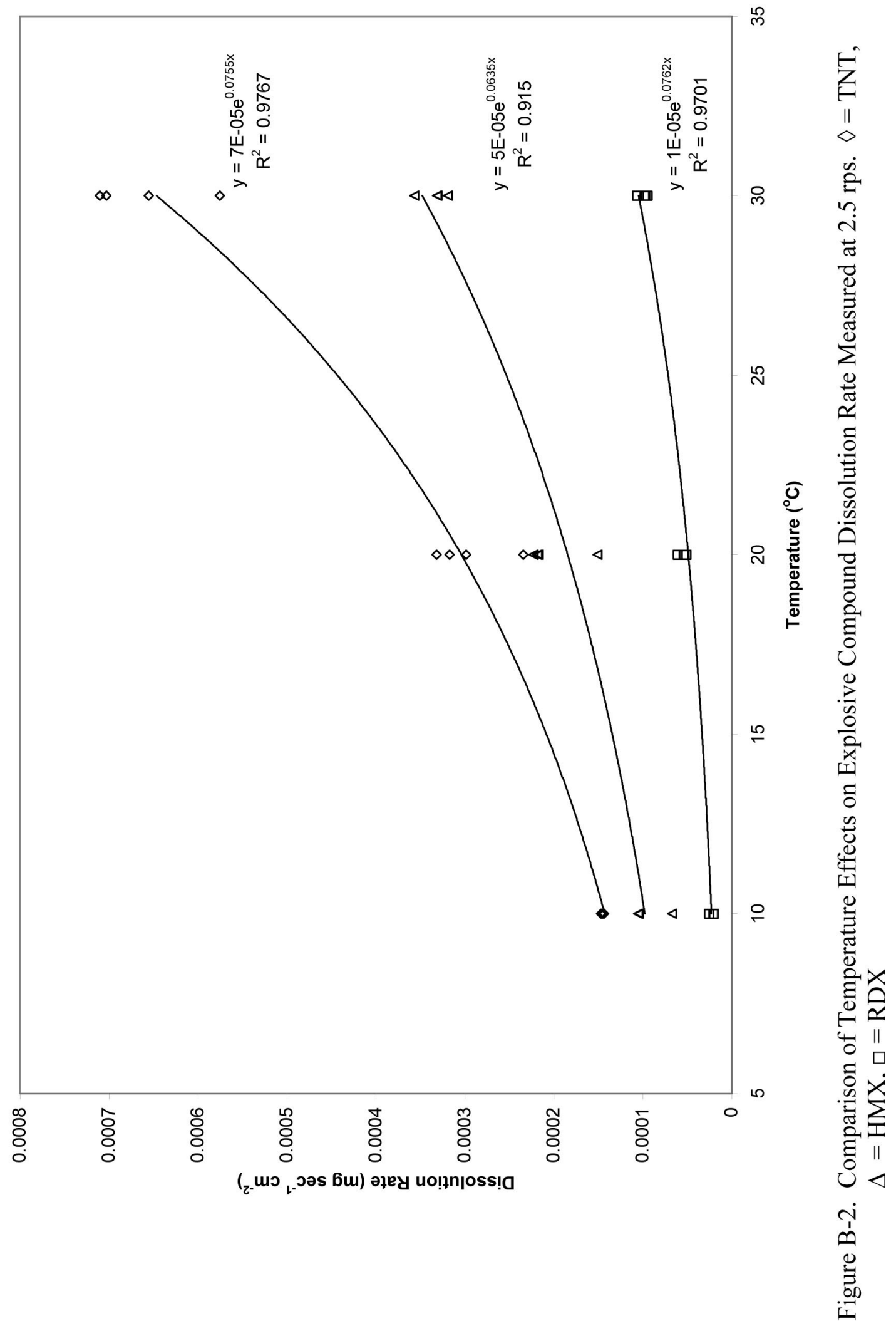




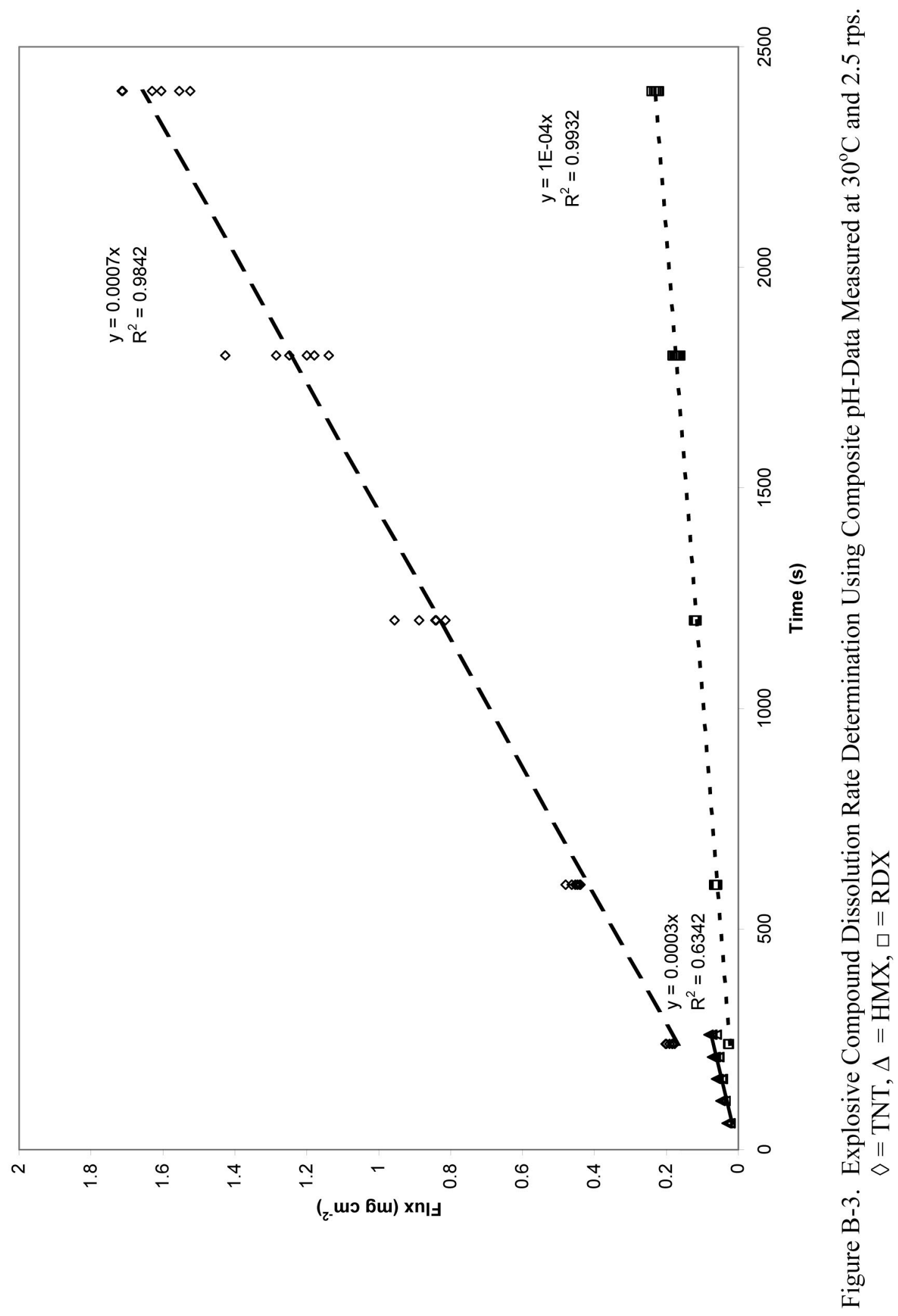




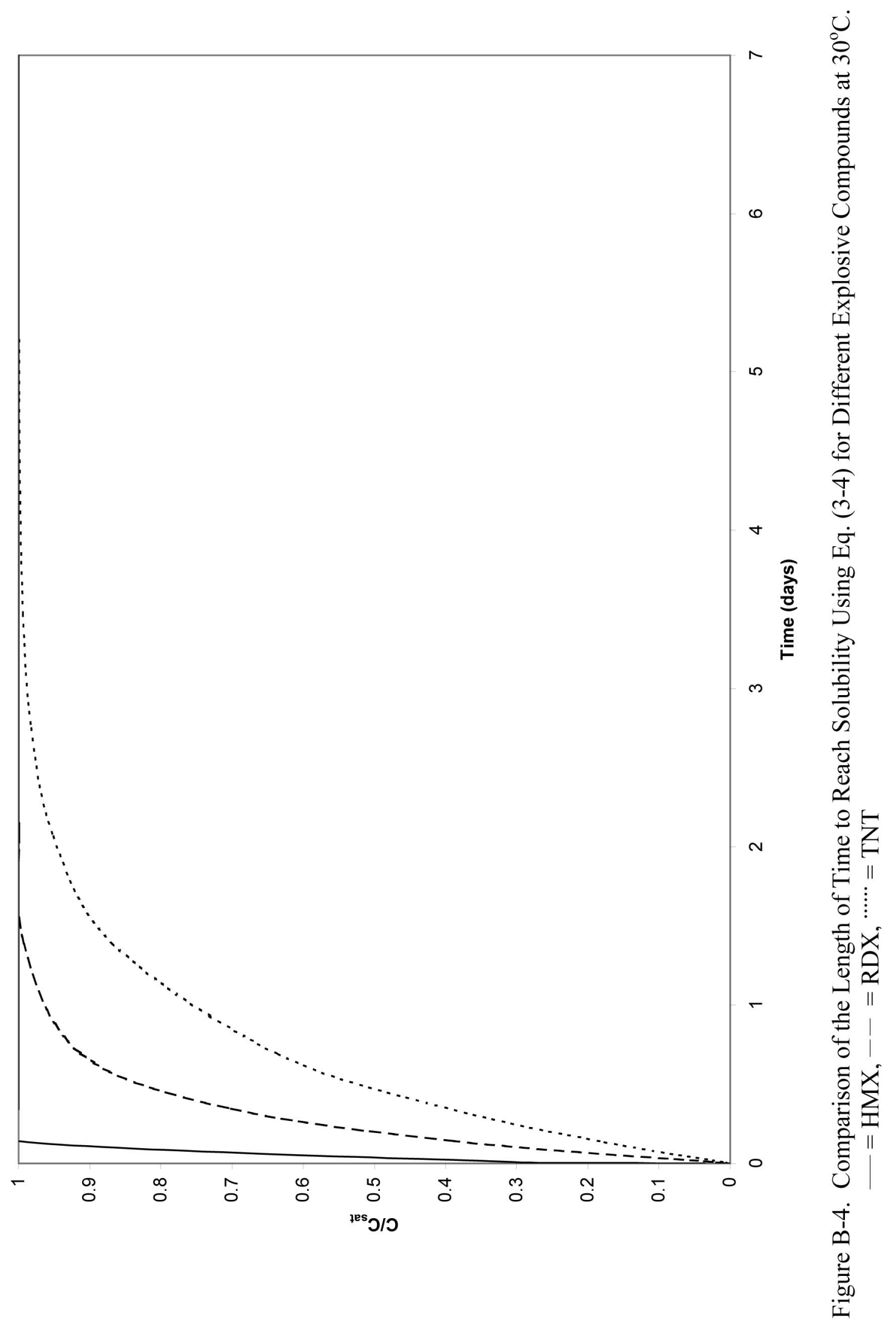




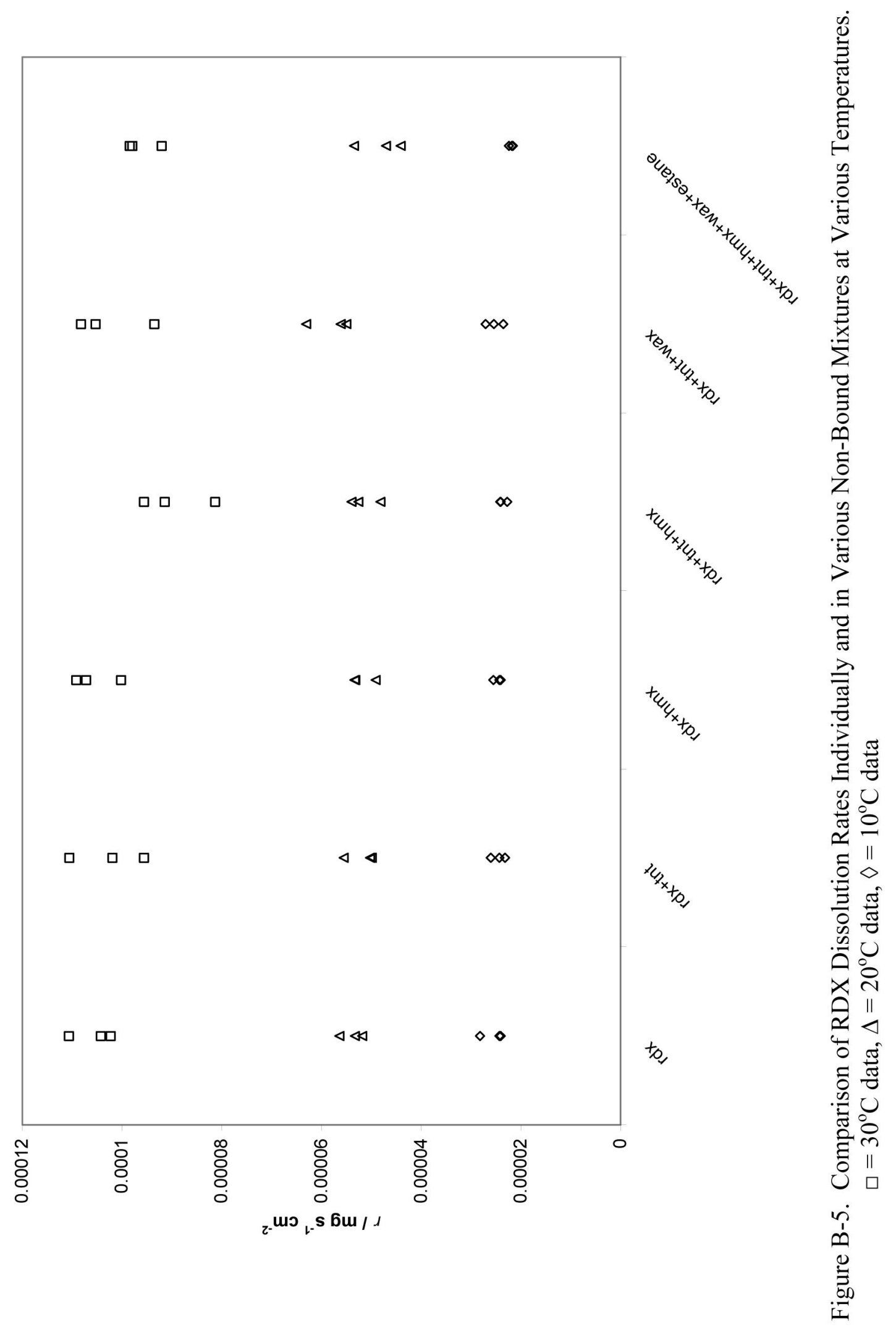




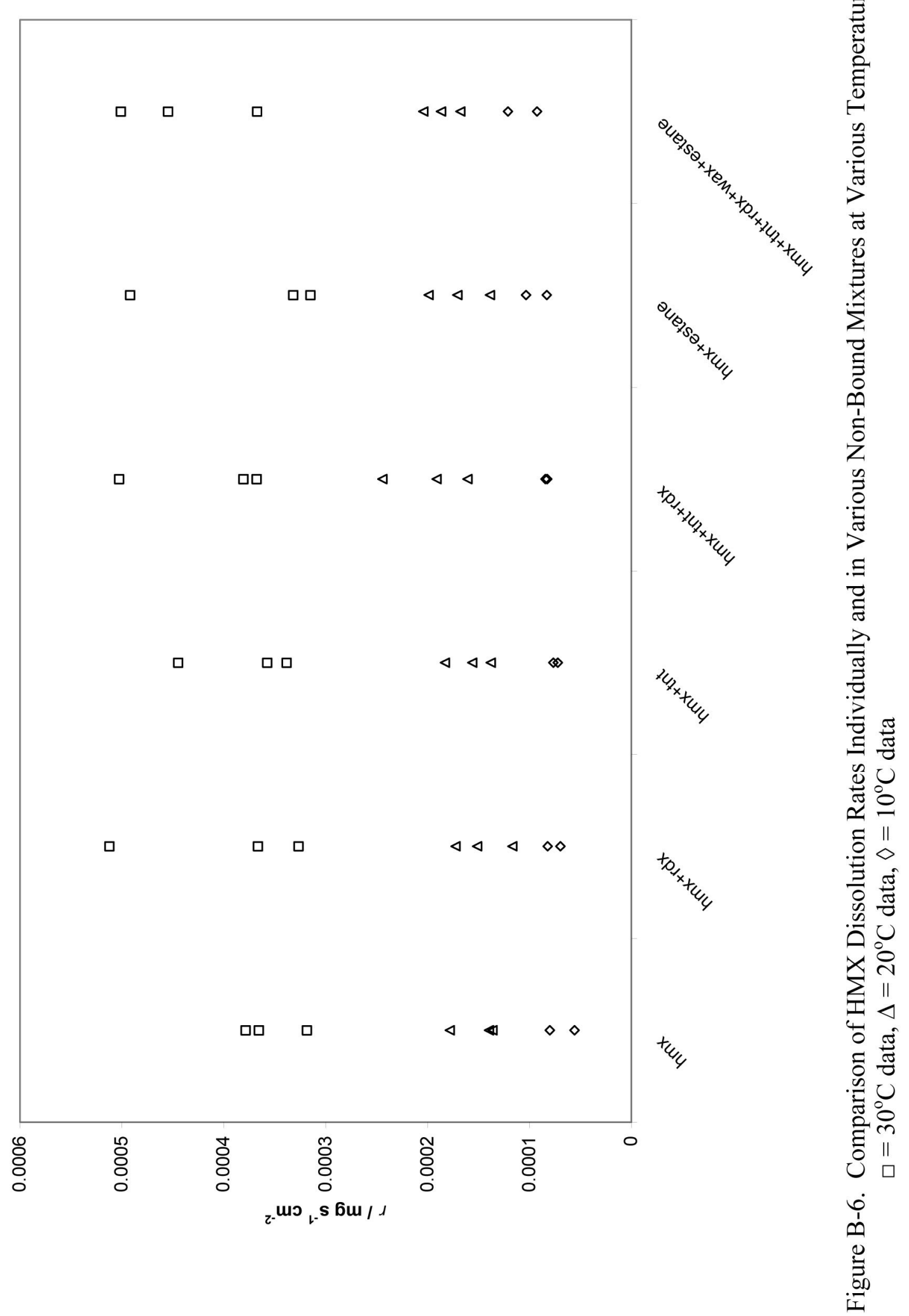


APPENDIX C

SUPPLEMENTAL INFORMATION: PRECISION AND ACCURACY DATA 
Table C-1. TNT Replicate Samples and Average Percent Differences for Precision Determination

\begin{tabular}{|c|c|c|c|c|c|c|c|}
\hline Run & 1st & Duplicate & APD $\%$ & $20 B$ & 7.063 & 6.599 & 6.793 \\
\hline T1 & 1.43 & 1.42 & 0.702 & $20 \mathrm{C}$ & 4.625 & 4.294 & 7.422 \\
\hline T1 & 5.711 & 5.553 & 2.805 & $22 \mathrm{~A}$ & 0.47 & 0.461 & 1.933 \\
\hline T1 & 11.008 & 10.464 & 5.067 & $22 B$ & 0.452 & 0.411 & 9.502 \\
\hline T2 & 3.149 & 3.051 & 3.161 & $22 \mathrm{C}$ & 0.873 & 0.802 & 8.478 \\
\hline T3 & 9.717 & 9.53 & 1.943 & $23 \mathrm{~A}$ & 0.673 & 0.651 & 3.323 \\
\hline $1 \mathrm{~A}$ & 2.456 & 2.405 & 2.098 & $23 B$ & 0.649 & 0.585 & 10.373 \\
\hline $1 B$ & 2.59 & 2.438 & 6.046 & $23 C$ & 0.882 & 0.851 & 3.578 \\
\hline $1 C$ & 2.723 & 2.534 & 7.190 & $24 \mathrm{~A}$ & 4.832 & 4.591 & 5.115 \\
\hline $4 A S$ & 13.377 & 13.093 & 2.146 & $24 B$ & 4.71 & 4.327 & 8.476 \\
\hline $4 B$ & 16.241 & 15.169 & 6.826 & $24 C$ & 2.66 & 2.481 & 6.964 \\
\hline $4 C$ & 13.398 & 12.32 & 8.383 & $26 \mathrm{~A}$ & 0.876 & 0.87 & 0.687 \\
\hline $7 \mathrm{~A}$ & 4.859 & 4.808 & 1.055 & $26 B$ & 0.627 & 0.61 & 2.749 \\
\hline $7 B$ & 11.83 & 10.632 & 10.667 & $26 C$ & 0.508 & 0.483 & 5.045 \\
\hline $7 C$ & 9.293 & 8.623 & 7.479 & $27 \mathrm{~A}$ & 3.009 & 2.685 & 11.380 \\
\hline $10 \mathrm{~A}$ & 5.61 & 5.147 & 8.608 & $27 B$ & 3.099 & 2.89 & 6.979 \\
\hline $10 \mathrm{~B}$ & 12.523 & 11.413 & 9.275 & $27 C$ & 2.504 & 2.447 & 2.303 \\
\hline $10 \mathrm{C}$ & 8.995 & 7.91 & 12.836 & $30 \mathrm{~A}$ & 2.756 & 2.579 & 6.635 \\
\hline $12 \mathrm{~A}$ & 0.974 & 0.938 & 3.766 & $30 B$ & 2.471 & 2.422 & 2.003 \\
\hline $12 B$ & 1.029 & 0.946 & 8.405 & $30 \mathrm{C}$ & 2.733 & 2.713 & 0.734 \\
\hline $12 \mathrm{C}$ & 1.593 & 1.405 & 12.541 & $32 \mathrm{~A}$ & 0.235 & 0.232 & 1.285 \\
\hline $13 \mathrm{~A}$ & 1.694 & 1.635 & 3.545 & $32 \mathrm{~B}$ & 0.288 & 0.288 & 0.000 \\
\hline $13 B$ & 1.967 & 1.781 & 9.925 & $32 \mathrm{C}$ & 0.275 & 0.276 & 0.363 \\
\hline $13 C$ & 1.462 & 1.457 & 0.343 & $33 \mathrm{~A}$ & 0.284 & 0.259 & 9.208 \\
\hline $14 \mathrm{~A}$ & 9.537 & 8.952 & 6.328 & $33 B$ & 0.297 & 0.29 & 2.385 \\
\hline $14 B$ & 14.9 & 13.449 & 10.237 & $33 C$ & 0.266 & 0.265 & 0.377 \\
\hline $14 \mathrm{C}$ & 15.07 & 13.217 & 13.101 & $34 \mathrm{~A}$ & 3.732 & 3.467 & 7.362 \\
\hline $16 \mathrm{~A}$ & 1.904 & 1.857 & 2.499 & $34 \mathrm{~B}$ & 2.927 & 2.764 & 5.728 \\
\hline $16 B$ & 2.014 & 1.973 & 2.057 & $34 \mathrm{C}$ & 2.929 & 2.892 & 1.271 \\
\hline $16 \mathrm{C}$ & 2.01 & 1.962 & 2.417 & $36 \mathrm{~A}$ & 0.299 & 0.293 & 2.027 \\
\hline $17 \mathrm{~A}$ & 2.142 & 2.018 & 5.962 & $36 \mathrm{~B}$ & 0.268 & 0.27 & 0.743 \\
\hline 17B & 5.563 & 4.958 & 11.501 & $36 \mathrm{C}$ & 0.299 & 0.299 & 0.000 \\
\hline $17 \mathrm{C}$ & 4.102 & 3.641 & 11.908 & & & & \\
\hline $20 A$ & 2.262 & 2.11 & 6.953 & & & & \\
\hline
\end{tabular}


Table C-2. RDX Replicate Samples and Average Percent Differences for Precision Determination.

\begin{tabular}{|c|c|c|c|c|c|c|c|}
\hline Run & $1 \mathrm{st}$ & Duplicate & APD $\%$ & $20 C$ & 1.229 & 1.126 & 8.747 \\
\hline $2 \mathrm{R}$ & 0.808 & 0.795 & 1.622 & $21 \mathrm{~A}$ & 0.131 & 0.116 & 12.146 \\
\hline $3 R$ & 2.192 & 1.99 & 9.660 & $21 B$ & 0.11 & 0.107 & 2.765 \\
\hline $2 \mathrm{~A}$ & 0.385 & 0.341 & 12.121 & $21 C$ & 0.104 & 0.088 & 16.667 \\
\hline $2 B$ & 0.368 & 0.309 & 17.430 & $23 \mathrm{~A}$ & 0.155 & 0.146 & 5.980 \\
\hline $2 \mathrm{C}$ & 0.357 & 0.309 & 14.414 & $23 B$ & 0.164 & 0.144 & 12.987 \\
\hline $5 \mathrm{~A}$ & 2.09 & 1.873 & 10.951 & $23 C$ & 0.181 & 0.175 & 3.371 \\
\hline $5 B$ & 2.528 & 2.034 & 21.657 & $24 \mathrm{~A}$ & 0.851 & 0.802 & 5.929 \\
\hline $5 C$ & 2.231 & 1.839 & 19.263 & $24 B$ & 0.899 & 0.815 & 9.802 \\
\hline $8 \mathrm{~A}$ & 1.251 & 1.172 & 6.521 & $24 C$ & 0.522 & 0.481 & 8.175 \\
\hline $8 B$ & 0.915 & 0.792 & 14.411 & $26 \mathrm{~A}$ & 0.179 & 0.177 & 1.124 \\
\hline $8 C$ & 2.263 & 2.181 & 3.690 & $26 B$ & 0.176 & 0.17 & 3.468 \\
\hline $10 \mathrm{~A}$ & 0.841 & 0.764 & 9.595 & $26 \mathrm{C}$ & 0.129 & 0.12 & 7.229 \\
\hline $10 \mathrm{~B}$ & 2.416 & 2.169 & 10.774 & $28 \mathrm{~A}$ & 0.532 & 0.486 & 9.037 \\
\hline $10 \mathrm{C}$ & 1.645 & 1.408 & 15.526 & $28 \mathrm{~B}$ & 0.462 & 0.436 & 5.791 \\
\hline $11 \mathrm{~A}$ & 0.334 & 0.295 & 12.401 & $28 \mathrm{C}$ & 0.453 & 0.452 & 0.221 \\
\hline $11 \mathrm{~B}$ & 0.247 & 0.238 & 3.711 & $30 A$ & 0.491 & 0.457 & 7.173 \\
\hline $11 \mathrm{C}$ & 0.35 & 0.325 & 7.407 & $30 \mathrm{~B}$ & 0.448 & 0.438 & 2.257 \\
\hline $13 \mathrm{~A}$ & 0.313 & 0.3 & 4.241 & $30 \mathrm{C}$ & 0.519 & 0.517 & 0.386 \\
\hline $13 B$ & 0.352 & 0.315 & 11.094 & $31 \mathrm{~A}$ & 0.058 & 0.054 & 7.143 \\
\hline $13 C$ & 0.309 & 0.306 & 0.976 & $31 \mathrm{~B}$ & 0.072 & 0.069 & 4.255 \\
\hline $14 \mathrm{~A}$ & 1.441 & 1.34 & 7.264 & $31 \mathrm{C}$ & 0.069 & 0.07 & 1.439 \\
\hline $14 B$ & 2.357 & 2.081 & 12.438 & $33 \mathrm{~A}$ & 0.068 & 0.06 & 12.500 \\
\hline $14 \mathrm{C}$ & 2.541 & 2.168 & 15.842 & $33 B$ & 0.073 & 0.072 & 1.379 \\
\hline $16 \mathrm{~A}$ & 0.392 & 0.381 & 2.846 & $33 C$ & 0.083 & 0.082 & 1.212 \\
\hline $16 \mathrm{~B}$ & 0.402 & 0.392 & 2.519 & $34 \mathrm{~A}$ & 0.55 & 0.505 & 8.531 \\
\hline $16 \mathrm{C}$ & 0.402 & 0.391 & 2.774 & $34 \mathrm{~B}$ & 0.538 & 0.502 & 6.923 \\
\hline $18 \mathrm{~A}$ & 0.448 & 0.402 & 10.824 & $34 \mathrm{C}$ & 0.461 & 0.464 & 0.649 \\
\hline $18 \mathrm{~B}$ & 0.448 & 0.399 & 11.570 & $36 \mathrm{~A}$ & 0.074 & 0.072 & 2.740 \\
\hline $18 \mathrm{C}$ & 0.399 & 0.398 & 0.251 & $36 \mathrm{~B}$ & 0.077 & 0.077 & 0.000 \\
\hline $20 \mathrm{~A}$ & 0.443 & 0.413 & 7.009 & $36 \mathrm{C}$ & 0.073 & 0.073 & 0.000 \\
\hline $20 B$ & 1.081 & 0.996 & 8.185 & & & & \\
\hline
\end{tabular}


Table C-3. HMX Replicate Samples and Average Percent Differences for Precision Determination.

\begin{tabular}{|c|c|c|c|c|c|c|c|}
\hline Run & $1 \mathrm{st}$ & Duplicate & APD\% & $19 A$ & 0.299 & 0.281 & 6.207 \\
\hline $2 \mathrm{H}$ & 0.789 & 0.706 & 11.104 & $19 \mathrm{~B}$ & 0.244 & 0.228 & 6.780 \\
\hline $3 \mathrm{H}$ & 0.315 & 0.291 & 7.921 & $19 \mathrm{C}$ & 0.396 & 0.39 & 1.527 \\
\hline $3 A$ & 0.453 & 0.448 & 1.110 & $21 \mathrm{~A}$ & 0.41 & 0.377 & 8.386 \\
\hline $3 C$ & 0.432 & 0.4 & 7.692 & $21 \mathrm{~B}$ & 0.268 & 0.263 & 1.883 \\
\hline $3 B$ & 0.358 & 0.344 & 3.989 & $21 \mathrm{C}$ & 0.218 & 0.2 & 8.612 \\
\hline $6 \mathrm{~A}$ & 1.127 & 1.089 & 3.430 & $22 \mathrm{~A}$ & 0.312 & 0.307 & 1.616 \\
\hline $6 \mathrm{~B}$ & 1.114 & 1.071 & 3.936 & $22 \mathrm{~B}$ & 0.274 & 0.252 & 8.365 \\
\hline $6 \mathrm{CS}$ & 0.999 & 0.948 & 5.239 & $22 \mathrm{C}$ & 0.379 & 0.353 & 7.104 \\
\hline $95 A$ & 0.144 & 0.146 & 1.379 & $23 \mathrm{~A}$ & 0.561 & 0.55 & 1.980 \\
\hline $95 \mathrm{~B}$ & 0.15 & 0.148 & 1.342 & $23 B$ & 0.373 & 0.34 & 9.257 \\
\hline $95 \mathrm{C}$ & 0.117 & 0.116 & 0.858 & $23 C$ & 0.531 & 0.518 & 2.479 \\
\hline $65 A$ & 0.115 & 0.116 & 0.866 & $25 \mathrm{~A}$ & 0.546 & 0.524 & 4.112 \\
\hline $65 B$ & 0.095 & 0.089 & 6.522 & $25 B$ & 0.315 & 0.285 & 10.000 \\
\hline $65 C$ & 0.085 & 0.082 & 3.593 & $25 \mathrm{C}$ & 0.365 & 0.36 & 1.379 \\
\hline $35 \mathrm{D}$ & 0.093 & 0.092 & 1.081 & $26 \mathrm{~A}$ & 0.563 & 0.562 & 0.178 \\
\hline $35 \mathrm{E}$ & 0.065 & 0.067 & 3.030 & $26 B$ & 0.383 & 0.377 & 1.579 \\
\hline $35 \mathrm{~F}$ & 0.068 & 0.069 & 1.456 & $26 C$ & 0.324 & 0.309 & 4.739 \\
\hline $9 A$ & 0.848 & 0.767 & 10.031 & $29 A$ & 0.118 & 0.111 & 6.114 \\
\hline $9 \mathrm{~B}$ & 0.589 & 0.559 & 5.226 & $29 B$ & 0.156 & 0.158 & 1.274 \\
\hline $9 \mathrm{C}$ & 1 & 0.978 & 2.224 & $29 C$ & 0.136 & 0.132 & 2.985 \\
\hline $11 \mathrm{~A}$ & 1.218 & 1.112 & 9.099 & $31 \mathrm{~A}$ & 0.149 & 0.141 & 5.517 \\
\hline 11B & 0.607 & 0.596 & 1.829 & 31B & 0.175 & 0.169 & 3.488 \\
\hline $11 \mathrm{C}$ & 1.003 & 0.947 & 5.746 & $31 \mathrm{C}$ & 0.181 & 0.181 & 0.000 \\
\hline $12 \mathrm{~A}$ & 0.794 & 0.758 & 4.639 & $32 \mathrm{~A}$ & 0.148 & 0.148 & 0.000 \\
\hline $12 B$ & 0.597 & 0.555 & 7.292 & $32 \mathrm{~B}$ & 0.145 & 0.145 & 0.000 \\
\hline $12 \mathrm{C}$ & 0.848 & 0.757 & 11.340 & $32 \mathrm{C}$ & 0.151 & 0.15 & 0.664 \\
\hline $13 \mathrm{~A}$ & 1.199 & 1.148 & 4.346 & $33 \mathrm{~A}$ & 0.174 & 0.163 & 6.528 \\
\hline $13 B$ & 1.062 & 0.975 & 8.542 & $33 \mathrm{~B}$ & 0.17 & 0.166 & 2.381 \\
\hline $13 C$ & 0.872 & 0.882 & 1.140 & $33 C$ & 0.17 & 0.169 & 0.590 \\
\hline $15 A$ & 0.932 & 0.874 & 6.423 & $35 \mathrm{~A}$ & 0.198 & 0.192 & 3.077 \\
\hline $15 B$ & 0.851 & 0.815 & 4.322 & $35 B$ & 0.169 & 0.168 & 0.593 \\
\hline $15 \mathrm{C}$ & 1.373 & 1.3 & 5.462 & $35 \mathrm{C}$ & 0.174 & 0.174 & 0.000 \\
\hline $16 \mathrm{~A}$ & 1.029 & 1.003 & 2.559 & $36 \mathrm{~A}$ & 0.257 & 0.251 & 2.362 \\
\hline $16 \mathrm{~B}$ & 1.245 & 1.225 & 1.619 & $36 \mathrm{~B}$ & 0.194 & 0.194 & 0.000 \\
\hline $16 \mathrm{C}$ & 1.379 & 1.348 & 2.273 & $36 \mathrm{C}$ & 0.238 & 0.24 & 0.837 \\
\hline
\end{tabular}


Table C-4. Replicate Samples and Average Percent Differences for Explosive Formulations and TNT Mold Precision Determination.

Octol

\begin{tabular}{lrrr}
\multicolumn{4}{c}{ TNT } \\
RUN & \multicolumn{1}{c}{$1^{\text {ST }}$ DUP } & \multicolumn{1}{c}{ APD\% } \\
\hline 44A & 5.197 & 5.056 & 2.750 \\
44B & 4.963 & 4.705 & 5.337 \\
44C & 4.708 & 4.311 & 8.804 \\
39A & 2.385 & 2.367 & 0.758 \\
39B & 2.35 & 2.334 & 0.683 \\
39C & 2.846 & 2.571 & 10.153 \\
49A & 8.74 & 8.694 & 0.528 \\
49B & 9.833 & 8.945 & 9.458 \\
49C & 9.959 & 9.054 & 9.520 \\
\hline
\end{tabular}

\begin{tabular}{crr}
\multicolumn{3}{c}{ HMX } \\
\multicolumn{1}{c}{ ST } & \multicolumn{1}{c}{ DUP } & \multicolumn{1}{c}{ APD\% } \\
\hline 0.188 & 0.183 & 2.695 \\
0.167 & 0.161 & 3.659 \\
0.176 & 0.164 & 7.059 \\
0.097 & 0.096 & 1.036 \\
0.085 & 0.086 & 1.170 \\
0.107 & 0.1 & 6.763 \\
0.239 & 0.238 & 0.419 \\
0.308 & 0.285 & 7.757 \\
0.331 & 0.3 & 9.826 \\
\hline
\end{tabular}

Composition B

\begin{tabular}{lccccrrrr} 
& \multicolumn{2}{c}{ TNT } & & \multicolumn{3}{c}{ RDX } \\
RUN & 1ST & DUP & APD\% & & 1ST & \multicolumn{1}{c}{ DUP } & \multicolumn{1}{c}{ APD\% } \\
\hline 45A & 2.714 & 2.643 & 2.651 & & 0.678 & 0.66 & 2.691 \\
45B & 3.861 & 3.626 & 6.278 & & 0.973 & 0.904 & 7.352 \\
45C & 3.754 & 3.516 & 6.548 & & 1.002 & 0.934 & 7.025 \\
40A & 2.927 & 2.913 & 0.479 & & 0.717 & 0.712 & 0.700 \\
40B & 3.019 & 2.849 & 5.794 & & 0.776 & 0.73 & 6.109 \\
40C & 2.466 & 2.487 & 0.848 & & 0.688 & 0.69 & 0.290 \\
50A & 4.911 & 4.835 & 1.560 & & 0.756 & 0.747 & 1.198 \\
50B & 5.778 & 5.722 & 0.974 & & 1.325 & 1.292 & 2.522 \\
50C & 6.694 & 6.093 & 9.400 & & 1.473 & 1.326 & 10.504
\end{tabular}

\begin{tabular}{lrrr}
\multicolumn{4}{c}{ LX-14 } \\
RUN & \multicolumn{1}{c}{ HMX } & \\
\hline ST & \multicolumn{1}{c}{ DUP } & \multicolumn{1}{c}{ APD\% } \\
\hline 43A & 0.182 & 0.18 & 1.105 \\
43B & 0.161 & 0.157 & 2.516 \\
43C & 0.163 & 0.155 & 5.031 \\
38A & 0.1 & 0.1 & 0.000 \\
38B & 0.093 & 0.094 & 1.070 \\
38C & 0.092 & 0.091 & 1.093 \\
48A & 0.505 & 0.508 & 0.592 \\
48B & 0.491 & 0.483 & 1.643 \\
48C & 0.486 & 0.474 & 2.500 \\
\hline
\end{tabular}

\begin{tabular}{lcrr}
\multicolumn{4}{c}{ TNT Mold } \\
RUN & 1ST & \multicolumn{1}{c}{ DUP } & \multicolumn{1}{c}{ APD $\%$} \\
\hline 42A & 2.508 & 2.465 & 1.729 \\
42B & 3.023 & 2.696 & 11.436 \\
42C & 3.284 & 2.896 & 12.557 \\
37A & 2.572 & 2.567 & 0.195 \\
37B & 2.555 & 2.534 & 0.825 \\
37A' & 2.997 & 2.997 & 0.000 \\
47A & 5.029 & 4.973 & 1.120 \\
47B & 6.043 & 5.82 & 3.760 \\
47B' & 6.126 & 5.791 & 5.622 \\
\hline
\end{tabular}


Table C-5. Replicate Standard Analyses for Average Percent Recoveries for Accuracy TNT RDX HMX

RUN STD MEASUR \%DIFF STD MEASUR \%DIFF STD MEASUR \%DIFF

\begin{tabular}{|c|c|c|c|c|c|c|c|c|c|}
\hline $\mathrm{T} 1$ & 5 & 5.148 & 2.917 & 5 & 5.112 & 2.215 & 5 & 5.094 & 1.862 \\
\hline T2 & 5 & 5.114 & 2.254 & 5 & 5.092 & 1.823 & 5 & 4.997 & 0.060 \\
\hline T3 & 5 & 5.063 & 1.252 & 5 & 5.038 & 0.757 & 5 & 4.998 & 0.040 \\
\hline $5 \backslash 29$ & 5 & 5.018 & 0.359 & 5 & 5.026 & 0.519 & 5 & 4.985 & 0.300 \\
\hline $5 \backslash 29$ & 5 & 5.037 & 0.737 & 5 & 5.067 & 1.331 & 5 & 5.024 & 0.479 \\
\hline $5 \backslash 31$ & 5 & 4.957 & 0.864 & 5 & 4.987 & 0.260 & 5 & 4.987 & 0.260 \\
\hline 618 & 5 & 5.075 & 1.489 & 5 & 5.105 & 2.078 & 5 & 5.027 & 0.539 \\
\hline 617 & 5 & 5.019 & 0.379 & 5 & 5.023 & 0.459 & 5 & 4.954 & 0.924 \\
\hline 616 & 5 & 5.015 & 0.299 & 5 & 5.039 & 0.777 & 5 & 4.998 & 0.040 \\
\hline 615 & 5 & 5.053 & 1.054 & 5 & 5.055 & 1.094 & 5 & 4.982 & 0.361 \\
\hline $6 \backslash 4$ & 5 & 4.934 & 1.329 & 5 & 4.925 & 1.511 & 5 & 4.864 & 2.758 \\
\hline 613 & 5 & 5.043 & 0.856 & 5 & 5.080 & 1.587 & 5 & 5.055 & 1.094 \\
\hline 612 & 5 & 5.060 & 1.193 & 5 & 5.120 & 2.372 & 5 & 5.108 & 2.137 \\
\hline $5 \backslash 31$ & 5 & 5.042 & 0.836 & 5 & 5.074 & 1.469 & 5 & 5.065 & 1.292 \\
\hline $7 \backslash 6$ & 4 & 3.936 & 1.613 & 4 & 3.923 & 1.944 & 4 & 3.931 & 1.740 \\
\hline $7 \backslash 7$ & 4 & 3.913 & 2.199 & 4 & 3.916 & 2.122 & 4 & 3.936 & 1.613 \\
\hline 618 & 5 & 5.024 & 0.479 & 5 & 5.068 & 1.351 & 5 & 4.995 & 0.100 \\
\hline $6 \backslash 11$ & 5 & 4.912 & 1.776 & 5 & 4.953 & 0.944 & 5 & 4.952 & 0.965 \\
\hline $6 \backslash 12$ & 5 & 4.938 & 1.248 & 5 & 4.974 & 0.521 & 5 & 4.912 & 1.776 \\
\hline $6 \backslash 13$ & 5 & 4.893 & 2.163 & 5 & 4.932 & 1.369 & 5 & 4.866 & 2.716 \\
\hline $6 \backslash 14$ & 5 & 4.972 & 0.562 & 5 & 5.001 & 0.020 & 5 & 4.98 & 0.401 \\
\hline $6 \backslash 15$ & 5 & 5.095 & 1.882 & 5 & 5.016 & 0.319 & 5 & 4.965 & 0.702 \\
\hline $6 \backslash 16$ & 5 & 4.915 & 1.715 & 5 & 4.973 & 0.541 & 5 & 4.936 & 1.288 \\
\hline $6 \backslash 17$ & 5 & 4.983 & 0.341 & 5 & 5.009 & 0.180 & 5 & 4.986 & 0.280 \\
\hline $6 \backslash 27$ & 5 & 5.047 & 0.936 & 5 & 5.159 & 3.130 & 5 & 5.129 & 2.547 \\
\hline $6 \backslash 28$ & 5 & 4.828 & 3.500 & 5 & 4.872 & 2.593 & 5 & 4.895 & 2.122 \\
\hline $6 \backslash 29$ & 5 & 4.788 & 4.332 & 5 & 4.832 & 3.417 & 5 & 4.8 & 4.082 \\
\hline 6130 & 5 & 4.862 & 2.799 & 5 & 4.854 & 2.963 & 5 & 4.829 & 3.479 \\
\hline $7 \backslash 1$ & 5 & 4.846 & 3.128 & 5 & 4.843 & 3.190 & 5 & 4.796 & 4.165 \\
\hline $7 \backslash 2$ & 5 & 4.801 & 4.061 & 5 & 4.84 & 3.252 & 5 & 4.823 & 3.604 \\
\hline $6 \backslash 18$ & 5 & 4.993 & 0.140 & 5 & 5.045 & 0.896 & 5 & 4.999 & 0.020 \\
\hline $6 \backslash 20$ & 5 & 4.929 & 1.430 & 5 & 4.949 & 1.025 & 5 & 4.94 & 1.207 \\
\hline $6 \backslash 21$ & 5 & 5.017 & 0.339 & 5 & 5.036 & 0.717 & 5 & 5.029 & 0.578 \\
\hline $7 \backslash 3$ & 5 & 4.866 & 2.716 & 5 & 4.88 & 2.429 & 5 & 4.82 & 3.666 \\
\hline $7 \backslash 4$ & 5 & 4.813 & 3.811 & 5 & 4.848 & 3.087 & 5 & 4.817 & 3.728 \\
\hline $7 \backslash 5$ & 5 & 4.746 & 5.212 & 5 & 4.79 & 4.290 & 5 & 4.754 & 5.044 \\
\hline $7 \backslash 9$ & 4 & 3.904 & 2.429 & 4 & 3.916 & 2.122 & 4 & 3.952 & 1.207 \\
\hline $7 \backslash 10$ & 4 & 3.928 & 1.816 & 4 & 3.92 & 2.020 & 4 & 3.911 & 2.250 \\
\hline $7 \backslash 11$ & 4 & 3.901 & 2.506 & 4 & 3.924 & 1.918 & 4 & 3.944 & 1.410 \\
\hline
\end{tabular}




\section{APPENDIX D \\ EXPERIMENTAL SET UP DIMENSIONS}

$\underline{600 \mathrm{~mL} \text { Beaker }}$

- Height

$11.8 \mathrm{~cm}$

- Inner Diameter

$8.2 \mathrm{~cm}$

- Height of $500 \mathrm{~mL}$ water

$9.7 \mathrm{~cm}$

$\underline{\text { Rod and Propeller }}$

- Rod Diameter $1 \mathrm{~cm}$

- Propeller \# of Blades 4

- Propeller Total Diameter $6 \mathrm{~cm}$

- Blade Diameter $2.4 \mathrm{~cm}$

- Propeller Center Diameter $\quad 1.2 \mathrm{~cm}$ 


\section{LIST OF REFERENCES}

Agency for Toxic Substances and Disease Registry (ATSDR), 1996. 2,4,6-

Trinitrotoluene (TNT) Fact Sheet. [Online]. Available:

http://www.atsdr.cdc.gov/tfacts81.html [November 1, 2000].

ATSDR, 1996. RDX Fact Sheet. [Online]. Available:

http://www.atsdr.cdc.gov/tfacts78.html [November 1, 2000].

ATSDR, 1997. HMX Fact Sheet. [Online]. Available:

http://www.atsdr.cdc.gov/tfacts $98 . h t m l$ [November 1, 2000].

ATSDR, 2002. Toxicological Profile Information Sheet [Online]. Available: http://www.atsdr.cdc.gov/toxpro2.html [January 7, 2002].

Arnold, Major, 2000. Unexploded Ordnance(UXO): An Explosive Issue? The Army Law. Department of the Army Pamphlet 27-50-335, October 2000, 34-35.

Atkins, P.W., 1982. Physical Chemistry $2^{\text {nd }}$ ed., W. H. Freeman and Company: San Francisco, CA.

Bart, J., Judd, L., Hoffman, K., Wilkins, A., Kusterbeck, A., 1997. Application of a Portable Immunosensor to Detect the Explosives TNT and RDX in Groundwater Samples. Environ. Sci. Technol., 31: 1505 - 1511.

Best, E., Sprecher, S., Larson, S., Fredrickson, H., Bader, D., 1999. Environmental Behavior of Explosives in Groundwater from the Milan Army Ammunition Plant in Aquatic and Wetland Plant Treatments. Removal, Mass Balances, and Fate in Groundwater of TNT and RDX. Chemosphere, 38: 3383-3396.

Bhadra, R., Wayment, D. G., Williams, R., Barman, S., Stone, M., Hughes, J., Shanks, J., 2001. Studies on Plant-Mediated Fate of the Explosives RDX, and HMX.

Chemosphere, 44: 1259 - 1264.

Boopathy, R., Manning, J. F., 2000. Laboratory Treatability Study on Hexahydro-1,3,5trinitro-1,3,5-triazine (RDX) Contaminated Soil from the Iowa Army

Ammunition Plant, Burlington, Iowa. Water Environ. Res., 72: 238 - 241.

Brannon, J., Deliman, P., Ruiz, C., Price, C., Qasim, M., Gerald, J., Hayes, C., Yost, S., 1999. Conceptual Model and Process Descriptor Formulations for Fate and Transport of UXO. U.S. Army Engineer Waterways Experiment Station Technical Report IRRP-99-1, Vicksburg, Mississippi. 
Brannon, J. M., Price, C. B., Hayes, C, 1998. Abiotic Transformation of TNT in Montmorillite and Soil Suspensions Under Reducing Conditions. Chemosphere, 36: $1453-1462$.

Burnside, N. J., Son, S. F., Asay, B. W., Skidmore, C. B., 1997. Particle Characterization of Pressed Granular HMX. $10^{\text {th }}$ Biennial International Conference of the American Physical Society Topical Group on Shock Compression of Condensed Matter, University of Massachusetts, Amherst, MA.

Carmichael, G. R., Shah, S. A., Parrott, E. L., 1981. General Model for Dissolution Rates on n-Component, Nondisintegrating Spheres. J. Pharm. Sci., 70: 1331 - 1338.

Crockett, A., Craig, H., and Jenkins, T., 1999. Field Sampling and Selecting On-site Analytical Methods for Explosives in Water. Environmental Protection Agency Publication EPA/600/S-99/002.

Cussler, E. L., 1997. Diffusion Mass Transfer in Fluid Systems, $2^{\text {nd }}$ ed. Cambridge Press, New York NY.

Daniels, J., Knezovich, J., 1994. Human Health Risks from TNT, RDX, and HMX in Environmental Media and Consideration of the U.S. Regulatory Environment. Proceedings of the 1994 Luxembourg International Symposium on the Rehabilitation of Former Military Sites and Demilitarization of Explosive Ordnance. Kirchberg, Luxembourg, 229 - 237.

Gibbs, T., Popolato, A., eds., 1980. LASL Explosive Property Data. University of California Press, Berkley, CA.

Gilcrease, P., Murphy, V., Reardon, K., 1996. Bioremediation of Solid TNT Particles in a Soil Slurry Reactor: Mass Transfer Considerations. In Proceedings of the HRSC/WERC Joint Conference on the Environment, Albuquerque, NM, May 1996.

Gilcrease, P., Murphy, V., Reardon, K., 2001. Simultaneous Grinding and Dissolution of TNT Solids in an Agitated Slurry. Am. Inst. Chem. Eng., 47: 572-581.

Goodpaster, J. V., McGuffin, V. L., 2001. Florescence Quenching as an Indirect Detection Method for Nitrated Explosives. Anal. Chem., 73: 2004 - 2011.

Groom, C. A., Beaudet, S., Halasz, A., Paquet, L., Hawari, J., 2001. Detection of the Cyclic Nitramine Explosives Hexahydro-1,3,5-trinitro-1,3,5-triazine (RDX) and Octahydro-1,3,5,7-tetranitro-1,3,5,7-tetrazine (HMX) and Their Degradation Products in Soil Environments. J. Chromatogr. A, 909: 53 - 60. 
Hawari, J., Beaudet, S., Halasz, A., Thiboutot, S., Ampleman, G., 2000. Microbial Degradation of Explosives: Biotransformation Versus Mineralization. Appl. Microbiol. Biot., 54: $605-618$.

Hawthorne, S. B., Lagadec, A. J., Kalderis, D., Lilke, A. V., Miller, D. J., 2000. PilotScale Destruction of TNT, RDX, and HMX on Contaminated Soils Using Subcritical Water. Environ. Sci. Technol., 34: 3224 - 3228.

Henry, J.G., and Heinke, G.W., 1996. Environmental Science and Engineering, $2^{\text {nd }}$ ed. Prentice Hall, Inc., New Jersey.

Houston, S., Doe, W., Shaw, R., 2001. Environmental Risk of Army Ranges and Impact Areas: An Ecological Framework for Assessment. Fed. Facil. Environ. J., Spring, 2001: $93-111$.

Huang, G., Xiao, H., Chi, J., Shiu, W., MacKay, D., 2000. Effects of pH on the Aqueous Solubility of Selected Chlorinated Phenols. J. Chem. Eng. Data, 45: 411-414.

Jenkins, T. F., Walsh, M. E., Miyares, P. H., Hewitt, A. D., Collins, N. H., Ranney, T. A., 2002. Use of Snow-Covered Ranges to Estimate Explosives Residues from HighOrder Detonations of Army Munitions. Thermochim Acta, in press, posted November 5, 2001.

Keystone Center, 2000. National policy Dialogue on Military Munitions Final Report September, 2000.

LeGrega, M. D., Buckingham, P. L., Evans, J. C., 1994. Hazardous Waste Management, McGraw-Hill Inc., New York.

Levins, D., Glastonbury, J., 1972a. Particle-Liquid Hydrodynamics and Mass transfer in a Stirred Vessel Part I - Particle-Liquid Motion. Transactions of the Institution of Chemical Engineers, 50: 32-41.

Levins, D., Glastonbury, J., 1972b. Particle-Liquid Hydrodynamics and Mass transfer in a Stirred Vessel Part II - Mass Transfer. Transactions of the Institution of Chemical Engineers, 50: 132-146.

Lynch, J., Brannon, J., Delfino, J., 2002a. Dissolution Rate of High Explosive Compounds. Chemosphere, accepted for publication January 16, 2002.

Lynch, J., Brannon, J., Delfino, J., 2002b. Effects of Component Interactions on the Aqueous Solubilities and Dissolution Rates of the Explosive Formulations Octol, Composition B, and LX-14. J. Chem. Eng. Data, accepted for publication February 11, 2002. 
Lynch, J., Myers, K., Brannon, J., Delfino, J., 2001. Effects of pH and Temperature on the Aqueous Solubility and Dissolution Rate of 2,4,6-Trinitrotoluene (TNT), Hexahydro-1,3,5-trinitro-1,3,5-triazine (RDX), and Octahydro-1,3,5,7-tetranitro1,3,5,7-tetrazocine (HMX). J. Chem. Eng. Data, 46: 1549-1555.

Macdonald, J. A., 2001. Cleaning Up Unexploded Ordnance. Environ. Sci. Technol., 35: $372 a-376 a$.

May, P., 2001. Molecules in Motion: An Active Chemical Exploratorium [Online]. Available: http://www.ch.ic.ac.uk/mim/environmental/html/tnt.htm [November 5, 2001].

National Atmospheric Deposition Program, 1998. Hydrogen Ion Concentration as pH from Measurements Made at the Field Laboratories [Online]. Available: http://nadp.sws.uiuc.edu/isopleths/maps1998/phfield.gif [May 5, 2000].

Pennington, J. C., Brannon, J. M., 2002. Environmental Fate of Explosives. Thermochim. Acta, in press, posted November 6, 2001.

Phelan, J. B., Barnett, J. L., 2001. Solubility of 2,4-Dinitrotoluene and 2,4,6Trinitrotoluene in Water. J. Chem. Eng. Data, 46: 375-376.

Price, C. B., Brannon, J. M., Hayes, C. A., 1997. Effect of Redox Potential and pH on TNT Transformation in Soil-Water Slurries. J. Environ. Eng., 123: 988-992.

Price, C. B., Brannon, J. M., Yost, S. L., 1998. Transformation of RDX and HMX Under Controlled Eh/pH Conditions, Technical Report IRRP-99-1, U.S. Army Engineer Waterways Experiment Station: Vicksburg, Mississippi.

Radtke, C. W., Gianotto, D., Roberto, F. F., 2002. Effects of Particulate Explosives on Estimating Contamination at a Historical Explosives Testing Area. Chemosphere, 46: $3-9$.

Ro, K. S., Venugopal, A., Adrian, D. D., Constant, D., Qaisi, K., Valsaraj, K. T., Thibodeaux, L. J., Roy, D., 1996. Solubility of 2,4,6-Trinitrotoluene (TNT) in Water. J. Chem. Eng. Data, 41: 758 - 761.

Sarisuta, N., Jateleela, S., Tourip, T., 2000. Dissolution Kinetics of Three-Compound Compressed Solid Mixtures with Largely Different Solubilities: Flaking Spheres. J. Pharm. Sci., 89: 1196 - 1211.

Selim, H. M., Xue, S. K., Iskandar, I. K., 1995. Transport of 2,4,6-Trinitrotoluene and Hexahydro-1,3,5-trinitro-1,3,5-triazine in Soils. Soil Sci., 160: 328 - 339.

Scarborough, R., 2002 January 10. Puerto Rico Leader Praises Decision on Navy's Live Firing. The Washington Times, natl. ed. 
Schafer, S., 2001 July 8. Pentagon Starts Search to Replace Vieques. Chicago Tribune, natl. ed.

Simini, M., Wentsel, R. S., Checkai, R. T., Phillips, C. T., Chester, N. A., Major, M. A., Amos, J., 1995. Evaluation of Soil Toxicity at Joliet Army Ammunition Plant. Environ. Toxicol. Chem., 14: 623 - 630.

Simpson, M., Parrott, E. L., 1983. Dissolution Kinetics of a Three-Component Solid I: Ethylparaben, Phenacetin, and Salicylamide. J. Pharm. Sci., 72: 757 - 764.

Spanggord, R. J., Mabey, W. R., Mill, T., Chou, T. W., Smith, J. H., Lee, S., Roberts, D., 1983. Environmental Fate Studies on Certain Munitions Wastewater Constituents, LSU-7934, AD-A138550, SRI International: Menlo Park, CA.

Stone, A., 2001 July 9. U.S. Military Ranges Around the World Face Battles. USA Today, natl. ed.

Stumm, W., Morgan, J., 1996. Aquatic Chemistry - Chemical Equilibria and Rates in Natural Waters, $3^{\text {rd }}$ ed. John Wiley and Sons, New York.

Superfund Hazardous Waste Site Advanced Query Form [Online], Available: http://www.epa.gov/superfund/sites/query/advquery.htm, United States Environmental Protection Agency, [August 19, 2001].

Talmage, S. S., Opresko, D. M., Maxwell, C. J., Welsh, C. J., Cretella, F. M., Reno, P. H., Daniel, F. B., 1999. Nitroaromatic Munition Compounds: Environmental Effects and Screening Values. Rev. Environ. Contam. Toxicol., 161: 1- 156.

Taylor, C. A., Rinkenbach, W. H., 1923. The Solubility of Trinitrotoluene in Organic Solvents. J. Am. Chem. Soc., 45: 44 - 59.

Tchobanoglous, G., Schroeder, E. D., 1987. Water Quality Characteristics, Modeling, Modification. Addison-Wesley Publishing Co., Reading, Massachusetts.

Thiboutot, S., Ampleman, G., Gagnon, A., Marios, A., Jenkins, T. F., Walsh, M. E., Thorne, P. G., Ranney, T. A., 1998. Characterization of Antitank Firing Ranges at CFB Valcartier, WATC Wainwright, and CFAD Dundurn. Research and Development Branch, Department of National Defense, Canada.

Townsend, D., Myers, T., 1996. Recent Developments in Formulating Model Descriptors for Subsurface Transformation and Sorption of TNT, RDX, and HMX. U.S. Army Engineer Waterways Experiment Station Technical Report IRRP-96-1, Vicksburg, Mississippi.

United States Department of Agriculture, 2000. Revised Universal Soil Loss Equation. [Online]. Available: http://www.sedlab.olemiss.edu/rusle/ [July 14, 2000]. 
United States Environmental Protection Agency, 1999. Code of Federal Regulations Title 40 Protection of Environment, Chapter I, Part 260, Hazardous Waste Management System, Washington D.C..

United States Environmental Protection Agency, 1994. Test Methods for Evaluating Solid Waste, Physical/Chemical Methods SW-846, $3^{\text {rd }}$ ed. Update II, Washington D.C.

United States Pharmacopeial Convention, Inc., 1990. The United States Pharmacopeia and The National Formulary, $22^{\text {nd }}$ rev., $17^{\text {th }}$ ed., Rockville, Maryland.

Van Deuren, J., Wang, Z., Ledbetter, J., 1977. Properties and Behavior of Explosives. In: Remediation Technologies Screening Matrix and Reference Guide, 3rd ed. [Online]. Available: http://www.frtr.gov/matrix $2 /$ section1/toc.html [November $28,2001]$.

Voudrais, E. A., Assaf, K. S., 1996. Theoretical Evaluation of Dissolution and Biochemical Reduction of TNT for Phytoremediation of Contaminated Sediments. J. Contam. Hydrol., 23: 245 - 261.

Williams, W., 2000. Toxins on the Firing Ranges. Sci. Am., 282: 18 - 20. 


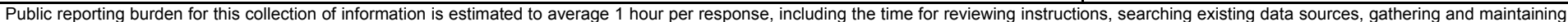

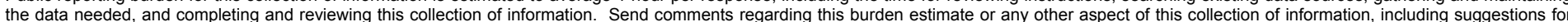

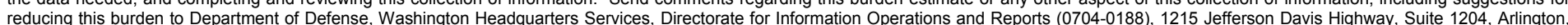

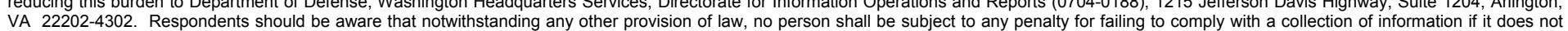
VA 22202-4302. Respondents should be aware that notwithstanding any other provision of law, no person shall be sube
display a currently valid OMB control number. PLEASE DO NOT RETURN YOUR FORM TO THE ABOVE ADDRESS.
1. REPORT DATE (DD-MM-YYYY)
September 2002
2. REPORT TYPE
Final report

4. TITLE AND SUBTITLE

Dissolution Kinetics of High Explosive Compounds (TNT, RDX, HMX)

3. DATES COVERED (From - To)

5a. CONTRACT NUMBER

5b. GRANT NUMBER

5c. PROGRAM ELEMENT NUMBER

\section{AUTHOR(S)}

Jason C. Lynch

7. PERFORMING ORGANIZATION NAME(S) AND ADDRESS(ES)

U.S. Army Engineer Research and Development Center

Environmental Laboratory

3909 Halls Ferry Road

Vicksburg, MS 39180-6199

\section{SPONSORING / MONITORING AGENCY NAME(S) AND ADDRESS(ES)}

U.S. Army Corps of Engineers

Washington, DC 20314-1000

\section{5d. PROJECT NUMBER}

SERDP CP1155

5e. TASK NUMBER

\section{5f. WORK UNIT NUMBER}

8. PERFORMING ORGANIZATION REPORT NUMBER

ERDC/EL TR-02-23

10. SPONSOR/MONITOR'S ACRONYM(S)

11. SPONSOR/MONITOR'S REPORT NUMBER(S)

\section{DISTRIBUTION / AVAILABILITY STATEMENT}

Approved for public release; distribution is unlimited.

\section{SUPPLEMENTARY NOTES}

\section{ABSTRACT}

The production and usage of high explosive compounds such as 2,4,6-trinitrotoluene (TNT), hexahydro-1,3,5-trinitro-1,3,5-triazine (RDX), and octahydro-1,3,5,7-tetranitro-1,3,5,7-tetrazocine (HMX) have resulted in their release in the environment. These compounds pose potential harm because of their reactivity and effects on health. Agencies that use high explosive compounds are working to better understand the physical and chemical properties surrounding these explosive compounds to include their fate and transport, effects on health, and remediation alternatives.

Though dissolution is a primary method making explosive compounds available for other processes, research on this topic has been limited. The objective of this study was to describe the dissolution rate and solubility of TNT, RDX, and HMX individually and as components in the explosive formulations octol, Composition B, and LX-14. Modifying a batch reactor dissolution methodology used by the pharmaceutical industry, experiments were conducted where concentration was measured as a function of temperature, solid surface area, and mixing rate. Solubility of explosive compounds was measured as a function of temperature. Sample analysis was performed using high performance liquid chromatography with ultraviolet detection.

(Continued)

\begin{tabular}{|c|c|c|c|c|c|}
\hline \multirow{3}{*}{$\begin{array}{l}\text { 15. SUBJECT TERMS } \\
\text { Composition B } \\
\text { Dissolution kinetics }\end{array}$} & \multicolumn{2}{|c|}{ Explosives } & Octol & \multicolumn{2}{|r|}{ TNT } \\
\hline & \multicolumn{2}{|l|}{ HMX } & \multicolumn{3}{|l|}{ RDX } \\
\hline & \multicolumn{2}{|l|}{ LX-14 } & \multicolumn{3}{|l|}{ Solubility } \\
\hline \multicolumn{3}{|c|}{ 16. SECURITY CLASSIFICATION OF: } & $\begin{array}{l}\text { 17. LIMITATION } \\
\text { OF ABSTRACT }\end{array}$ & $\begin{array}{l}\text { 18. NUMBER } \\
\text { OF PAGES }\end{array}$ & $\begin{array}{l}\text { 19a. NAME OF RESPONSIBLE } \\
\text { PERSON }\end{array}$ \\
\hline $\begin{array}{l}\text { a. REPORT } \\
\text { UNCLASSIFIED }\end{array}$ & $\begin{array}{l}\text { b. ABSTRACT } \\
\text { UNCLASSIFIED }\end{array}$ & $\begin{array}{l}\text { c. THIS PAGE } \\
\text { UNCLASSIFIED }\end{array}$ & & 131 & $\begin{array}{l}\text { 19b. TELEPHONE NUMBER (include } \\
\text { area code) }\end{array}$ \\
\hline
\end{tabular}




\section{4. (Concluded)}

Results show that increases in temperature, explosive surface area, and mixing rate caused increases in the explosive compound's dissolution rate. Of the three explosive compounds, TNT had the fastest dissolution rate followed by HMX and then RDX. Dissolution rates were essentially the same for explosive compounds determined separately and in individual compound mixtures. Dissolution rates of explosive compounds in explosive formulations were not comparable to those of individual compounds. TNT had the largest solubility followed by RDX and then HMX. Solubilities of these explosive compounds remained essentially the same under all measurement conditions.

Correlation equations describing dissolution rates and solubilities for the three explosive compounds and three explosive formulations studied were developed. These equations can be used to estimate solid explosive compound persistence on and flux loading from contaminated sites. These equations can also be integrated into models predicting risk and evaluating remediation alternatives. 